\title{
Dynamic and structural artery wall properties : short and long term effects of female sex hormones
}

Citation for published version (APA):

Willekes, C. (2000). Dynamic and structural artery wall properties : short and long term effects of female sex hormones. [Doctoral Thesis, Maastricht University]. Datawyse / Universitaire Pers Maastricht. https://doi.org/10.26481/dis.20000908cw

Document status and date:

Published: 01/01/2000

DOI:

$10.26481 /$ dis.20000908cw

Document Version:

Publisher's PDF, also known as Version of record

\section{Please check the document version of this publication:}

- A submitted manuscript is the version of the article upon submission and before peer-review. There can be important differences between the submitted version and the official published version of record.

People interested in the research are advised to contact the author for the final version of the publication, or visit the DOI to the publisher's website.

- The final author version and the galley proof are versions of the publication after peer review.

- The final published version features the final layout of the paper including the volume, issue and page numbers.

Link to publication

\footnotetext{
General rights rights.

- You may freely distribute the URL identifying the publication in the public portal. please follow below link for the End User Agreement:

www.umlib.nl/taverne-license

Take down policy

If you believe that this document breaches copyright please contact us at:

repository@maastrichtuniversity.nl

providing details and we will investigate your claim.
}

Copyright and moral rights for the publications made accessible in the public portal are retained by the authors and/or other copyright owners and it is a condition of accessing publications that users recognise and abide by the legal requirements associated with these

- Users may download and print one copy of any publication from the public portal for the purpose of private study or research.

- You may not further distribute the material or use it for any profit-making activity or commercial gain

If the publication is distributed under the terms of Article $25 \mathrm{fa}$ of the Dutch Copyright Act, indicated by the "Taverne" license above, 
Dynamic and structural artery wall properties 
Q Christine Willekes, Maastricht 2000

ISBN 9052782822

vormgeving en druk: Datawyse | Universitaire Pers Mastricht 


\section{Dynamic and structural artery wall properties short and long term effects of female sex hormones}

\section{Proefschrift}

ter verkrijging van de graad van doctor aan de Universiteit Maastricht, op gezag van de Rector Magnificus,

Prof. dr. A.C. Nieuwenhuijzen Kruseman, volgens het besluit van het College van Decanen, in het openbaar te verdedigen

op vrijdag 8 september 2000 om 14.00 uur

door

\section{Christine Willekes}

geboren op 27 maart 1966 te Amsterdam

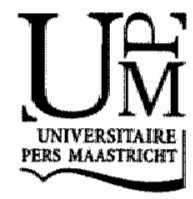




\section{Prownotores}

Prof. dr. R.S. Reneman

Prof dr. A.P.G. Hoeks

Co-promotores

Dr. HJ. Hoogland

Dr. H.A. Keizer

Beoordelingscommissie

Prof. dr, P.J.E.H.M. Kitslaar (voorzitter)

Prof. dr. K. Bom (Erasmus Universiteit Rotterdam)

Dr. L.M.A.B. van Bortel

Prof. dr. T.W.A. de Bruin

Prof. dr. J.L.H. Evers

Finarcial support by the Netherlands Heart Foundation for the publication of this thesis is gratefully acknowledged.

De publikatie van dit proefschrift werd mede mogelijk gemaakt door: Pie Medical, SWOOF, Schering, Organon, Ferring, Serono, Novo Nordisk, Wyeth, Astra Zeneca en Triforius Software. 
I keep six honest-serving men (They taught me all I knew) Their names are What and Why and When and How and Where and Who

Rudyard Kipling In "Just so stories for little children" 1902: The elephant's child (London) 


\section{Contents}

CHAPTER 1

General introduction

CHAPTER 2

Bladder filling reduces femoral artery wall distension and strain:

beware of a full bladder!

\section{CHAPTER 3}

Female sex homones do not influence arterial wall properties during the normal menstrual cycle

CHAPTER 4

Three months use of third generation oral contraceptives does not affect artery wall properties

CHAPTER 5

Automated detection of local artery wall thickness based on M-line signal processing

CHAPTER 6

Evaluation of off-line automated intima-media thickness detection of the common carotid artery based on M-line signal processing

CHAPTER 7

Assessment of local differences in intima-media thickness in the human common carotid artery

CHAPTER 8

Hormone replacement therapy in postmenopausal women increases absolute and relative distension of the common carotid artery and beneficially affects the lipid profile 
CHAPTER 9

General discussion and conclusions

Summary

Samenvatting

Dankwoond

Curriculum vitae

List of publications 


\section{General introduction}

1.1 Introduction 10

1.2 Artery wall anatomy 11

1.3 Artery wall function 12

1.4 Artery wall thickness 16

1.5 Female sex hormones 18

1.6 Aim of the thesis 22 


\subsection{Introduction}

The arterial system changes under the influence of ageing $[1,2]$ which, amongst others, can be visualized macroscopically and non-invasively by means of ultrasound. With this technique, we can measure anatomical changes in large arteries, e.g. (local) wall thickening, and assess formation of atherosclerotic plaques and stenoses [3-5]. At microscopical level, changes in artery wall composition occur due to the ageing process, which are complex and subject of ongoing research. The change in composition of the arterial wall leads to an increase in wall thickness and a change in its mechanical properties and function $[6,7]$.

One of the main functions of large elastic arteries is to store temporarily the blood ejected by the heart during systole. This is also known as the cushioning function with a favourable effect on pulse pressure, i.e. the difference between systolic and diastolic blood pressure. The pulse pressure increase, due to the increase in blood volume ejected into the circulation by the heart, is limited as a consequence of the distension of the arterial wall. Large arteries exhibit also a conduit function, transporting blood to the peripheral circulation while maintaining mean arterial pressure. Both functions are partly governed by the capacity to store an absolute increase in volume $(\Delta V)$ in the arterial system due to a change in pressure $(\Delta \mathrm{P})$, also known as compliance [8].

Due to ageing arteries show a stiffer behaviour, resulting in an increase in systolic blood pressure and hence, pulse pressure, causing an increased transmural pressure over the arterial wall [9]. Part of these effects are counteracted by a compensatory increase in diameter in an attempt to keep compliance as constant as possible with increasing age [1]. Simultaneously, the afterload of the heart increases, leading to an increased ventricular load. All these sequelae add to the cardiovascular risk known to increase due to the normal ageing process. The transmural pressure results in a circumferential stress. Because of the balance of forces the transmural pressure $P$ times artery radius $R$ should equal the wall thickness times circumferential stress (Law of Laplace) [10]. Consequently, a higher blood pressure is associated with a larger wall thickness, especially for elastic arteries where a higher blood pressure can not be compensated for by a smaller radius as may happen in muscular arteries. Artery wall thickness will be addressed in a separate section. The dynamic stress-strain relationship of the arterial wall is expressed by the distensibility, defined as the relative increase in volume of an arterial segment divided by the pulse pressure. It is a measure of the dynamic load of the wall, while the Law of Laplace considers the static load.

Women tend to differ from men regarding the development of cardiovascular disease; they seem to be protected during their reproductive life $[11,12]$. After the menopause, they catch up with men as far as the prevalence of cardiovascular 
disease is concerned. The disappearance of the difference between men and women has been argued to be due to the lack of female sex homones, especialiy oestrogen, after the menopause $[11,13,14]$. Oestrogen replacement therapy has a protective effect on cardiovascular disease unlikely to be explained by confounding factors [15]. A meta-analysis of 31 studies calculated a relative risk of 0.56 (95\% CI 0.50-0.61). It may quite well be that female sex hormones influence arterial wall properties, because female sex hormone receptors have been shown to be present in the artery wall on both endothelium and vascular smooth muscle cells [16-21]. In two studies, it was shown that the distensibility of the aorta [22] and of the carotid artery [23] was significantly lower in male subjects than in age-matched females. François found stiffer carotid, brachial and leg arteries in men than in women of the same age. In contrast, the findings of Riley et al. indicate that the carotid artery is less distensible in females than in males [25]. Similar results were obtained in a study by Van Merode et al., who found distensibility and compliance to be significantly lower in females than in males in all age categories investigated [26]. A possible explanation for these discrepancies could be that different levels of circulating endogenous or exogenous hormone levels were present during the examinations in women, because the menstrual cycle and the use of oral contraceptives were not considered in these studies. Furthermore, several of these studies were cross-sectional in nature not taking into account any time effects. An overview is given in Table 1.

\subsection{Artery wall anatomy}

The arterial wall can be subdivided into three layers: the intima, the media, and the adventitia (Figure 1). The intima consists of a single layer of endothelial cells supported by smooth muscle cells. The intima is separated from the media by the lamina elastica interna, consisting solely of elastic lamellae [27]. The media consists of elastin and collagen fibrils and vascular smooth muscle cells [28]. The amount of elastin decreases relative to the amount of collagen from central to peripheral arteries, whereas the number of vascular smooth muscle cells increases [29]. Therefore, the proximal arteries are more elastic and have a buffering function, while the distal arteries are muscular and have a mainly conductive function [10]. The adventitia is composed of proteoglycans, fibroblasts and collagen arranged in bundles. 


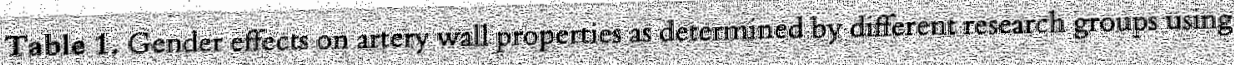
diferent ine thods:

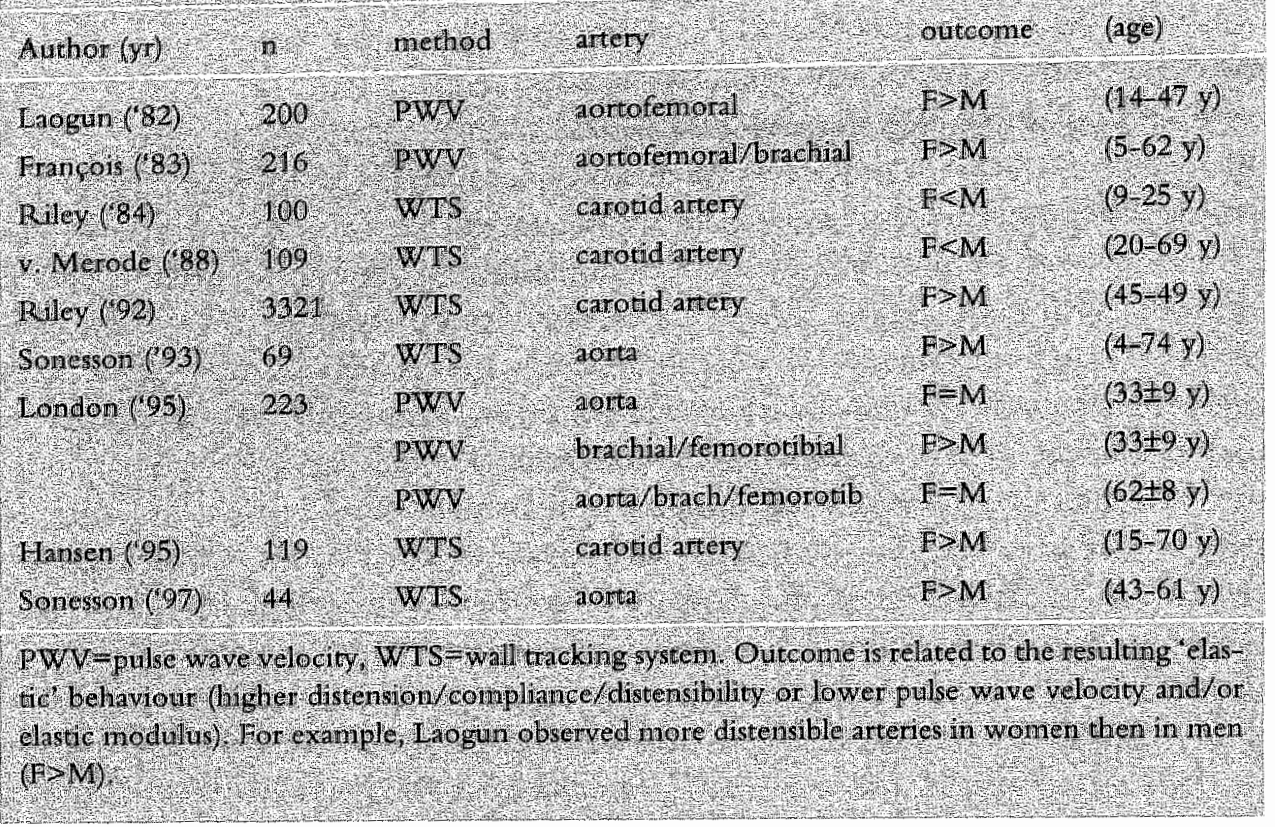

\subsection{Artery wall function}

The functional behaviour of the arterial system can be described in terms of compliance and distensibility as a representative of dynamic artery wall properties. The compliance, the absolute change in volume for a change in pressure, represents the cushioning function of the arterial system to the workload exerted on it by the heart, whereas the distensibility, the relative change in volume of an arterial segment as a consequence of a change in pressure, describes the pressure/strain relation of an artery. Assuming that arteries are tethered at their in vivo length and that the change in volume occurs mostly due to a change in cross-sectional area, the change in volume can be replaced by a change in area [30]. Under the assumption that arteries are circular in shape and that the relative increase in area is small relative to the absolute area, the change in area can be replaced by a change in diameter. Then the capacity to store a volume of blood in an artery is given by the compliance coefficient $\mathrm{CC}$ :

$$
\mathrm{CC}=(\pi \mathrm{D} \Delta \mathrm{D}) /(2 \Delta \mathrm{P})
$$




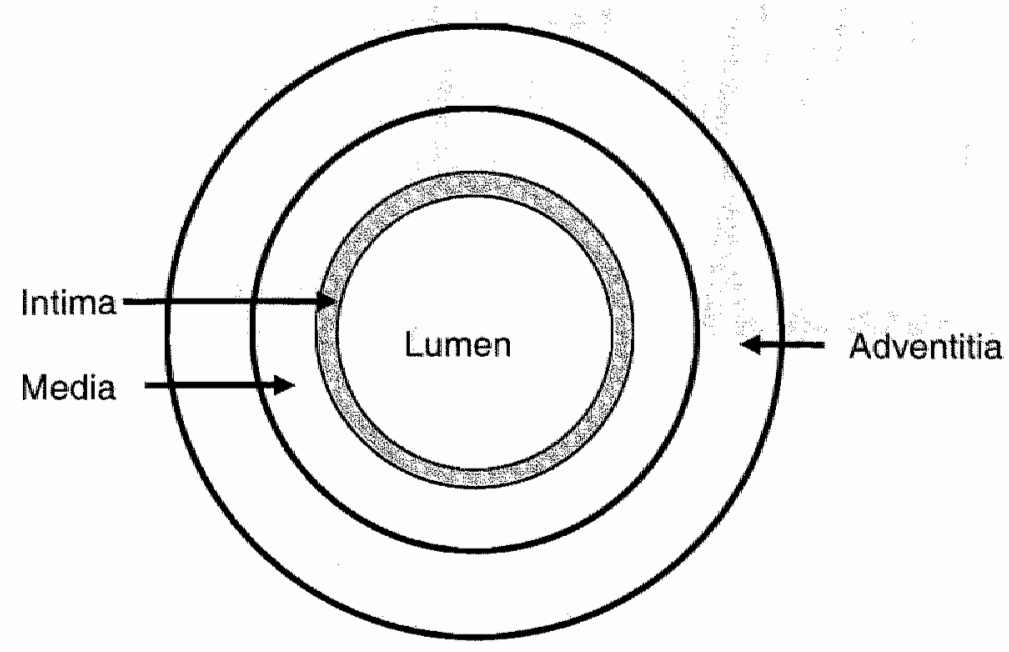

Fïgure 1. Schematic presentarion of the different layers of the wascular wall.

The mechanical stress-strain relationship of the arterial wall is described by the distensibility coefficient $\mathrm{DC}$ :

$$
\mathrm{DC}=2(\Delta \mathrm{D} / \mathrm{D}) / \Delta \mathrm{P}
$$

where $\mathrm{D}=$ end-diastolic diameter, $\Delta \mathrm{D}=$ change in diameter from diastole to systole, $\Delta \mathrm{D} / \mathrm{D}=$ strain and $\Delta \mathrm{P}=$ arterial pulse pressure.

$\mathrm{CC}$ and DC represent dynamic characteristics of artery wall behaviour. The incremental elastic modulus (or Young's modulus) characterises the intrinsic elastic properties of the artery wall by relating the distensibility coefficient (DC) to the ratio of wall thickness (h) and end-diastolic internal artery diameter (D):

$$
\mathrm{E}=\mathrm{D} /(\mathrm{hDC})
$$

The propagation speed $(\mathrm{VP})$ of the pulse wave along arteries is also related to the distensibility coefficient DC in the Moens-Korteweg equation:

$$
\mathrm{Vp}=1 / \sqrt{ }(\rho \cdot \mathrm{DC})
$$

where $p$ is the mass density of blood $\left(10^{3} \mathrm{~kg} / \mathrm{m}^{3}\right)$. The measurement of pulse wave velocity has the advantage that $\mathrm{DC}$ can be assessed without the necessity to assess pressure. 


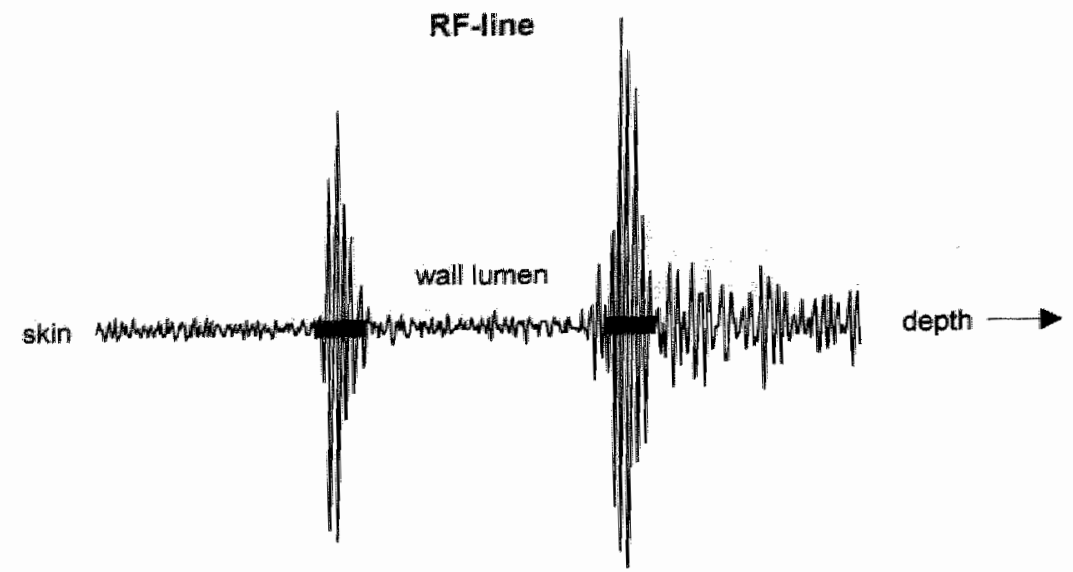

Figure 2. Radiofrequency (RF) line showing the reflections of the anterior wall (left peak) and the posterior wall (right peak) of the common carotid artery of a young volunteer.

From the above equations it can be concluded that measurement of the end-diastolic diameter, the change in diameter and the artery wall thickness will suffice to describe artery wall behaviour.

We used the ultrasonic vessel wall tracking system. (WTS) to determine D and $\Delta D$, as described in detail before [31]. In short, the instrument consists of a conventional ultrasound inaging system with a $7.5 \mathrm{MHz}$ linear array probe (Pie Medical, Maastricht, The Netherlands), and a data-acquisition system connected to a personal computer. The measured pulse length at $-6 \mathrm{~dB}$ received from a target at a distance of $20 \mathrm{~mm}$ is $350 \mathrm{~ns}$, corresponding to an axial resolution of approximately $260 \mu \mathrm{m}$. During the vascular examination the artery of interest was imaged in B-mode in a longitudinal section, $2-3 \mathrm{~cm}$ proximal to the flow divider, where after an M-line was positioned perpendicular to the vessel wall. The ultrasound system was switched to $M$-mode and synchronous with the ECG data were collected during a period of about 4 seconds covering 3-5 heart beats. The raw radiofrequency (RF) data were temporarily stored in an $1 \mathrm{MByte}$ large memory. The anterior and posterior walls of the artery were identified manually by placing sample volumes (cursors) by the examiner on the wall reflections as seen in the first captured RF-line, displayed on the computer monitor (Figure 2).

Consecutively, the data were transferred line by line to the computer. A cross-correlation algorithm calculated the cumulative change in phase between corresponding segments of successive RF lines for both walls, hereby continuously following the artery walls during motion (tracking). Eventually, the displacement of the anterior and the posterior wall was shown simultaneously with the difference between these displacements, representing the change in diameter during the 


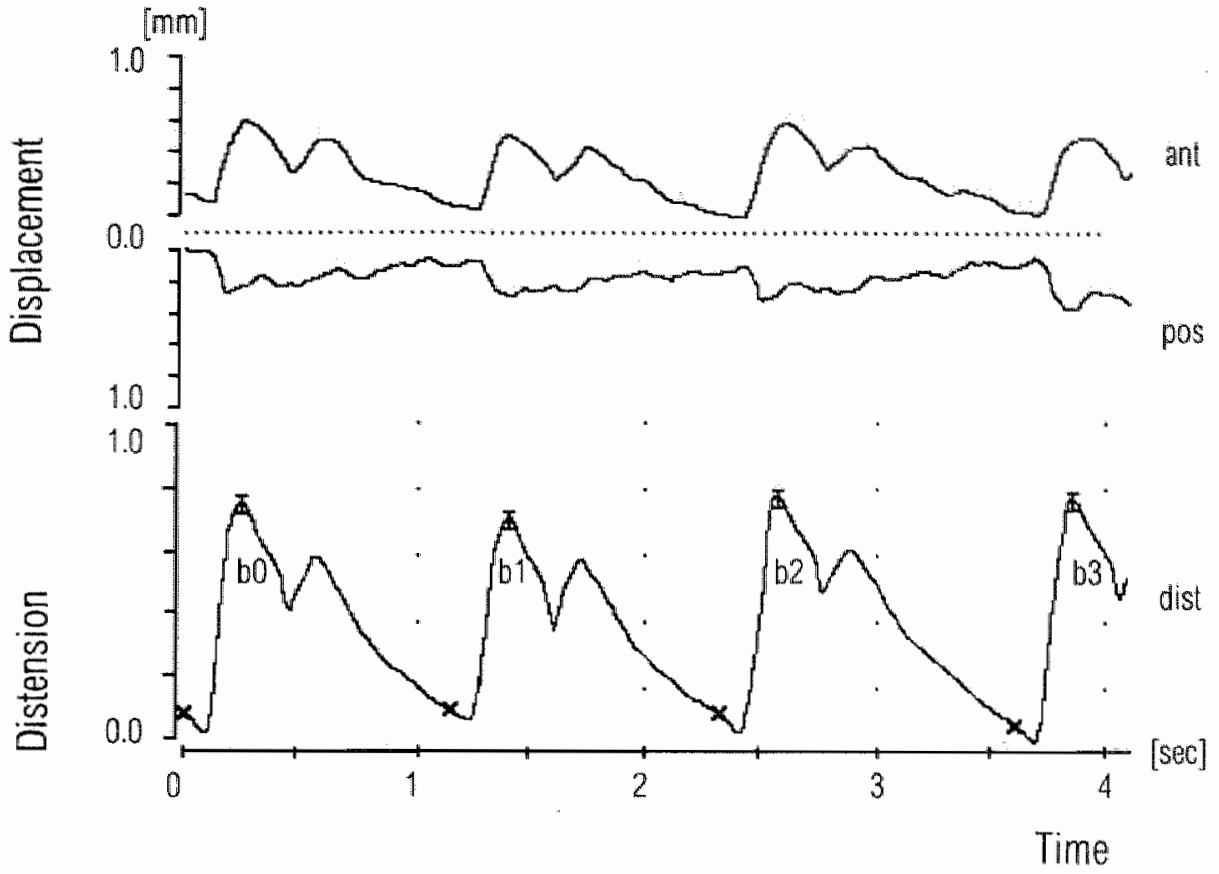

Figure 3. Displacement curves of the anterior (ant) and posterior (pos) walls of the common carocid artery in a healthy young female (age 20 years). The bottom trace is the difference between the displacements of both arterial walls and represents the change in arterial diameter during the cardiac cycle. The first sign of the distension tracing refers to the trigger of the R-wave of the ECG (x), after which detection of end diastole and peak systole (I) starts. Abbreviations: $b=$ heart beat; dist $=$ distension.

cardiac cycle (distension; Figure 3 ). The arterial end-diastolic diameter (D) and the change in diameter from diastole to systole $(\Delta \mathrm{D})$ for each captured heart beat were provided as well.

Simultaneously arterial blood pressure measurements were obtained every three minutes at the level of the brachial artery by means of a semi-automated oscillometric device (DINAMAP; Criticon, Tampa, FL, USA). Pulse pressure (PP), defined as systolic minus diastolic blood pressure, was determined by averaging the three measurements nearest to the distension measurements. Three reproducible (standard deviation of 3-5 heartbeats< $10 \%$ ) measurements were obtained and averaged for further calculation. Measurements were compared using the cardiac cycle because of the linear range of distension and because of the practicality for comparison. 
Reliable assessment of distensibility and compliance requires the determination of $\Delta \mathrm{P}$ at the site of measurement of $\mathrm{D}$ and $\Delta \mathrm{D}$ or at a representative site elsewhere. It has been shown that for the assessment of these parameters in the carotid artery brachial $\Delta P$ is a good substitute [32]. The femoral artery pulse pressure can not be substituted by the brachial artery pulse pressure, as we have observed in our institute. However, we will compare differences in time in the same person, thereby assuming that the measurement difference will be methodological in nature and not influence the direction of the change observed.

Different parts of the arterial tree can be accessed enabling the comparison of wall properties in elastic and muscular type arteries. It is of importance to separate both types of arteries, because of the difference in wall composition and the different functional behaviour. Elastic type arteries, containing more elastic lamellae in the extracellular matrix, can be seen as passive arteries changing their end-diastolic diameter and distension under the influence of local changes in transmural pressure. On the other hand, muscular type arteries, having a larger relative proportion of vascular smooth muscle cells and collagen in the extracellular matrix, try to maintain blood flow and mean wall shear stress by varying the arterial end-diastolic diameter and distension (absolute change in diameter from diastole to systole). This is achieved by release of vasoactive substances by the endothelium under the influence of transmural pressure and wall shear stress leading to changes in vascular smooth muscle cell activation in the media. Therefore, different types of arteries may exhibit different functional behaviour as a result of their passive and active nature.

\subsection{Artery wall thickness}

As indicated already by balancing forces exerted on the arterial wall, arteries can adapt to an increase in transmural pressure by an increase in artery wall thickness. With non-invasive ultrasound techniques, the physiological and/or pathological state of arteries can be investigated with only minimal discomfort or intervention. Conventionally, two dimensional brightness mode was used to visualise the artery of interest in a plane perpendicular to the ultrasound beam, thereby optimising the reflections of the different artery wall layers. Only transitions with a substantial change in acoustic impedance will be seen (Figure 4).

The transition of the intima to the lumen will induce a relatively weak signal while the media-adventitia transition will give a relatively large signal. The media will be seen as a dark, relatively hypo-echoic layer in between the intima and the adventitia. From the B-mode image, the lumen diameter and the wall thickness can be obtained. The transition between the adventitia and the surrounding tissue 


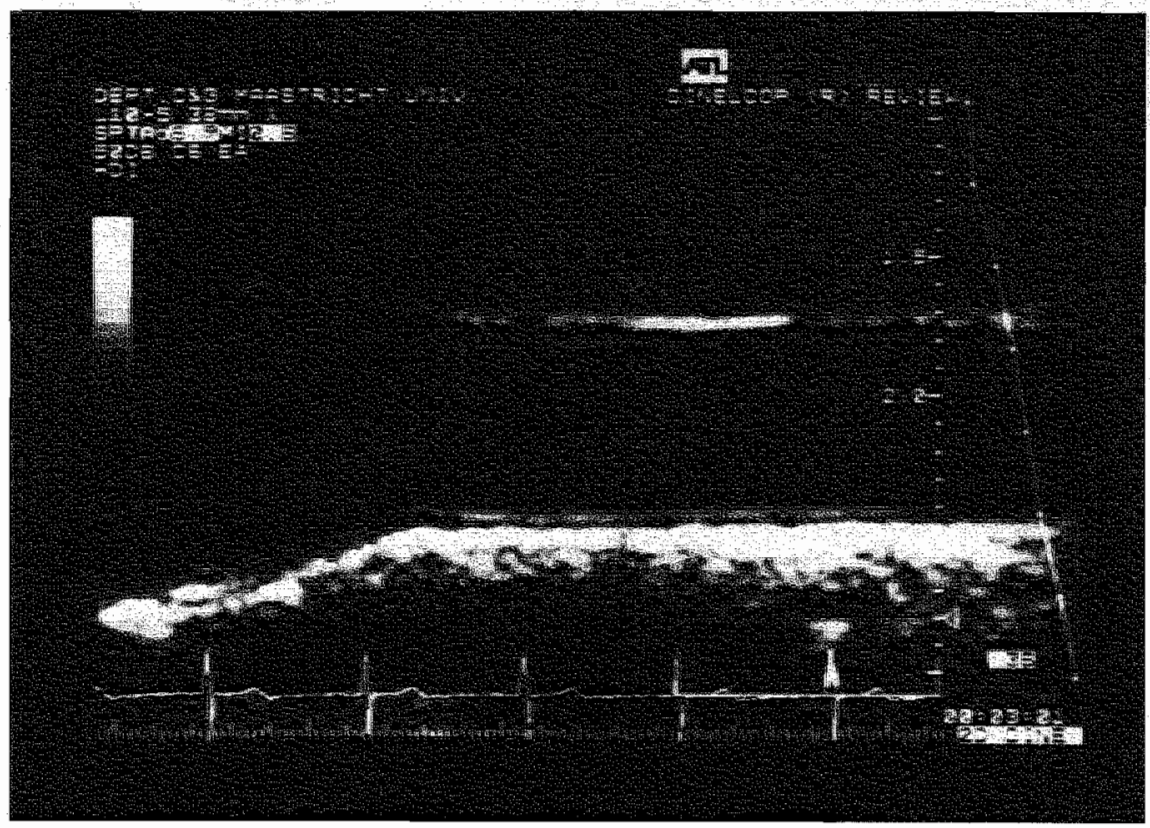

Figure 4. B-mode photography of the right common carotid artery in a 52 -y-old healthy volunteer obtained using the Ultramark 9. The intma-nedia complex clearly is visible at the posterior and anterior common carotid artery wall over a distance of at least $1 \mathrm{~cm}$. At the left, the widening of the bulb is used as a landmark for intima-media thickness measurements.

is unclear as the connective tissue in which arteries are embedded also exhibit high ultrasound signals. Therefore, not wall thickness, but only intima-media thickness (IMT) can be obtained as a representative. Intima-media thickness is normally obtained only at the posterior wall, because the trailing edge of the adventitia signal of the anterior wall will partly obscure the media and influence the measurement of the intima-media thickness of the anterior wall.

In the past decade, IMT of the artery wall has gained increasing attention, because it is assumed to represent the endothelial adaptive response to physiological and pathophysiological processes as, for example, seen in ageing and hypertension [33-37]. A variety of IMT measurement protocols, based on difterent ultrasound methods, have been developed and improved in order to obtain reliable and reproducible results [37-44].

In 1984, Pignoli et al., using calipers, already showed that in vitro artery wall thickness can be assessed reliably and accurately by means of B-mode inaging and the results obtained correlated well with histological examinations [45]. In 1986, it was demonstrated that IMT can also be assessed in vivo and that it indeed represents the true intima-media complex as confirmed by histological recognition 
[46]. The method, however, shows considerable variation. This can partly be attributed to the limited axial resolution and the relatively poor magnification of the $\mathrm{B}$-mode imagers at that time. Thanks to technical improvements in displaying the received B-mode sigual and better zoom passibilities, the current ultrasound devices are capable of disceming intina-media complexes more accurately with a precision of $0.1 \mathrm{~mm}[47]$

One of the other methods to measure IMT used automated digitisation of the B-mode innage, after capturing it in a preselected phase of the cardiac cycle with a frame grabber, and subsequent off-line analysis $[41,48]$. To delineate the different boundaries of the intima and media, markers had to be placed manually on the video inage $[48,49]$. This is time-consuming and introduces some subjectivity, dependent on the reflectivity of the structures and the gain setting and signal compression characteristics of the ultrasound system. The process was improved and speeded up by automated interpolation of the intima-media complex after simple identification by the observer $[50,51]$. This improved the reproducibility of the procedure and rendered it more user-independent. Additionally, automated spatial averaging procedures circumvented the dependence of the outcome on the threshold level by adjusting the threshold according to the local characteristics of the non-linear B-mode signal $[42,44]$. The off-line manual as well as off-line automated B-mode IMT methods provide a mean IMT over a length of at least 10 mm. On the other hand, it is of interest to assess local changes in artery wall behaviour and thickness because the arterial tree is heterogeneous and locations near arterial branching and divisions are especially prone for the development of atherosclerosis. The $\mathrm{B}$ - and $\mathrm{M}$-mode signals displayed on the ultrasound monitor are derived from the received raw radiofrequent (RF) signals, which can also be used to measure IMT locally by manually placing markers on amplitude signals of the blood intima interface and the media adventitia interface as induced by the end-diastolic R.F-line (figure 5).

Besides information on changes in artery wall thickness, IMT can also be used to calculate the Young's modulus representing structural artery wall behaviour (see above).

\subsection{Fimale sex hormones}

Oestradiol (E2) and Progesterone (P) are the two main female endogeneous sex hormones produced by the ovaries due to a rise in plasma levels of follicular stimulating hormone (FSH) and luteinising homone ( $\mathrm{CH})$. In the first part of the menstrual cycle, also known as the follicular phase, a rise in oestrogen in the venous blood is observed. In the second phase, the luteal phase, progesterone is 


\section{RF-line Wall Track System}

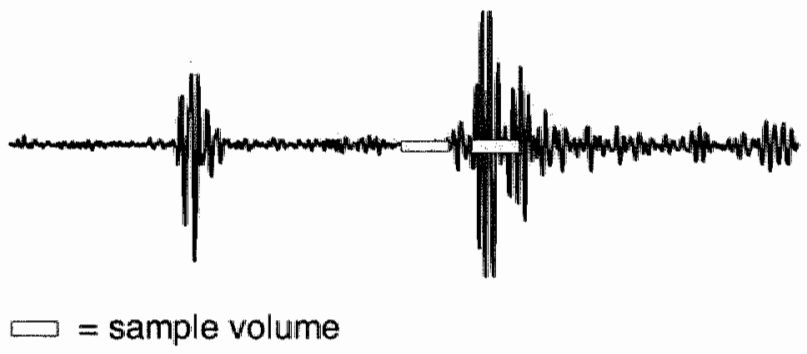

Figure 5. Off-line detection of the intima-media thickness of the posterior wall of the common carotid artery by placement of the right side of the left sample volume at the beginning of the lumen-intima reflection and the left side of the right sample volume at the beginning of the media-adventita tansition. The distance between both edges of the sample volumes is presented with a precision of two decimal places.

also detected in the venous plasma, mainly after ovulation, i.e. the rupture of the follicle. The two phases can be further subdivided according to different levels of oestrogen and progesterone in respect to the central event of the reproductive cycle, namely ovulation.

Exogenous female sex hormones are steroid structures mimicing the endogenous function of female sex hormones with one main difference that when they are ingested orally, the liver reduces the plasma levels of circulating hormones drastically [52]. Oral administration of oestradiol leads to hormone concentrations 4 to 5 times higher in hepatic sinusoidal blood than in peripheral blood. As a consequence of this so called "first pass effect", liver metabolism is influenced and especially protein synthesis. The main effects are a beneficial change in the lipid profile [53]. Progesterone has opposite effects on lipid metabolism, depending on the type of oral progesterone used. It seems that the 19-nortestosteron derivatives gestodene and desogestrel have low androgenic properties and therefore exhibit less countereffects on the beneficial changes in lipid plasma levels induced by oestrogen $[54,55]$. By means of indirect effects of hormone replacement therapy (especially estrogen) on lipid metabolism, it is bellieved that $25-50 \%$ of the risk for cardiovascular disease can be explained [56].

Endogenous and exogenous female sex hormone also have a variety of direct effects on the arterial system. Oestrogens exert effects on vascular function and structure of the vessel wall involving numerous cellular and molecular mechanisms 
[57] (Figure 6). Endogenous oestrogens can uncrease nitric oxide production via stimulation of endothelial nitric oxide synthase (eNOS) and decrease endothelin-1 levels in wivo $[58,59]$. Furthermore, $17 \beta$-oestradiol is an inhibitor of vascular smooth muscle cell proliferation and migration, phenomena that play a role in atherosclerotic vascular disease and in the remodelling process [60]. 17 $\beta$-oestradio] can also acutely affect vascular tone in human arteries and attenuate constriction induced by contractile agents [61]. Acetylcholine-minduced vasoconstriction in the coronary circulation is attenuated [62], or abolished [63] after the administration of oestrogen in post-menopausal women with atherosclenotic coronary arteries. Finally, clinical studies have shown that $17 \beta$-oestradiol can acutely and chronically ameliorate vascular function in women with and without vascular disease [64-67].

Exogenous oestrogens have been studied extensively regarding their effect on the arterial wall in in vitro studies and in pivo studies in animals and humans. Several animal studies have shown that oestrogen has a beneficial effect on the formation and development of atherosclerotic placques [68-70] by reducing LDL accumulation, arterial cholesterol infux and hydrolysis in the arterial wall. Oestrogen reduces arterial smooth muscle cell proliferation [71] and inhibits stress-induced and mechanically injury induced myointimal proliferation [72]. Oestrogen produces a decrease in production of elastin and especially of collagen [73-75]. $\mathrm{m}$ viwo studies in animals have demonstrated that conjugated equine estrogens in cynomolgous monkeys induced inhibition of initiation and progression of coronary artery atherosclerosis compared to a control group devoid of oestrogen replacement therapy [76]. Last but not least, in vivo studies in humans have shown a decrease in the peripheral resistance measured by the pulsatility index (PI) in several parts of the arterial tree $[77,78]$, but especially in target organ vessels as the uterine arteries $[79,807$. Also, the resistance in the cerebral circulation has been shown to be beneficially influenced by the administration of oestrogen $[81,83]$. The importance of the role of oestrogen is also indicated by the observation of a study on artery wall properties in age-matched healthy pre-and postmenopausal women showing a decrease in arterial distension of the carotid artery in postmenopausal compared to premenopausal women [84].

Female sex homones can indace changes in arterial wall composition and function by means of a direct effect. The underlying mechanisms are still subject of investigation, but some propositions have been made. It is clear that functional oestrogen receptors are present in the endothelium and in vascular smooth muscle cells of different vascular beds $[16,19,20,85]$. This may account for part of the long term effects of female sex homones. However, oestrogen can induce rapid changes in artarial blood flow[86], believed to be mediated, amongst others, by endothelium-dependent and-independent mechanisms. Changes in the production of endothelium derived relaxing factor (EDRF), also known as nitric oxide 


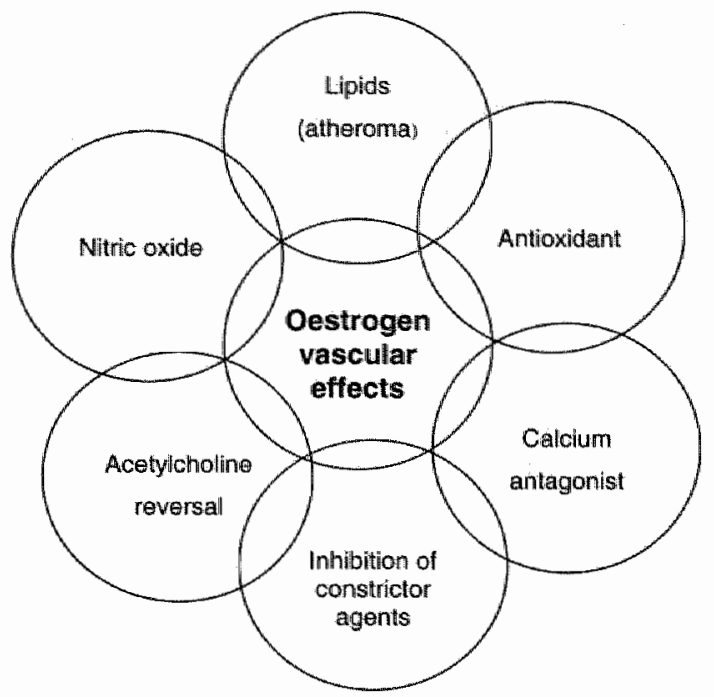

Figure 6. Potential mechanisms of oestrogen on the vascular wall.

(NO), and endothelin-1 (ET-1) in the endothelial cell give rise to either vasodilatation or vasoconstriction by a change in the production of cyclic GMP in the vascular smooth muscle cell. Oestrogen is believed to directly affect the production of $\mathrm{NO}$ by stimulation of $\mathrm{NO}$-synthase, and indirectly by muscarinic receptors $[58,87]$. Oestrogen has calcium-antagonistic effects, leading to an indirect increased release of $\mathrm{NO}$, and direct vascular smooth muscle cell relaxation [88]. Also, long-term effects of oestrogen of oestrogen in atherosclerotic, ovariectomized cynomolgus monkeys showed a decrease in coronary atheroma, possibly due to calcium antagonistic properties in vivo [89]. Inhibition of atherogenesis, as a result of oestrogen substitution, may be the result of a reduction of LDL accumulation and arterial cholesterol influx and hydrolysis in the arterial wall. Also, oxidation of LDL is decreased in an oestrogen environment. Atherosclerosis impairs acetylcholine mediated vascular responses $[76,90]$, whereas reversal of acetylcholine induced vasoconstriction occurs after administration of physiological doses of intra-coronary 17ß-oestradiol [91]. All the above mentioned mechanisms will likely be synergistic in action. 


\subsection{Aims of the study}

The process of arterial decay already starts at reproductive age as demonstrated by a decrease in the arterial distensibility and compliance, especially in elastic arteries. With increasing age, especially blood systolic pressure rises and hypertension is more likely to develop, whereas atherosclerosis is seen more frequently during (non-)invasive investigations. Compared to men, women seem to be protected from cardiovascular disease until menopause. The difference in circulating levels of (female) sex hormones in various age categories has been the subject of many investigations, but their results have not been conclusive. However, in studies on the effect of gender on artery wall behaviour, no account was taken of the phase of the menstrual cycle of the women or whether they did use oral contraceptives. At higher ages, use of hormone replacement therapy was not mentioned.

In this light, the aims of the present study were:

1. to assess the short term influence of different levels of endogenous and exogenous fernale sex hormones on the wall properties of the common carotid artery as well as the common fenoral artery in women of reproductive age (Chapters 3 and 4 ).

2. to determine the long term effect of hormone replacement therapy on the dynamic properties of the wall of the common carotid artery and the common femoral as well as the structure of the common carotid artery in postmenopausal women (Chapter 8).

3. Because we wanted to investigate dynamic artery wall properties simultaneously with the structure of the arterial wall i.e., artery wall thickness, we developed a new method to assess locally intima-media thickness as a representative of artery wall thickness (Chapter 5)

4. The reproducibility of this method was established in a phantom and its in vivo intra- and intersession reproducibility was assessed (Chapters 5, 6 and 7)

5. The sensitivity and selectivity of this new method was demonstrated by the assessment of the intima-media thickness at different locations in the common carocid artery in different age groups (Chapter 7).

6. Because we noticed in pilot experiments that a full bladder might influence dynamic wall properties of the femoral artery, the effect of a full bladder was investigated (Chapter 2)

The thesis ends with a general discussion (Chapter 9) 


\section{References}

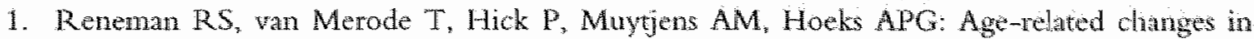
carotid artery wall properties in men. Ultrasound Med Biol. 1986:12(6):465-71.

2. Safar M: Ageing and its effects on the cardiovascular system. Drugs. 1990;39 Suppl 1:1-8.

3. van Merode T, Lodder J, Smeets FAM, Hoeks APG, Reneman RS: Accurate nonimwasive method to diagnose minor atherosclerotic lesions in carotid artery bulb. Stroke. $1989 ; 20(10): 1336-40$.

4. Bond MG. Conceptual issues in the quantification and monitoning of atherosclerosis. Procedings

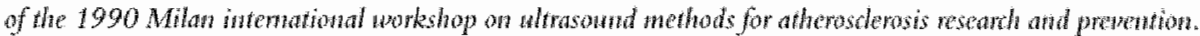
Milan, Italy; 1990.

5. Wendelhag 1 , Wiklund $O$, Wikstrand $]$ : On quantifying plaque size and intima-media thickness in carotid and femoral arteries. Comments on results from a prospective ulltrasound study in patients with familial hypercholesteroliemia. Arterioscler Thromb Vasc Biol. 1996:16(7):843-50.

6. Glagow $\mathrm{S}, \mathrm{Vito} \mathrm{R}$, Giddens $\mathrm{DP}$, Zarins $\mathrm{CK}$ : Micro-architecture and composition of artery walls: relationship to location, dimeter and the distribution of mechanical stress. I Hypartens Suppl. $1992 ; 10(6): \$ 101-4$.

7. Learoyd BM, Taylor MG: Alterations with age in the viscoellastic propertics of human arterial walls. Circ Res. 1966;18(3):278-92.

8. Reneman RS, Hoeks APG, Westerhof N: Non-invasive assessment of attery wall properties in humans - methods and interpretations. J Vasc Invest. 1996;2:53-64.

9. Hoeks APG, Brands PJ, Willigers JM, Remenan RS: Non-invasive measurement of mechanical properties of arteries in health and disease. Proc Instn Mech Engrs. 1999:213(H):195-202.

10. Nichols WN, ORourke MF. McDonald's blood flow in arteries. London: Edward Annold; 1990.

11. Colditz GA, Willett WC, Stampfer MJ, Rosner B, Speizer FE, Hemekens CH: Menopause and the risk of coronary heart disease in women. N Eng J Med. 1987;3 $16(18): 1105-10$.

12. Barrett-Connor E, Bush TL: Estrogen and coronary heart disease in wonnen. JAMA. $1991 ; 265: 1861-7$.

13. Bush TL, Barrett Connor E, Cowan LD, Criquil MH, Wallace RB, Suchindwan CM, Tyroler HA, Rifkind BM: Cardiovascular mortality and noncontraceptive use of estrogen in wonen: results from the Lipid Research Clinics Program Follow-up Study. Circulation. 1987; $75(6)$ : $1.102-9$.

14. Grady D, Rubin SM, Petitti DB, Fox CS, Black D, Ertinger B, Enster VL, Cummings SR: Homone therapy to prevent disease and prolong life in posmenopatual women lsece conments]. Ann Intern Med. 1992;117(12):1016-37.

15. Stampfer MJ, Colditz GA: Estrogen replacement therapy and coronary theart disease: a quantitative assessment of the epidemologic evidence. Prev Med. 1991;20(1):47-63.

16. Campisi D, Bivona A, Paterna S, Valenza M, Albiero R: Oestrogen binding sites in fresh human aortic tissue. Int J Tissue React. 1987;9(5)-393-8.

17. Lin AL, Shain SA: Estrogen-mediated cytoplasmic and nuclear distribution of rat cardiowascular estrogen receptors. Arteriosclerosis. 1985;5(6):668-77.

18. Lin AL, Gonzalez R, Jr., Carey KD, Shain SA: Estradiol-17 beta affects estrogen receptor distribution and elevates progesterone receptor content in baboon aonta. Arteriosclerosis. $1986 ; 6(5): 495-504$.

19. Lin AL, Gonzalez R, Jr., Carey KD. Shain SA: Gender and baboon aortic steroid homone receptors. Arteriosclerosis. 1987;7(3):248-55. 
20. Perrot Applanat M, Groyer Picard MT, Garcia E, Lorenzo F, Milgron E: Immunocytochemical demonstration of estrogen and progesterone receptors in muscle cells of uterine arteries in rabbits and humans. Endocrinology. 1988:123(3):1511-9.

21. Lonordo DW, Kearney M, Kun EA, Jekanowski J, Isner JM: Variable expression of the estrogen receptor in momal and atherosclerotic coronary arteries of premenopausal women. Circulation. $1994 ; 89: 1501-10$.

22. Laogum A.A. Gosing RG: In wo arterial compliance in man. Clin Phys Physiol Meas. 1982;3(3): $201-12$

23. Hansen $\mathbb{F}_{*}$ Mangel P, Sonesson B, Lâne T: Diameter and compliance in the human common. carotid artery w wariations with age and sex. Ultrasound Med Biol. 1995;21(1):1-9.

24. François B: Alteration in arterial wall elasticity in the young. Clin Gen. 1983;24:287.

25. Riley WA, Barnes RW, Schey HM: An approach to the non-invasive periodic assessment of arterial ellasticity in the young. Prevent Med. 1984;13:169-84.

26. Merode wan T. Hick PJ, Hoeks APG, Smeets FAM, Reneman RS. Differences in carotid artery wall properties between presumed-healthy men and women. Ultrasound Med Biof. 1988;14(7): $571-4$

27. Stary HC, Blankenhorn DH, Bleakley Chandler A, Glagov S, Insull Jr. W, Richardson M, Rosenfeld ME, Schaffer A, Schwartz C, Wagner WD, Wissler RW: A definition of the intima of human arteries and of its atherosclerosis-prone regions. A report from the committee on vascular lesions of the council on arteriosclerosis, American Heart Association. Arterioscler Thromb. 1992;12(1):120-34.

28. Greenwald SE, Berry CL: Static mechanical properties and chemical composition of the aorta of spontaneously hypertensive rats: a comparison with the effects of induced hypertension. Cardiovasc Res. 1978; 12:364-72.

29. Harkness MLR, Harkness RD, McDonald DA: The collagen and ellastin content of the arteral wall in the dog. Proc Royal Soc. 1957;146B:541-51.

30. Reneman RS, Hoeks APG: Diameter and compliance in the human aorta - variations with age and sex. Ultrasound Med Biol, 1996;22:271-2.

31. Hocks APG, Brands PJ, Smeets FAM. Reneman RS: Assessment of the distensibility of superficial arteries. Ultrasound Med Biol. 1990;16(2) 121-8.

32. Reneman RS, van Merode T, Brands PJ. Hoeks APG: Inhomogeneities in arterial all properties under normal and pathological conditions. J Hypertens Suppl. 1992;10(6):535-9.

33. Salonen R. Salonen JT: Progression of carotid atherosclerosis and its determinants: at population-based ultrasonography study. Atherosclerosis. $1990 ; 81(1): 33-40$.

34. Salonem JT, Sallonen R: Ultrasonographically assessed carotid morphology and the risk of coronary heart disease. Arterioscler Thromb. 1991;11(5):1245-9.

35. Person I, Formgren J, Isaelsson $\mathbb{B}$. Berglund $G$ : Ultrasound-detemined intimamedia thickness and athenoscleroxis. Direct and indirect validation. Arterioscler Thromb. 1994;14(2):261-4.

36. O'Leary DH, Polak JF, Kronmal R.A. Savage PJ, Borhani NO, Kitmer SJ, Tracy R, Gardin JM, Price TR, Furbetg CD: Thickening of the carotid wall. A marker for atherosclerosis in the dderly? Cardiovascular Health Study Collabonative Research Group. Stroke. 1996:27(2): $224-31$

37. Wong M, Edwstein J, Wollnan J, Bond MG: Ultrasonic-pathological comparison of the humatn arterial wall. Verification of intina-nedia thickness. Arterioscler Thromb. 1993;13(4):482-6.

38. Salonen R, Hapanen A, Salonen JT: Measurement of intima-media thickness of common arotid arteries with high-resolution B-mode ultrasonography: inter- and intra-observer variability. Ultrasound Med Biol. 1991:17(3):225-30.

39. Pignoli P. Longo T: Ultrasonnd evaluation of atherosclerosis. Methodological problems and technological developments. Eur Surg Res. 1986;18(3-4):238-53 
40. Persson J, Stavenow L, Wikstraid J, Israelsson B, Formgren J, Berghund G: Nominwaive quartification of atherosclerotic lesions. Reproducibility of thtrasonograpliz meaturenent of arterial wall thickness and plaque size. Arterioscter Thromb, 1992;12(2):261-6.

41. Riley WA, Barnes RW, Applegate WI, Dempsey R, Hartwell T, Davis VG, Bond MG, Furberg CD: Reproducibility of noninwasiwe ultrasonic measurement of carotid atheroscherosis: The Asymptomatic Carotid Artery Plaque Study. Stroke. 1992;23(8):1062-8.

42. Selzer RH, Hodis HN, Kwong Fu H, Mack WJ, Lee PL, Liu CR, Lia CH: Evaluation of computerized edge tracking for quantifying intimamedia thickness of the common carotid artery from B-mode ultrasound images. Atherosclerosis. $1994 ; 111(1): 1-11$.

43. Hoeks APG, Willekes C, Boutouyrie P., Brands PJ, Willigers JM, Reneman RS: Automated detection of local artery wall thickness based on M-line signal processing. Ultrasound Med Biol. $1997 ; 23(7): 1017-23$.

44. Wendelhag I, Liang Q, Gustavsson T, Wikstrand I: A new automated computerized analyang system simplifies readings and reduces the variability in ultrasound measurement of intima-media thickness. Stroke. 1997;28(11):2195-200.

45. Pignoli $\mathrm{P}$ : Ultrasound $\mathrm{B}-$ mode imaging for arterial wall thickness measurement. Atheroscler Rev. 1984;12:177-84.

46. Pignoli P. Tremoli E, Poli A, Oreste P, Paoletti R: Intmall plus medial thickness of the arterial wall: a direct measurement with ultrasound imaging. Circulation. 1986;74(6):1399-406.

47. Bots ML, Hofman A, Grobbee DE: Common carotid intma-media thickness and lower extremity arterial atherosclerosis. The Rotterdam Study. Arterioscler Thromb. 1994;14(12): $1885-91$.

48. Bond GM, Bames RW, Riley WA, Wilmoth SK, Chambless LE, Howard G, Owens B: The ARIC Study Group. High-resolution B-mode ultrasound scanning methods in the atherosclerosis risk in communities study (ARIC). J Neuroimag. 1991;1(2):68-73.

49. Wendelhag I, Gustavsson T, Suurkula M, Berglund $G$, Wikstrand J: Ultrasound measurement of wall thickness in the carotid artery: fundamental principles and description of a computerized analysing system. Clin Physiol. 1991;11(6):565-77.

50. Chambless LE, Zhong MM, Amett D, Folsom AR, Riley WA, Heiss G: Variability in B-mode uitrasound measurements in the atherosclerosis risk in communities (ARJC) study. Ultrasound Mad Biol. 1996:22(5):545-54.

51. Riley WA, Craven T, Romon: A, Furberg CD: Assessment of temponal bists in longitudinal measurements of carotid intimal-medial thickness in the Asymptomatic Carotid Artery Progression Study (ACAPS). ACAPS Research Group. Ultrasound Med Biol. 199622(4): $405-11$.

52. Bolt HM: Metabolism of estrogens-matural and synthetic. Plarmacol Ther. $1979 ; 4(1): 155-81$.

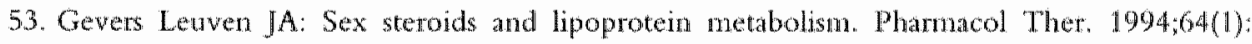
$99-126$.

54. Anderson FD: Selectivity and minimal androgenicity of norgestimate in monophasic and triphasic oral contraceptives. Acta Obstet Gynecol Scand Suppl. 1992;156:15-21.

55. Gaspard UJ: Metabolic effects of onal contraceptives. An J Obstet Gynecol. 1987;157(4 Pt 2): $1029-41$.

56. Bush TL: Evidence for primary and secondary prevention of coronaty attery disease in women taking oestrogen replacement therapy. Eur Heart J. 1996;17(Stuppl D):9-14.

5\%. Beale CM, Collins P: The menopause and the cardiovascular system. Clin Obstet Gynecol. 1996;10(3):483-513.

58. Weiner CP, Lizasoain I, Baylis SA, Knowles $R G$, Charles IG. Moncada S: Induction of calcium-dependent nitric oxide synthases by sex homones. Proc Natl Acad Sci U S A. $1994: 91(11): 5212-6$. 
59. Polderman KH, Stehowwer CDA, van Kamp GI, Dekker GA, Verheugt FWA, Gooren LJG: Influence of sex homones on plasma endothelin levels. Ann Intern Med. 1993;118:429-32.

60. Farhat MY, Lavigne MC, Ranwell PW: The vascular protective effects of estrogen. Faseb J. $1996 ; 10(5): 615-24$

61. Jiang C. Sarre PM, Poole Wilson PA, Collins P: Accte effect of 17 beta-estradiol on rabbit coronary artery contractile responses to endothelin-1. Ani f Physiol. 1992;263(1 Pr 2):H271-5.

62. Reis SE, Gloth SI, Blumenthal RS, Zacur H, Gerstenblith G, Brinker JA: Acute effects of intravenous estrogen on coronary artery vasoreactivity in postrmenopausal women. Circulation. $1992,86(4)$ I $I-866$.

63. Collins P. Rosano GMC, Sartel PM, al e: Estradiol-17B atienuates acetylcholine-induced coronary arterial constriction in women but not in men with coronary heart disease. Circulation. $1995 ; 92: 24-30$.

64. Sarrel PM: Ovarian hormones and the circulation. Maturitas. 1990;12(3):287-98.

65. Rosano GMC, Sarrel PM, Poole-Wilson PA, Collins P. Beneficial effect of oestrogen on exercise-induced myocardial ischaemia in women with coronary artery disease. Lancet. 1993; $342: 133-6$.

66. Gilligan DM, Badar DM, Panza JA, Quyyumi AA, Cannorn RO, 3rd: Acute vascular effects of estrogen in postmenopausal women. Circularion. 1994;90(2):786-91.

67. Volterrani M, Rosano GMC, Coats A, Beale C, Collins P: Estrogen acutely increases peripheral blood flow in postmenopausal women. Am J Medi. 1995;99:119-22.

68. Haarbo J, Leth Espensen $P_{*}$ Stender S, Christiansen C: Estrogen monotherapy and combined estrogen-progestogen replacement therapy attenuate aortic accumulation of cholesterol in ovariectomized cholesterol-fed rabbits. J Clin Invest. 1991;87:1274-9.

69. Hantbo J, Svendsen $O L$, Christiansen $C$ : Progestogens do not affect aortic accumulation of cholesterol in ovariectomized cholesterol-fed rabbits. Circ Res. 1992;70:1198-202.

70. Hough JL, Zilversmith DB: Effect of 17 beta estradiol on aortic cholesterol content and metabolism in cholesterol-fed rabbits. Arteriosclerosis. 1986;6(1):57-63.

71. Vargas RV, Wroblewska B, Rego A, Hatch J, Ramwell PW: Oestradiol inhibics smooth muscle cell proliferation of pig coronary artery. Br J Pharmacol. 1993;109:612-7.

72. Cheng LP, Kuwara M, Jacobsson J, Foegh ML: Inhibition of myointimal hyperplasia and macrophage infiltration by estradiol in aorta allografts. Transplantation. 1991;52(6):967-72.

73. Fischer GM: In vivo effects of estradiol on collagen and elastin dynamics in rat aorta. Endocrinology. 1972;91:1227-32.

74. Fischer GM. Swain ML: Effects of estradiol and progesterone on the increased synthesis of collagen in atherosclerotic rabbit aortas. Atherosclerosis. 1985;54:177-85.

75. Beldekas JC, Smith B, Gerstenfeld LC, Soneshein GE, Franzblat C. Effects of $17 \beta$-estradiol on the biosynthesis of collagen in cultured bovine aortic smooth muscle cells. Biochemistry. 1.98: $: 20: 313-20$.

76. Willians JK, Adams MR, Klopfenstein HS: Estrogen modulates responses of atherosclerotic Coronary arteries. Circulation, 1990,81(5):1680-7.

77. Lau TK, Chung TKH, Haines CJ: A preliminary study on the effect of homone replacement therapy on peripheral thow velocity in postmenopatusal women. Maturitas. 1997:26:53-56.

78. Lau TK, Wan D, Ym SF, Sanderson JE, Haines CJ: Prospective, randonized, controlled study of the effect of hormone replacement therapy on peripheral blood tlow velocity in postmenopausal women. Fertil Steril. 1998:70(2):284-288.

79. de Ziegler D, Bessis R, Frydman R: Vascular resistance of uterine arteries: physiological effects of estradiol and progesterone. Fertil Steril. 1991;55(4):775-9. 
80. Hillard TC, Boume TH, Whitehead MI Cayford TB, Collins WP. Camplell S: Differential effects of transdermal estradiol and sequential progestogens on impedance to fow within the uterine arteries of postmenopausal women. Fertil Steril 1992,58(5,959-63.

81. Gangar KF, Vyas S, Whitehead M, Crook D, Meire H, Campbell S. Pulsatiliny index in intermal carotid artery in relation to transdermal oestradiol and time since monopause. Lancet. $1991 ; 338(8771): 839-42$

82. Penoti M, Nencioni T, Gabrielli L, Farina M, Castiglioni E, Polvani F: Blood flow variations in internal carotid and middle cerebral arteries induced by postmenopausal homone rephacement therapy. Am J Obstet Gynecol. 1993;169(5):1226-32.

83. Paganini-Hill A, Ross $\mathbb{R K}$, Henderson BE: Postmenopausal oestrogen treatment and stroke: a prospective study. BMJ. 1988;297(6647):519-22.

84. Westendorp 1CD, Bots ML, Grobbee DE, Reneman RS, Hoeks APG, Van Popele NM, Hofman A, M. WJC: Menopausal status and distensibility of the common carotid arrery. Arterioscler Thromb Vasc Biol. 1998;19(3):713-7.

85. Baysal K. Losordo DW: Oestrogen receptors and cardiovascular disease. Clin Exp Pharmacol Physiol. 1996;23:537-48.

86. Magness RR, Rosenfeld CR: Local and systemic estradiol-17ß: effects on uterine and systemic vasodilation. Am J Physiol. 1989;256(4 Pt 1):E536-42.

87. Hayashi T, Fukuto JM, Ignarro LJ, Chandhuri G: Basal release of nitric oxide from aortic rings is greater in female rabbits than in male cabbits: implications for atheroselerosis. Proc Natl Acad Sci U S A. 1992;89(23):11259-63.

88. Collins P, Beale CM, Rosano GMC: Oestrogen as a calcium channel blocker. Eur Heart J. 1996:17(Suppl D):27-31.

89. Adams MR, Kaplan JR, Manuck CB, Kontnik DR, Parks JS, Wolfe MS, Clarkson TB: Inhibition of coronary artery atherosclerosis by $17 \beta$ estradiol in ovariectomized monkeys. Lack. of an effect of added progesterone. Arteriosclerosis. 1990;10:1051-7.

90. Williams JK, Adams MR, Herrington DM, Clarkson TB: Short-term administration of estrogen. and vascular responses of atherosclerotic cononary arteries [see comments]. J Am Coll Cardiol. $1992 ; 20(2): 452-7$.

91. Gilligan DM., Quyyumi AA, Cannon ROI: Effects of physiological levels of estrogen on coronary vasomotor function in postmenopausal women. Circulation. 1994;89:2545-51. 



\section{Bladder filling reduces femoral artery wall distension and strain: beware of a full bladder!}

C. Willekes ${ }^{1}$, H.J. Hoogland", A.P.G. Hoeks ${ }^{3}$, R.S. Reneman ${ }^{1}$

Department of Physiology", Bioplyysics", and Gynatecology?" Cardiovascular Resenrch Institute Maastricht, Maastricht University and Acadenic Hospital Maastricht. 


\begin{abstract}
During a previous study, we noted that the distension and strain of the femoral artery were relatively low when the bladder was full, a situation normally necessary for transabdominal echography. Therefore, in the present study we investigated the influence of bladder filling, if any, on wall properties of the common femoral artery. The results obtained were compaired with those obtaned in the common carotid artery. The study was performed on the right common carotid and right common femoral arteries of normotensive young $(18-35 y)$ female wolunteers $(n=24)$. Using a specially designed ultrasonic wall-tracking device and attomatic brachial artery cuff blood pressure measurements, arterial distension (absolute change in diamerer during the cardiac cycle; $\Delta D$ ), strain ( $\triangle \mathrm{D} D / D)$, and cross-sectional distensibility (DC) and compliance (CC) were determined before and after voiding. Distension and strain of the common femoral artery were significandy lower for a full than for an empty bladder. DC and $\mathrm{CC}$ were lower when the bladder was filled, but these differences did wot reach the level of significance. Blood pressure as measured at the level of the brachial artery and hare rate were not statistically significantly different during a full and an enpry bladder. It is concluded that bladder filling affects femoral artery wall properties, an observation that should be kept in mind when performing studies on artery wall propertices at this lewel of the circulation.
\end{abstract}




\section{Introduction}

In a previous study, we investigated artery wall properties during different phases of the menstrual cycle and measured follicle size by transabdominal ultrasonography requiring bladder filling [1]. In that study, we noted that the distension and strain of the femoral artery were lower than the values obtained in control subjects with an empty bladder. An effect of bladder filling on artery wall properties of the muscular femoral artery may be feasible via the bladder viscerovascular reflex [2-4], initiated by tension changes, especially in the bladder trigone and neck.

It was the aim of the present study to investigate the influence of bladder filling, if any, on the common femoral artery wall properties in healthy young female volunteers. The effect on the common femoral artery was compared with that on the elastic common carotid artery to establish possible regional effects.

\section{Material and methods}

\section{Subjects}

The study was performed on 24 healthy young female volunteers (18-35 years of age). All volunteers were normotensive and did not use any medication. No important systemic disease was reported by any of then. B-mode ultrasound examinations did not reveal any relewant arterial disease in either of the volunteers. Informed consent was given at the beginning of the study after oral information. The study was approved by the joint Medical Ethics Committee of the Maastricht: University and the Academic Hospital Maastricht from the Netherlands.

\section{Study design}

Each volunteer was instructed to start drinking water about $2 \mathrm{~h}$ before the examination at a rate of $250-300 \mathrm{ml}$ every half hour until a total amount of $1-1.5$ litre had been consumed. They were asked to refrain from smoking and drinking caffeine- or quinine-containing beverages two to three hours prior to the examination. After a 10-15 minute supine rest, when blood pressure had stabilized, the dynamic wall properties of the elastic common carotid artery and the muscular common femoral artery were determined in the same sequence before and 10-15 min after voiding. The interval after voiding was introduced for blood pressure and heart rate stabilization. In a subpopulation $(n=20)$ the bladder volume was determined by collecting the urine in a measuring jug. Simultaneously, blood 
pressure and heart rate were determined every three minutes at the level of the brachial artery.

\section{Methods}

Artery wall properties were assessed by means of a conventional ultrasound inaging system with a $7.5 \mathrm{MHz}$ linear probe and a data-acquisition system connected to a personal computer (Pie Medical, Maastricht, the Netherlands). The technique has been described in detail before $[5,6]$. In short, during vascular examination the artery of interest was imaged in B-mode in longitudinall section and an $\mathrm{M}$-line was positioned perpendicular to the vessel wall. The ultrasound system was switched to M-mode and ECG-triggered collection of data was started during a period of about 4 seconds capturing 3-5 heart beats. The transferred raw radio frequent (RF) data were temporarily stored in a 1 MByte memory. The anterior and posterior artery walls were identified by placing markers on the first captured RF-line which was displayed on the monitor. Consecutively, the data were transferred line by line to the computer. A cross-correlation algorithm calculated the cumulative change in phase between successive RF lines, continuously tracking the artery walls during motion (Figure 1). Eventually, for each heart beat captured, the displacement waveforms of the anterior and posterior walls were displayed. From the distension waveform for each heart cycle considered, key parameters, i.e., the end-diastolic diameter (D), the change in diameter from end-diastole to end-systole ( $\Delta \mathrm{D}$, distension) and the distension normalized for the end-diastolic diameter $(\Delta D \cdot 100 \% / D)$ were presented. At each location, three measurements were performed, taking about 10 minutes. The average of these measurements was calculated and used for further analysis in order to reduce the influence of physiological variations (e.g., breathing).

Simulaneously, arterial blood pressure measurements were performed every 3 minutes at the level of the brachial artery by means of a semiautomated oscillometric device (DINAMAP; Criticon, Tampa, FL, USA). Pulse pressure measurements $(\Delta P)$, defined as systolic minus diastolic blood pressure, were obtained by averaging three measurements recorded approximately at the same time as the distension measurements. Heart rate was derived from the pressure pulses. With this method, pulse pressure and heart rate can be assessed reliably.

From $\mathrm{D}, \Delta \mathrm{D}$ and $\Delta \mathrm{P}$, the cross-sectional artery wall distensibility (DC) and compliance (CC) coefficients were calculated according to the following equations [7]:

$$
\mathrm{DC}=(2 \Delta \mathrm{D} / \mathrm{D}) / \Delta \mathrm{P}
$$




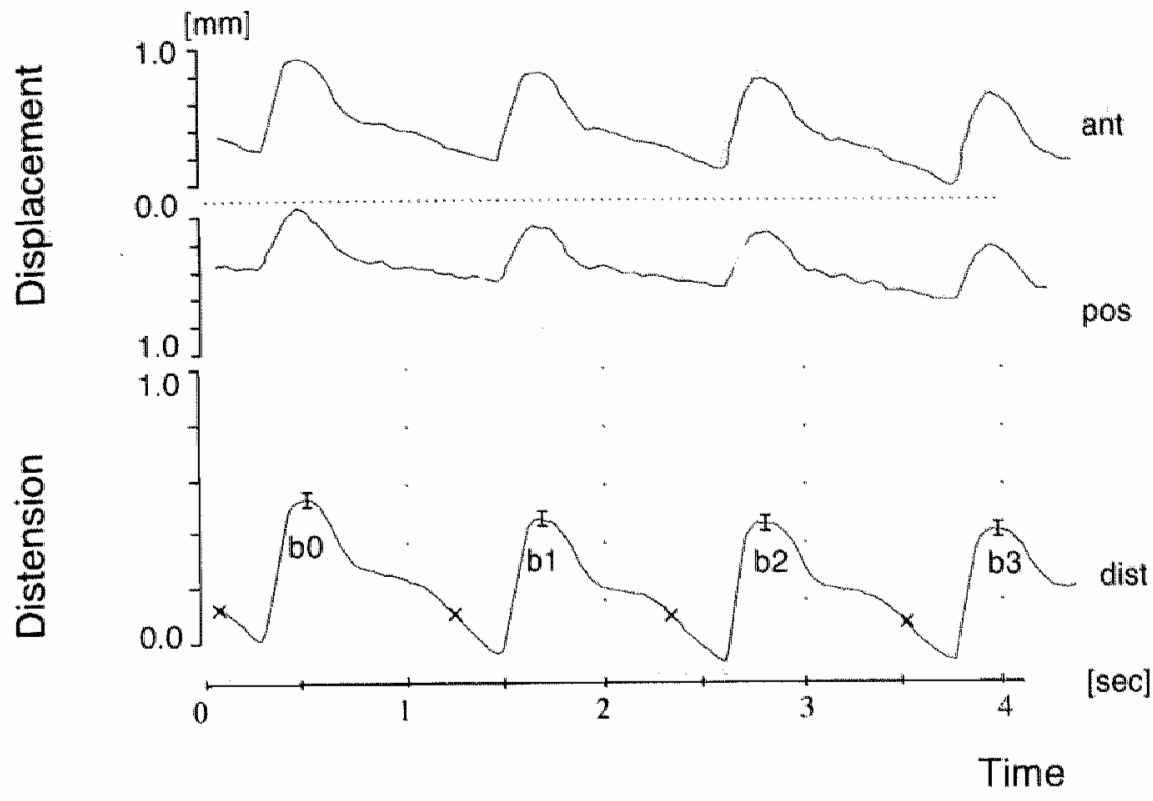

Figure 1. Displacenent curves of the anterior (ant) and posterior (pos) walls of the common femoral antery in a healthy young female (age 20 y). The bottom trace is the difference between the displacements of both arterial walls and represents the change in arterial diameter during the cardiac cycle. Despite total displacement along the ultrasound beam of the whole artery, the distension waveform can be derived. The first sign on the distension trace refers to the trigger of the $\mathrm{R}$-wave of the ECG (X), after which detection of end-diastole and peak systole (I) starts. $b=$ heart beat; dist $=$ distension.

$$
\mathrm{CC}=\pi \mathrm{D} \cdot \Delta \mathrm{D} /(2 \Delta \mathrm{P})
$$

With the wall tracking system, displacements of a few micrometers can be resolved and $\mathrm{D}, \Delta \mathrm{D}, \Delta \mathrm{D} / \mathrm{D}, \mathrm{DC}$ and $\mathrm{CC}$ can be assessed reliably [8]. The common carotid artery and the common femoral artery were investigated $2 \mathrm{~cm}$ proximal to the distal flow divider. Investigations were performed only on the right side, because previous studies in our institute have shown that, under normal conditions, the artery wall properties of the right and left common carotid arteries as well as of the right and left femoral arteries are not significantly different (unpublished results).

Differences in artery wall properties, blood pressure and heart rate before and after voiding were evaluated for statistical significance by applying Wilcoxon statistical analysis using SPSS software packages. Bonferroni-Holm correction was used for the number of variables tested [9]. 


\section{Results}

The amount of urine produced by the volunteers was $623 \pm 239 \mathrm{ml}$ (mean $\pm \mathrm{SD}$ ). When the bladder was filled, $\Delta \mathrm{D}$ and $\Delta \mathrm{D} / \mathrm{D}$ of the common femoral artery were significantly lower than when the bladder was empty (Table 1). The CC and DC of the common femoral artery tended to be lower when the bladder was filled, but the difference with the empty state failed to reach the level of significance after correction for analysis of multiple variables. The end-diastolic diameter of the common femoral artery was not significantly different when the bladder was full or empty. The artery wall properties of the common carotid artery were not significantly different during a full and an empty bladder. Diastolic blood pressure showed a tendency to increase when the bladder was filled, but this change failed to reach the level of significance after correction for analysis of multiple variables. Systolic and pulse pressure, and heart rate were not significantly different before and after voiding.

No significant relation could be found between the degree of bladder filling and the degree of reduction of the wall properties of the common femoral artery (data not shown). We were also unable to establish a threshold value above which the artery wall properties changed (data not shown).

\section{Discussion}

The findings in the present study show that the wall properties of the common femoral artery are different when the urine bladder is filled than when it is empty. The distension and strain of the common femoral artery are significantly lower when the urine bladder is full, while no change in end-diastolic diameter is observed. The DC and CC show a tendency to decrease during a full bladder but this change failed to reach the level of significance after Bonferroni-Holm correction for multiple variables. The wall properties of the common carotid artery are not significantly influenced by bladder filling. Neither are arterial blood pressure and heart rate as measured at the level of the brachial artery. The observation that arterial blood pressure, heart rate and the wall properties of the common carotid artery did not change significantly during a full bladder suggests that the decrease in distension and strain of the common femoral artery is caused by a local mechanism.

The decrease in distension and strain of the common femoral artery during a full bladder was not associated with a significant decrease in the calculated cross-sectional distensibility and compliance of this artery after Bonferroni-Holm correction. This can likely be explained by the fact that arterial blood pressure was 


\begin{tabular}{|c|c|c|c|c|}
\hline & Full bl adder & Enpty lbladder & 20 & pordore \\
\hline \multicolumn{5}{|l|}{ Carotid artery } \\
\hline Diastolic diamerer (num) & $6.3 \pm 0$. & $6.3 \pm 0.6$ & 0 & NS \\
\hline Distension $(\mu \mathrm{m})$. & $697 \pm 161$ & $701 \pm 123$ & -1 & NS \\
\hline Relacive Distension $(\%)$ & $112+2,9$ & $112+2,3$ & n & NS \\
\hline $\left.\operatorname{CC}(n n) / \mathrm{kP}_{3}\right)$ & $111+02$ & $108+0.2$ & 3 & NS \\
\hline $\operatorname{BC}\left(10^{3} / \mathrm{kPa}\right)$ & $35.9+8.9$ & $342+8$ & 3 & NS \\
\hline Systolic pressure (minl Ig) & $114+9$ & $113+8$ & 1 & NS \\
\hline Diastolic pressure (mumlig) & $67 \pm 8$ & $64 \pm 7$ & 4 & NS \\
\hline Pulse pressure (numilg) & $47+5$ & $49+5$ & 4 & NS \\
\hline Heart rate (beals/min) & $60+10$ & $59+10$ & 2 & NS \\
\hline \multicolumn{5}{|l|}{ Femoral artery } \\
\hline Diastohic dianieter (min) & $91 \pm 0.8$ & 9.010 .7 & 1 & NS \\
\hline Disterision $($ Win) ? & $269 \pm 150$ & $304 \pm 175$ & 12 & 0,0002 \\
\hline Relanve Distension ( 0 ) & $300 \pm 17$ & $343+2.0$ & 13 & 0.0001 \\
\hline $\mathrm{CC}\left(\mathrm{mm}^{2} / \mathrm{kP}\right)$ & $0.64+0.4$ & $0.69+0.4$ & 7 & 0.07 \\
\hline $\mathrm{DC}\left(10^{3} / \mathrm{kPa}\right)$ & $100+62$ & $11.0 \pm 67$ & 9 & $0.02^{\prime}$ \\
\hline Sygtolic pressure (minl Ts) & $114 \pm 10$ & $113 \pm 8$ & (1) & $\mathrm{NS}$ \\
\hline Drastolic pressirite (ininu $\mathrm{Hg}$ ) & $68+9$ & $65 \pm 7$ & 4 & $0.05^{*}$ \\
\hline Pulse pressune (rimt lg) & $461+5$ & 4716 & 3 & $\mathrm{NS}$ \\
\hline Heant rate (beats / ning) & $62+10$ & $61+10$ & 2 & NS \\
\hline
\end{tabular}

Vilues are expressed as mean 1 SD. The percentage change $(\% \mathrm{~A})$ was calculated as follows: 1008 (full bladder enply bladder) (enpty bladder) * $A$ non significan difference following Bonferton- Holnh comection

measured on the arm rather than in the common femoral artery. It is quite possible that, due to an increase in local peripheral resistance during a full bladder (see below), leading to enhanced arterial wave reflections [10,11], pullse pressure in the common femoral artery is higher than the pulse pressure at the level of the brachial artery. Therefore, the reduction of femoral cross-sectional distensibility and compliance during a full bladder is likely to be underestimated when blood pressure is measured on the arm. In this light, the reduction of distension and strain during a full bladder likely reflects a stiffer behaviour of the common femoral artery.

The decrease in elastic behaviour of the common femoral artery during a full bladder can be explained by the bladder viscerovascular reflex [2-4]. Filling of the bladder leads to an increase in internal bladder pressure and hence, stretching of the bladder wall, which, especially in the bladder trigone and neck, induces an increase in sympathetic tone in the hypogastric and the pelvic splanchnic nerves [3,12-18]. This increase in sympathetic activity, enhancing vascular tone, can 
likely be held responsible for the stiffer behaviour of the common femoral artery during a full bladder [16,19]. The bladder viscerovascular reflex also catses an increase in peripheral artery resistance $[2-4,20]$.

The absence of a change in common femoral artery diameter during a full bladder is not necessarily in disagreement with an increase in vascular tone. During sympathetic stimulation of vascular smooth muscle cells, shortening of the contractile elements may be associated with stretching of the series-elastic elements, resulting in a limited or no change in actual muscle length [21]. As a consequence artery tone increases without a measurable influence on artery diameter [22]. A decrease in artery diameter due to an increase in muscle tone can also be counteracted by an increase in transmural pressure [23]. Although blood pressure, as measured on the arm, did not change, it cannot be excluded that blood pressure increased locally during a full bladder (see above).

The observation that filling of the bladder can lead to a stiffer behaviour of the common femoral artery should be kept in mind when performing studies on artery wall properties at this level of the circulation.

\section{References}

1. Willekes C, Hoogland HJ, Keizer HA, Hoeks APG, Reneman RS: The infuence of female sex hormones on artery wall properties during the normal menstrual cycle. Clinical Science. $1997 ; 92: 487-91$

2. Taylor: DEM: Reflex effects of slow bladder filling on the blood pressure in cats. Q I Exp Physiol. 1965;50:263-70.

3. Taylor DEM: Afferent pathways and efferent mecharnisms in the bladder viscerovascular reflex. QJ Exp Plyysiol. 1968:73:425-37.

4. Garnier B, Gloor J: Zur frage der Ausstralung autononer Refexe cler Abdominalorgane auf den Kreislauf. Kreshaufveranderungen bei blasenfüllung. Schwenz Med Wschr. 1967:97:309-20.

5. Hocks APG, Brands PJ, Smeets FAM, Reneman RS: Assessment of the distersibility of superficial arteries. Ultatsound Med Biol. 1990;16(2):121-8.

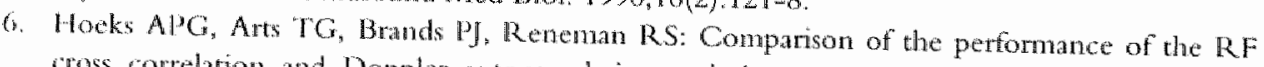
cross correlation and Doppler autoconetation technique to estimate the mean velocity of sinulated ultrisound signals. Ultrasound Med Biol. 1993;19(9):727-40.

7. Renenum RS, van Metode T, Hick P. Mwytiens AM. Hoeks APG: Age-related changes in carotid artery wall propertion in men. Ultrasound Med Biol. 1986;12(6):465-71.

8. Kool MJ, wan Merode T, Reneman RS, Hoeks APG, Struijker Boudicr HA, Van Bortel LM: Evaluation of reproducibility of a vessel wall movement detector system for assessment of large
artery properties. Cardhovase Res. $1994,28(5): 610-4$.

9. Holm S: A simple sequentially rejective multiple test procedure. Scand J Statist. 1979;6:65-70.

10. O'Rourke MF, Brumber HR: Introduction to arterial compliance and function. J Hypertens
Suppl. 1992; $10(6): S 3-5$.

11. Avolio A: Ageing and wave reflection. J Hyperters. 1992;10(suppl 6):583-6. 
12. Cumingham DJC, Gutmann L, Whitreridge D, Wyndham CH: Candiowascular nesponses to bladder distension in paraplegic patients. I Physiol. 1953,121:581-92.

13. de Burgh Daly $M$, Wood LM: Effect of distension of the urinary bladder on the cardiovascular reflexes from the carotid sinus baroreceptor reflex in the dog. I Physiol. 1982;325:16P.

14. de Burgh Daly M, Ward J, Wood LM: Effects of distension of the urinary bladder on the cardiovascular reflexes from the carotid baroreceptors in the dog. I Physiol Lond. $1993 ; 463: 545-64$.

15. Häbler IJ, Jäng W, Koltzenburg $M$, Lobenberg-Khostavi $N$ : Reflexes elicited in vasoconstrictor neurones by quantitative stimulation of afferents from che uninary bladder. Eur J Physiol. 1988;412:R61.

16. Medda BK, Koley J, Koley B: Sympathetic efferent activity in the viscerovascular reflexes induced by urinary bladder distension. Jpu J Physiol. 1995;45:265-77.

17. Medda BK, Koley J, Koley B: Sympatoadrenal activity in the visceral (viscerovascular) reflexes to distension of the urinary bladder. Jpu J Physiol. 1996;46:3-92.

18. Mukheree SR: Effect of bladder distension on arterial blood pressure and renal circulation: Role of splanchnic and buffer nerves. J Physiol. 1957;138:307-25.

19. Laurent S, Lacolley P, P. B, Safar M: Effects of short-lasting mental stress on systemic and brachial hemodynamics in arterial hypertension. Circulation. 1988;78(Suppl 4): IV175.

20. Taylor DEM: Cardiovascular disturbances in acute retention of urine. Lancet. 1963;i1:1033-5.

21. Barra JG, Armentano RL, Levenson J, Fischer EI, Pichel RH, Simon A: Assessment of smooth muscle contribution to descending thoracic aortic elastic mechanics in conscious dogs. Circ Res. $1993 ; 73(6): 1040-50$.

22. Milnor WR. Principles of hemodynamics. In: Mountcastle VB, ed. Medical Plyysiology. St. Louis: CV Mosby Company; 1974:914-29.

23. Milnor WR. Autonomic and peripheral control mechanisms. In: Mountcastle VB, ed. Medical Plysiology. St. Louis: CV Mosby Company; 1974:944-57. 



\section{Female sex hormones do not influence artery wall properties during the normal menstrual cycle}

Christine Willekes', Henk J. Hoogland ${ }^{2}$, Hans A. Keizer ${ }^{3}$, Arnold P. Hoeks and Robert $S$. Reneman!

Departments of Physiology', Gynaecology², Movement Sciences ${ }^{3}$ and Biophysics Cardiovascular Research Institute Maastrichr, Maastricht University, and Academic Hospital Mastricht, Maastricht, the Netherlands. 


\begin{abstract}
In previous studies the elastic properties of the common carotid artery were found to differ between men and women. In these studies, however, the phase of the menstrual cycle was not taken into consideration. It was the aim of the present study to investigate the effect of changing ovarian homone levels during the normal nenstral cycle on the artery wall properties of female large arteries. We investigated the elastic right common carotid artery and the muscular right common femoral artery of nomotensive young $(18-35$ years) female volunteers $(n=12)$. The arterial distensibility and cross-sectional compliance coefficients were determined by the use of a specially designed ultrasonic wall-tracking device and automatic brachial artery cuff blood pressure measurements. The phase of the menstrual cycle was assessed by ultrasonographic evaluation and $17 \beta$-oestradiol and progesterone blood plasna levels. The distensibility coefficuent and the cross-sectional compliance coefficient of both the common carotid and the common femoral artery did not change significantly during the normal menstrual cycle despite evidently changing ovarian homone levels. We conclude that the menstrual cycle does not influence the attery wall properties of either the elastic common carotid artery or the muscular conmon femoral artery.
\end{abstract}




\section{Introduction}

It has been known for quite some years that arteries, especially the larger elastic ones, become stiffer with increasing age [1-5]. For example, from the third decade of age on, distensibility and compliance of the elastic common carotid artery decrease linearly with age, the reduction in compliance being less steep than the reduction in distensibility [5]. The less pronounced decrease in compliance can be explained by the increase in arterial diameter observed with increasing age $[4,6,7]$. In two of these studies, it was shown that the distensibility of the aorta [2] and of the carotid artery [4] was significantly lower in male subjects than in age-matched females. François [8] found stiffer carotid, brachial and leg arteries in men than in women. In contrast, the findings of Riley et al. [9] indicated that the carotid artery is less distensible in females than in males. Similar results were obtained in a study by Van Merode et al. [10], who found distensibility and compliance to be significantly lower in females than in males. An explanation for these discrepancies may be that the phase of the menstrual cycle and the use of oral contraceptives were not considered in these studies. It is possible that female sex hormones influence artery wall properties, because sex hormone receptors have been shown to be present in the artery wall in both endothelium and vascular smooth muscle cells [11].

The aim of the present study was to investigate whether artery wall properties change during the normal menstrual cycle in relation to changes in the levels of female sex hormones during this cycle.

\section{Material and methods}

\section{Subjects}

The study was performed on 12 presumed healthy female volunteers, ranging in age from 18 to 35 years. According to the criteria of Vollmann [12] the duration of the menstrual cycle had to be between 28 and 32 days. Oral contraceptives were not taken at least 3 months prior to the study. Before subjects entered the study a physical examination was performed, measuring heigth, weight and blood pressure. The carotid and femoral arteries were screened for atherosclerotic disease using B-mode imaging (Ultramark IV; ATL, Bothell, WA, U.S.A.). No intima-media thickening or atherosclerotic disease could be detected. Blood was drawn from an antecubital vein for the analysis of $17 \beta$-oestradiol, progesterone, haemoglobin, thyroid-stimulating hormone, testosterone and prolactin. Six to eight examinations were performed during each menstrual cycle with an average interval of 4 days, involving the most important phases of the menstrual cycle. 
The study design was approved by the Medical Ethics Committee of the Academic Hospital Maastricht and Mastricht University, and informed consent was obtained from all subjects before they entered the study.

\section{Study design}

All measurements were performed after 10-15 min of rest in the supine position until blood pressure stabilized. Arterial blood pressure was recorded non-invasively in the right brachial artery, using a semi-automated oscillometric device (Dinamap; Criticon, Tampa, FL, U.S.A.). With this method the pulse pressure in the brachial artery can be assessed reliably [1.3]. In previous studies, the pulse pressure in the brachial artery has been proven to correlate well with the pulse pressure in the carotid artery [14]. The correlation between brachial artery and femoral artery pulse pressure, however, is relatively poor (C. Willekes, $S$. Samijo, A.P.G. Hoeks, R.S. Reneman, unpublished work). Because we compared brachial artery blood pressure at the same place at different moments in time in the same subject, and the brachial and fernoral artery are both muscular vessels, the error made was systematic in nature and did not influence the outcome of our study. The ultrasound investigations were performed with the subjects in the recumbent position and the head tilted at an angle of $45^{\circ}$ to the contralateral side when examining the right common carotid artery. The elastic common carotid artery, $2-3 \mathrm{~cm}$ proximal to the flow divider and the muscular femoral artery, $2 \mathrm{~cm}$ proximal to the flow divider were examined in a random order. The investigations were limited to the right common carotid and femoral arteries, because previous studies in our laboratories have shown that there is no significant difference between the right and left common carotid arteries and the right and left common femoral arteries as far as vessel wall properties are concerned ( $C$. Willekes, M. J. Kool, A. P. G. Hoeks, R. S. Reneman, unpublished work).

The room temperature was kept constant $\left(23 \pm 2^{\circ} \mathrm{C}\right)$ and the measurements were performed at the same time of the day to avoid diurnal variations in arterial wall properties. No alcohol, cigarettes or caffeine-containing beverages were consumed by the subjects at least 3 hours before the ultrasound examination. This was considered to be appropiate, because in a previous study we showed that the effect of cigarette-smoking on arterial wall properties are only short-term; no long-term differences could be demonstrated between smokers and non-smokers [15].

The plase of the menstrual cycle was assessed by ultrasonographic follicle size measurement, using a $5 \mathrm{MHz}$ curved array probe attached to an ultrasound system (Ultramark IX; ATL, Bothell, WA, U.S.A.). Before each vascular ultrasound examination the subjects were asked to empty their bladder, as a fill bladder was 
found to cause stimulation of the sympathetic nervous system reducing arterial wall distensibility (Chapter 2).

At the end of each examination, blood was sampled from an antecubital vein. After centrifugation the plasma was stored at $-20^{\circ} \mathrm{C}$. Analysis of plasma $17 \beta$-oestradiol and progesterone was performed in duplicate, using commercially available radioimmunoassay kits (Diagnostic Products Corporation, CA, USA). The mean intra-assay coefficient of variation, as calculated from replicate determinations, was $4-5 \%$ and $3-5 \%$ for $17 \beta$-oestradiol and progesterone, respectively. Interassay coefficients of variation were 12 and $10 \%$ for $17 \beta$-oestradiol and progesterone, respectively. Evaluation of vascular data was only performed in menstrual cycles showing adequate follicle growth and eventual ovulation.

\section{Methods}

Artery wall properties were determined by means of a vessel-wall-tracking system, as described in detail by Hoeks et al. $[16,17]$. The system used in the present study consists of a conventional ultrasound imaging system (Ultramark IV) and a dataacquisition system connected to a personal computer (Pie Medical, Maastricht, The Netherlands). A 7.5 MHz transducer was used to produce a two-dimensional $\mathrm{B}$-mode image of the vessel of interest. An M-line perpendicular to the vessel was selected. After the echo system was switched to M-mode, storage of data started. During three to five cardiac cycles, radiofrequency (RF) signals were digitized and temporarily stored in a $1 \mathrm{MByte}$ memory. The positions of the anterior and posterior arterial walls were marked by the observer by placing two data windows on the first RF signal stored and displayed on the scope of the personal comptuter. Linc after line the data were transferred to a personal computer. The cumulative change in phase between the successive RF lines was calculated for the anterior and the posterior wall windows, and the position of the sample gates was continuously adjusted according to the detected displacement (tracking). After processing all lines, the displacement of the anterior and posterior walls was displayed (Figure 1). The difference in displacement between the anterior and posterior walls represents arterial distension, which is the change in arterial diameter during the cardiac cycle. This procedure is an off-line analysis and provides data on arterial end-diastolic diameter (D) and distension ( $\Delta D)$ ) for each captured heart beat. Arterial blood pressure (see above) was recorded every $3 \mathrm{~min}$, and the mean of the three measurements nearest to the distension measurement was taken as the subject's reading. Pulse pressure $(\Delta \mathrm{P})$ was defined as systolic minus diastolic blood pressure. From $D, \Delta D$ and $\Delta P$, the cross-sectional arterial wall distensibility (DC) and compliance (CC) coefficients were calculated according to the following equations [5]: 


$$
\begin{aligned}
& \mathrm{DC}=(2 \Delta \mathrm{D} / \mathrm{D}) / \Delta \mathrm{P} \\
& \mathrm{CC}=\pi \mathrm{D}(\Delta \mathrm{D} / 2 \Delta \mathrm{P})
\end{aligned}
$$

With the wall-tracking system, displacements of a few micrometres can be resolved [18] and D, $\triangle \mathrm{D}, \triangle \mathrm{D} / \mathrm{D}, \mathrm{DC}$ and $\mathrm{CC}$ can be assessed reliably [19]. The artery wall properties, as determined in this way, reflect a combination of passive elastic characterstics of the wall and active components induced by smooth-muscle cells. The intra-observer intra-session coefficient of variation (= $\mathrm{SD} /$ mean $\times 100 \%$ for the determination of $\mathrm{D}, \triangle \mathrm{D} / \mathrm{D}, \mathrm{DC}$ and $\mathrm{CC}$ of the common carotid artery was $4.5,7.9,8.3$ and $9.1 \%$, respectively. In the common femoral artery the intra-observer intra-session coefficients of variation were $2.7 \%$ (D), $12.4 \%(\triangle \mathrm{D} / \mathrm{D}), 13.4 \%(\mathrm{DC})$ and $12.5 \%(\mathrm{CC})$. Intra-observer inter-session variability was comparable with intra-observer intra-session variability for all vessels.

Figure 2 shows the division into phases after correction for time of ovulation, being the central event for every menstrual cycle. A total of five phases was selected according to the height of the plasma levels of $17 \beta$-oestradiol and progesterone. In phase 1, 17 $\beta$-oestradiol and progesterone are low, while in phase 2 $17 \beta$-oestradiol rises and progesterone is still low. In phase $3,17 \beta$-oestradiol reaches its maximum value and a slow rise in progesterone is observed. In phase 4 , $17 \beta$-oestradiol decreases while progesterone continues to increase until the maximum value is reached in phase 5 . In this phase, $17 \beta$-oestradiol shows a second peak which, however, is not as high as the dirst one observed just before ovulation.

Wilcoxon non-parametric statistical analysis was performed, using SPSS software packages, to compare paired measurements in the menstrual cycle. Bonferroni correction for the level of statistically significant values was used for repeated analysis. A level of $\mathrm{P}<0.016$ was considered to be statistically significant $\{p<0.05 / \mathrm{g}(\mathrm{g}-1) / 2]$, where $\mathrm{g}$ is the number of pairwise comparisons $\}[20]$.

\section{Results}

Screening of the subjects for thyroid-stimulating hormone, restosterone, prolactin and haemoglobin in venous blood plasma revealed no abnormalities.

The mean values ( \pm SDs) of DC and CC and arterial blood pressure for the three most important phases of the menstrual cycle (phase 1,3 and 5) are shown in Table 1 . These phases were chosen because in phase 1 both $17 \beta$-oestradiol and progesterone are low, and in phase $317 \beta$-oestradiol is at its maximum value while progesterone, although increasing, is still low. Finally, in phase 5 , progesterone 


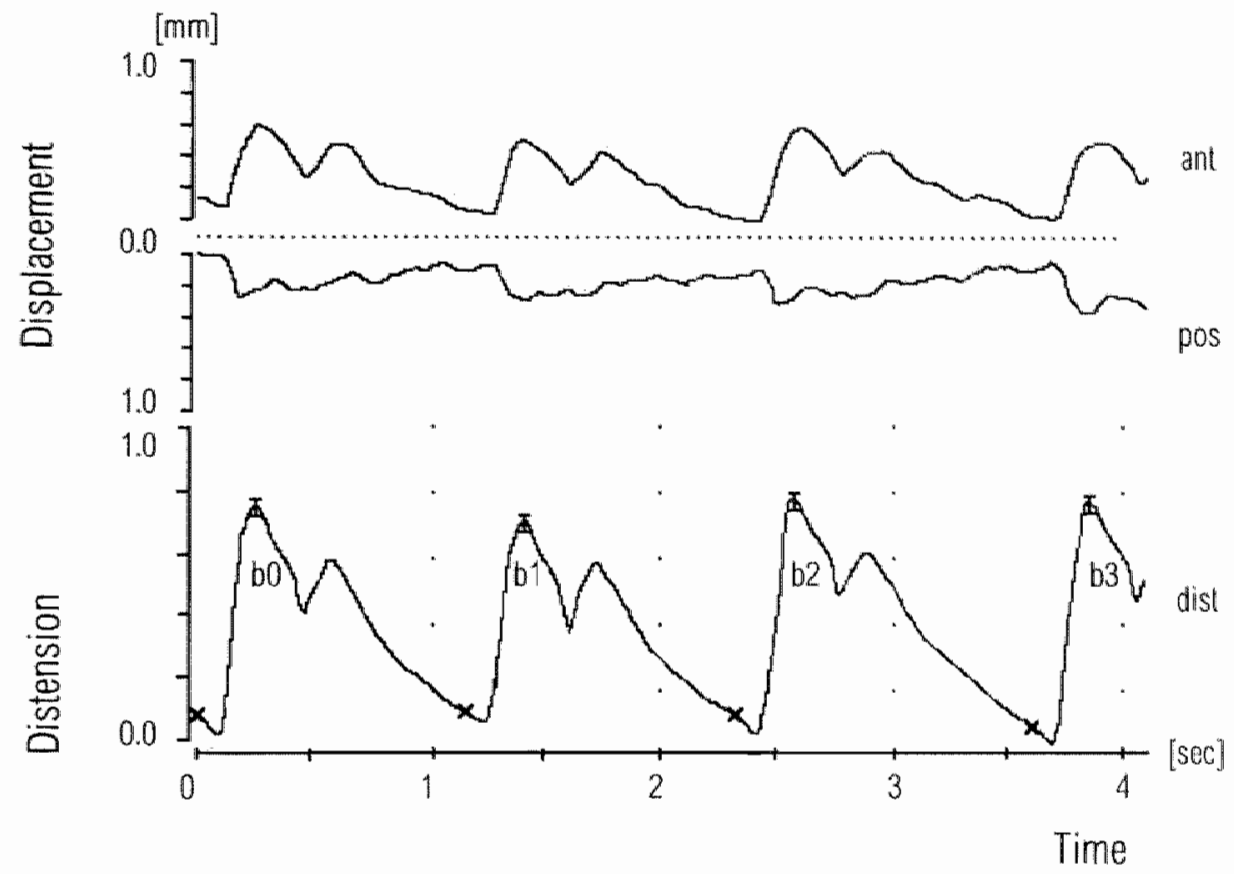

Figure 1. Displacement curves of the anterior (ant) and posterior (pos) walls of the common carotid artery in a healthy young femalle (age 20 years). The bottom trace is the difference between the displacements of both arterial walls and represents the change in arterial diameter during the cardiac aycle. The first sign on the distension tacing refers to the trigger of the $\mathrm{R}$-wave of the $\mathrm{ECO}(\mathrm{x})$ after which detection of end diastole and peak systole (I) starts. Abbreviations: $b=$ heartbeat; dist $=$ distension .

reaches its highest value while $17 \beta$-oestradiol, although still elevated, is lower than in phase 3.

No significant statistical differences in artery wall properties were found between these three phases, despite evidently different plasma levels of $17 \beta$-oestradiol and progesterone. Also, systolic and diastolic blood pressure were not significantly different between the three phases. There was a tendency to a lower diastolic blood pressure towards the end of the menstrual cycle, but this decrease did not reach the level of significance after Bonferroni correction. Pulse pressure and mean arterial pressure, calculated from systolic and diastolic pressure, did not change significantly under the influence of changes in the levels of either $17 \beta$-oestradiol and progesterone. Heart rate showed a slight, but non-significant increase towards the end of the menstrual cycle. 


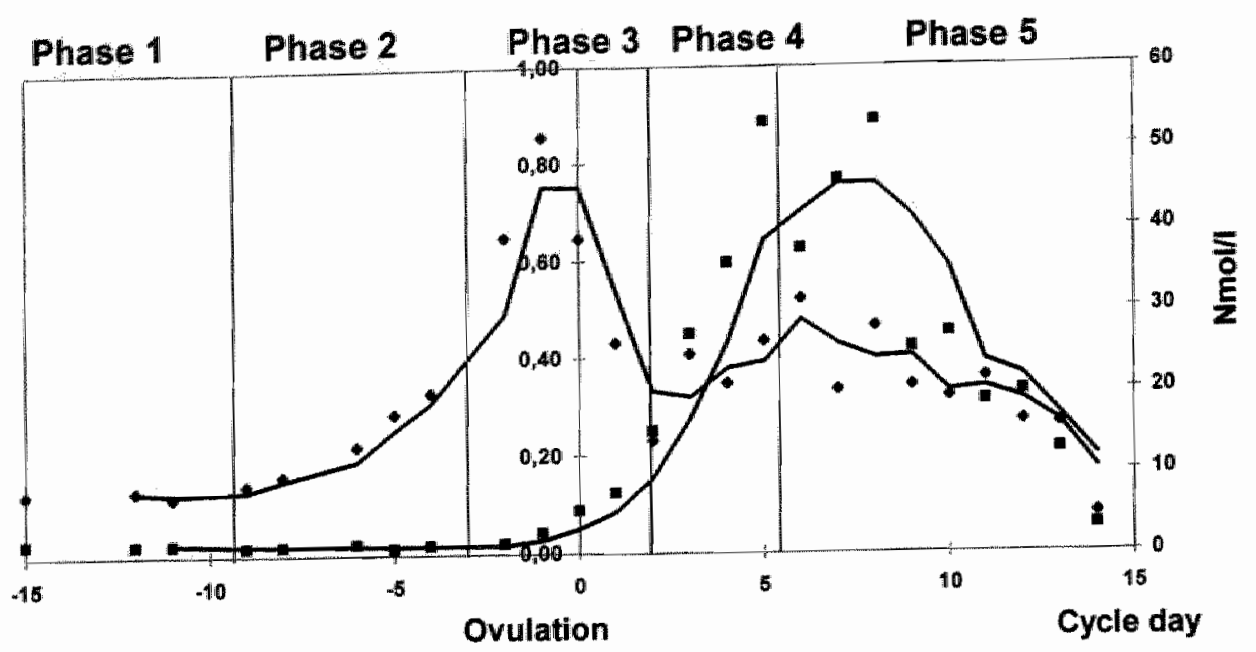

Figure 2. Changing ovarian hornone levels during the nomal ovalatory menstrual cycle $(n=12$ ). Different phases are discermed according to the height of the plasma $17 \beta$-oestradiol $(\bullet, n m o l /)$ and progesterone $(\mathbf{Q}$, nmol/l) levels. Cycle day $0=$ ovulation.

We also tested the above-mentioned variables in the remaining two phases of the menstrual cycle (phases 2 and 4), but again no statistically significant differences were found.

\section{Discussion}

The findings in the present study show that compliance and distensibility of the common carotid and common femoral arteries do not change during the normal menstrual cycle, despite pronounced changes in plasma levels of $17 \beta$-oestradiol and progesterone. Therefore, we may conclude that the different phases of the menstrual cycle cannot be held responsible for the discrepancies between the various studies as far as the differences in artery wall properties between men and women are concerned. In some studies the arteries were found to be less distensible in men than in women $[2,4,8]$, while in others women were found to have less distensible arteries $[9,10]$.

It may be argued that the discrepancies between the various studies result from differences in the methods used to assess arterial wall compliance and distensibility. Indeed, Laogun and Gosling [2] and François [8], who found the distensibility to be lower in men then in women, determined the pulse wave velocity over a considerable distance along the arterial tree to calculate distensibility by means of 


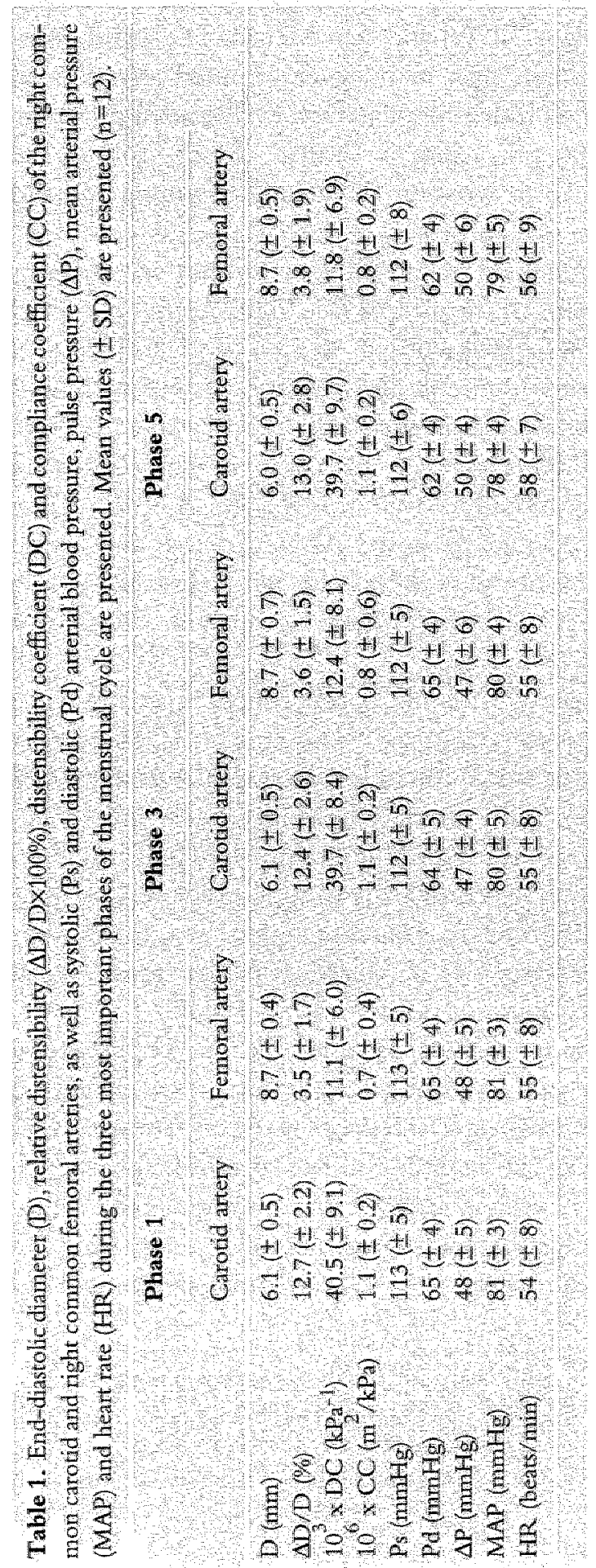


the Moens-Korteweg equation. Riley et al. [9] and Van Merode et al. [10], who found less distensible arteries in women than in men, detemined arterial wall distensibility and compliance locally with the use of a vessel-wall-tracking system. Recently, however, Hansen et al. [4], using a similar device, found the distensibility to be lower in men than in women, albeit only in young and old subjects.

The discrepancies between the findings in the different studies are also not explained by considering different parts of the arterial tree. The common carotid artery was found to be less distensible in women than in men by Riley et al. [9] and Van Merode et al. [10], and more distensible in women by François [8] and Hansen et al. [4]. It is of interest to note that in the study of Riley et al. [9], the elastic modulus was found to be higher in men than in women, suggesting reduced elasticity of the common carotid artery wall in men, which is discordant with the increased distensibility. It should be noted, however, that the elastic modulus characterizes the material properties of the arterial wall, while distensibility is a functional parameter. Changes in these two parameters are not necessarily in line with each other [21].

A role for the use of oral contraceptives cannot be explained, as this was not considered in any of the studies discussed.

It is important to note that in all the studies discussed the parameters measured to characterize artery wall properties show a large variability, with differences often within 1 SD of the mean. Moreover, most of the studies were performed on a relatively small group of subjects using statistical analyses applicable only to larger populations displaying a normal distribution. This raises the question as to whether there are differences in artery wall properties between males and females and whether the discrepancies between the various studies are real.

Whether the absence of changes in arterial wall properties during the menstrual cycle is a consequence of the short-term homonal wariations in this situation remains to be elucidated. The possibility that the effect of female sex homones on arterial wall properties is a slow proces with a time-constant cannot be excluded.

In conclusion, no significant differences in artery wall properties of the elastic common carotid artery and the muscular common femoral artery could be demonstrated during the menstrual cycle, despite pronounced changes in $17 \beta$-oestradiol and progesterone. 


\section{References}

1. Learoyd BM, Taylor MG: Alterations with age in the viscoelastic properties of human anterial walls. Circ Res. 1966:18(3):278-92.

2. Laogun AA, Gosling RG: In wiwo arterial compliance in man. Clin Phys Physiol Meas. $1982 ; 3(3): 20:-12$.

3. Avolio A: Ageing and wave reflection. J Hypertens. 1992;10(suppl 6):583-6.

4. Hansen $F$, Mangell P, Sonesson B, Lanne T: Dianeter and compliance in the human common carotid artery - variations with age and sex. Ultrasound Med Biol. 1995;21(1):1-9.

5. Reneman RS, van Merode T, Hick P. Muytjens AM, Hoeks APG: Age-related changes in carotid artery wall properties in men. Ultrasound Med Biol. 1986;12(6):465-71.

6. Reneman RS, van Merode T, Hick PJ, Hoeks APG: Flow velocity pattems in and distensibility of the carotid artery bulb in subjecs of various nges. Circulation. 1985;12:465-71.

7. Riley WA, Barnes RW, Evans GW, Burke GL: Ultrasonic measurement of the elastic modulus of the common carotid artery - the Atherosclerosis Risk in Communities (ARIC) study. Stroke. $1992 ; 23(7): 952-6$.

8. François B: Alteration in arterial wall elasticity in the young. Clin Gen. 1983;24:287.

9. Riley WA, Barnes $\mathbb{R} W$, Schey HM: An approach to the non-invasive periodic assessment of arterial elasticity in the young. Prevent Med. 1984;13:169-84.

10. van Merode T, Hick PJ, Hoeks APG, Smeets FAM, Reneman RS Differences in carotid artery wall properties between presumedwealthy men and women. Ultrasound Med Biol. 1988;14(7): $571-4$.

11. Sarrel PM: Ovarian hormones and the circulation. Maturitas, 1990;12(3):287-98.

12. Vollmann RF: The menstrual cycle. Major Probl Obstet Gynecol. 1977,7:1-193.

13. Pessenhofer H: Single cuff comparison of two methods for indirect measurement of arterial blood pressure: standard atscultatory method versus automatic oscillometric method. Basic Res Cardiol. 1986;81(1):101-9.

14. Reneman RS, van Merode T, Brands PJ, Hoeks APG: Inhomogeneities in arterial wall properties under normal and pathological conditions. J Hypertens Suppl. 1992;10(6):S35 -9 .

15. Kool MJ, Hoeks AP, Struijker Bondier HA, Reneman RS, Van Bortel LM: Short- and long-term effects of snoking on arterial wall properties in habitual snokers. J Am Coll Cardiol. $1993 ; 22(7): 1881-6$

16. Hoeks APG, Arts TG, Brands PJ, Reneman RS: Comparison of the performance of the RF cross correlation and Doppler autocotrelation technigue to stimate the mean velocity of simulated ultrasound signals. Ultrasound Med Biol. 1993;19(9):727 40.

17. Hoeks APG. Non-invasive study of the local mechanical arterial characteristics in humans. In: Safar ME. ORourke MF, eds. The anterial system in tryperesssion. Dordrecht/Boston/London: Kluwer Academic Publishers; 1993.

18. Hoeks APG, Brands PJ, Smeets FAM, Reneman RS: Assessment of the distensibility of superficial arteries. Ultrasound Med Biol. 1990;16(2):121-8.

19. Kool MJ, van Merode 'T', Reneman RS, Hocks APG, Struijker Botudier HA, Van Bortel LM: Evaluation of reproducibility of a vessel wall mowement detector system for asscsment of large artery properties. Cardiovase Res. 1994:28(5):610 4 .

20. Fleiss JL. The Bonferoni correction for multiple comparisons. In: Shewart WA, Wils SS, eds, The design and analysis of clinical experiments. New York: John Whiley and Sons; 1986:103-7.

21. Reneman RS, Hoeks APG: Diameter and compliance in the human aorta - vaniations with age and sex. Ultrasound Med Biol. 1996;22:271-2. 


\section{Three months use of third-generation oral contraceptives does not affect artery wall properties}

Christine Willekes' Henk J. Hoogland", Hans A. Keizer", Arnold P.G. Hoeks" Robert S. Reneman!.

Departments of Physiology', Gymaecology ${ }^{2}$, Movement Sciences ${ }^{3}$ and Biophysics Cardiovascular Research Institute Maastricht, Mastricht University, and Acadtenic Hospital Maastricht, Maastricht, the Netherlands. 


\begin{abstract}
In several studies, artery wall properties have been shown to differ between men and women. It has been hypothesized that these differences may result from hormonal influences but, in a previous study, we were unable to detect any influence of the menstrual cycle on artery wall properties. Therefore, we investigated the differences in artery wall properties, if any, between the menstrual cycle and the use of a thirc-generation oral contraceptive for 3 months. We investigated the right common carotid (CCA) and femoral (CFA) arteries of normotensive young $(18-25-y$-old) women volunteers $(n=14)$. The arterial cross-sectional distensibility and compliance coefficients were determined by means of a specially designed ultrasonic wall-tracking device and attomatic brachial artery cuff blood-pressure measurements. The menstrual cycles and the cycles during onal contraceptive use 30 $\mu \mathrm{g}$ ethinylestradiol and $75 \mu \mathrm{g}$ gestodene) were monitored by ultrasonographic evaluation and the assessment of plasma levels of $17 \beta$-oestradiol and progesterone. The distensibility and cross-sectional compliance coefficients of both the CCA and CFA did not differ significantly between the menstrual cycle and the use of oral contraceptiwes, despite different ovarian hormone levels. Brachial arterial blood pressure was also not affected. We conclude that 3 nonths use of a thind-generation onal contraceptive does not influence the wall properties of peripheral arteries and cannot explain the observed difference between genders. The absence of a rise in blood pressure and the low androgenic profile of this specific oral contraceptive may have contributed to our findings.
\end{abstract}




\section{Introduction}

In several studies, it has been shown that artery wall properties are different in males and females [1-5]. In general, arteries were found to be stiffer in men than in women [1-3], but, in some studies, the opposite was observed [4,5]. These conflicting results might be explained by differences in hormonal milieu because, in these studies, neither the phase of the spontaneous menstrual cycle nor the use of oral contraceptives was considered. In a previous study [6], however, we were unable to detect any difference in the cross-sectional distensibility and compliance coefficients (i.e. the absolute and relative change in diameter for a change in pres sure, respectively) of peripheral arteries between the phases of the spontaneous menstrual cycle, despite significantly different plasma ovarian hormone levels in these phases. If this allso holds for the application of exogenous steroid hormones, as in the use of oral contraceptives, for a longer period of time is unknown. Therefore, in the present study, we investigated the influence of oral contraceptives (OCs or 'the pill') on the wall properties of peripheral arteries after a run-in period of 3 months.

An additional reason for performing this study is the evidence that in females the risk of cardiovascular disease increased since the introduction of Ocs [7-10], possibly due to the higher systolic blood pressure observed during oral contraceptive use [11-13]. Because the increase in blood pressure during the use of OCs is relatively small [14], its importance as a risk factor for cardiovascular disease has been debated. One should keep in mind, however, that in patients with borderline hypertension, in whom the increase in blood pressure is limited and noticeable only for part of the day, compliance and distensibility of the common carotid artery are substantially reduced already at relatively young age $[5,15]$. This indicates that changes in artery wall properties are not necessarily related to increased blood pressure alone. In line with this idea is the recent observation that, in some forms of genetic hypertension, changes in artery wall properties precede the development of hypertension [16].

The study was performed on the elastic common carotid artery and the muscular femoral artery of healthy young females before and after 3 months of $O C$ use. 


\section{Material and methods}

\section{Subjects}

A total of 14 healthy female volunteers between 18 and 25 y old participated in the study. All had regular menstrual cycles according to the criteria of Vollmann [17] (24-32 days) and did not take oral contraceptives at least 3 months prior to the start of the study. No medical history of gynecological disorders or important systemic diseases was reported by any of the volunteers. Screening of the arteries of interest by means of B-mode ultrasound (Scanner 200, Pie Medical; Maastricht; The Netherlands) during the first examination did not reveal vascular disease. All volunteers had normal blood pressure levels at the start of the study and no other contraindications for oral contraceptive therapy. The joint Medical Ethics Committee of the Maastricht University and the Academic Hospital Maastricht approved the study. Informed consent was obtained from all volunteers before entering the study.

\section{Study design}

The examinations were performed in a quiet room with an average temperature of $23 \pm 2^{\circ} \mathrm{C}$. The measurements were made at the same moment of the day to avoid diumal variations, and after a 10-15 minute supine rest to stabilize blood pressure levels. Volunteers were asked to refrain from smoking and the consumption of alcohol-, caffeine- or quinine-containing beverages at least 3 hours prior to the examination. The phase of the menstrual cycle was assessed by determining, transabdominally, follicle-size and endometrial thickness with a $5 \mathrm{MHz}$ curved array probe connected to an ultrasound system (Ultramark IX; ATL, Bothell, WA). After determination of the phase of the menstrual cycle, the examinations of the vascular characteristics were made. A total of 5 to 8 vascular examinations were performed with an average time interval of 3 to 4 days covering all phases of the menstrual cycle. In addition to the ultrasound evaluation of follicle size and rupture, the phases of the menstrual cycle were monitored by means of plasma levels of $17 \beta$-oestradiol and progesterone, and the central event was considered to be the moment of ovulation [6]. Menstrual cycles of unusual duration were phase aligned according to ultrasound findings of follicle growth and endometrial thickness as well as venous plasma levels. Ovulation was considered to occur at the moment of disappearance of the ultrasonographically determined dominant follicle of at least $18 \mathrm{~mm}$ average diameter, and the venous plasma oestrogen peak and progesterone rise. For the determination of these plasma levels, blood was sampled from an antecubital vein at the end of each examination. After 
centrifugation the plasma was stored at $-20^{\circ} \mathrm{C}$. Analysis of plasma $17 \beta$-oestradiol and progesterone was performed in duplicate, using commercially available radio immunoassay kits (Diagnostic Products Corporation, CA). The mean intra-alsay coefficient of variation, as calculated from replicate determinations, was $4-5 \%$ and $3-5 \%$ for $17 \beta$-oestradiol and progesterone, respectively. Inter-assay coefficients of variation were $12 \%$ and $10 \%$ for $17 \beta$-oestradiol and progesterone, respectively. The venous samples were also analyzed for haemoglobin, thyroid stimulating hormone, testosterone and prolactin using standard assays.

After monitoring one full spontaneous menstrual cycle showing adequate follicle growth and rupture, $O C$ use was started. This consisted of $30 \mu \mathrm{g}$ of ethinylestradiol in combination with $75 \mu \mathrm{g}$ gestodene (Femodene, Schering, Berlin, Germany), a third-generation continuous combined oral contraceptive with a low androgenic profile. After an average run-in period of 3 months $O C$ use, measurements were repeated at the beginning of the fourth pill cycle. Five to seven measurements were performed during oral contraceptive use at intervals comparable to those during the spontaneous menstrual cycle of each volunteer. Again, blood was drawn and analyzed as described above to demonstrate the presence of low endogenous levels of $17 \beta$-oestradiol and progesterone during oral contraceptive use.

\section{Ultrasonic vascular examinations}

The ultrasonic vessel wall tracking system (W'TS) to determine arterial wall properties has been described in detail before $[18,19]$. In short, the instrument consists of a conventional ultrasound imaging system with a $7.5 \mathrm{MHz}$ linear array probe, and a data-acquisition system connected to a personal computer (Pie Medical). During the vascular examination, the artery of interest was imaged in B-mode in a longitudinal section, whereafter an $\mathrm{M}$-line was positioned perpendicular to the vessel wall. The ultrasound system was switched to $M$-mode and ECG-triggered collection of data was started during a period of about $4 \mathrm{~s}$ covering $3-5$ heart beats. The transferred raw radiofrequency (RF) data were temporarily stored in an 1 MByte large memory. The anterior and posterior walls of the artery were identified manually by the examiner placing sample volumes on the wall reflections as seen in the first captured RF-line, which was displayed on the computer monitor. Consecutively, the data were transferred line-by-line to the computer. A cross-correlation algorithm calculated the cumulative change in phase between corresponding segments of successive RF lines for both walls, hereby continuously following the artery walls during motion (tracking). Eventually, the displacement of the anterior and the posterior wall was displayed simultaneously with the difference between these displacements, representing the change in diameter during the 


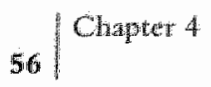

cardiac cycle (distension). The arterial end-diastolic diameter (D) and the change in diameter from diastole to systole $(\Delta D)$ nomalized for the end-diastolic diameter $(\Delta D / D)$ for each captured heart beat were provided as well. Simultaneously, arteral blood pressure measurements were obtained every 3 minutes at the level of the brachial artery by means of a semiautomated oscillometric device (DINAMAP; Criticon, Tampa, FL). Pulse pressure (PP), defined as systolic minus diastolic blood pressure, was determined by averaging the three measurements nearest to the distension measurements. With this method pulse pressure can be assessed reliably [20-22]. Reliable assessment of distensibility and compliance requires the detemination of PP at the site of measurement of $D$ and $\triangle D$ or at a representative site elsewhere. It has been shown that for the assessment of these parameters in the carotid artery, brachial PP is a good substitute [23]. Brachial artery PP, however, is not representative of $\mathrm{PP}$ in the femoral artery (unpublished results). One should realize, however, that errors due to differences in location between blood pressure measurement and artery wall property assessment will be methodological in nature and of the same order of magnitude at the various moments of determination, because intrasubject variation was determined in time.

From $D, \triangle D$ and $P P$, the arterial cross-sectional distensibility (DC) and compliance (CC) coefficients were calculated according to the following equations $[24]$ :

$$
\begin{aligned}
& \mathrm{DC}=(2 \Delta \mathrm{D} / \mathrm{D}) / \mathrm{PP} \\
& \mathrm{CC}=\pi \mathrm{D} \Delta \mathrm{D} /(2 \mathrm{PP})
\end{aligned}
$$

With the wall-tracking system, displacements of a few micrometers can be resolved $[25,26]$ and $D, \Delta D, \Delta D / D, D C$ and $C C$ can be assessed reliably and reproducibly [27].

The artery wall properties, as determined in this way, reflect a combination of passive elastic characteristics of the wall and active components induced by smooth muscle cells. Therefore, we investigated the elastic common carotid artery and the muscular common femoral artery. To save time, we investigated the right common carotid and the right common femoral artery. This is allowed because, in previous studies, the wall properties of the right and left common carotid artery as well as the right and left common femoral artery, were found to be not significantly different (Willekes C, Kool MJ, Hoeks APG, Reneman RS, umpublished results). All examinations were performed with an empty bladder, because recent studies in our institute have shown that a full bladder affects artery wall properties of the common femoral artery [28]. 


\section{Statistics}

SPSS-software packages were used to perform Wilcoxon non-parametric statistical analysis. For each volunteer, the data obtained during the spontaneous menstrual cycle and those obtained during oral contraceptive use were compared with each other in a paired way. We also evaluated the differences in the data between the pill-free interval (Days 25-28) and the previous measurement at we end of OC use (Days 19-21) for statistical significance. Bonferroni correction for the level of statistically significant values was used for repeated analysis. We considered a level of $p<0.016$ to be statistically significant $\{\mathrm{P}<0.05 / \mathrm{gg}(\mathrm{g}-1) / 2]$, where $\mathrm{g}$ is the number of pairwise comparisons\} [29].

\section{Results}

No statistically significant differences in artery wall properties could be detected between the spontaneous menstrual cycle and OC use (Table 1). Systolic, diastolic and mean arterial blood pressures were also not significantly different between these periods and no short-term effect (Days 19-21 vs Days 25-28) of oral contraceptive use on artery wall properties, blood pressure or hormone levels could be detected (Table 2). This analysis was performed on 13 rather than 14 women because 1 women could not be measured in the pill-free interval due to personal circumstances. The differences between the values of the various variables during the different phases of the spontaneous cycle and the corresponding periods during OC use were small and not significant (Figures 1 and 2). Plasma levels of $17 \beta$-oestradiol and progesterone were significantly higher during the various phases of the spontaneous menstrual cycle than during $\mathrm{OC}$ use when these levels were below the lower limit of determination (17/-oestradiol) or low (progesterone). In 2 volunteers, venous blood sampling was not performed during $\mathrm{OC}$ use. In these subjects, no escape-ovulation, a sign of significant endogenous hormone production, could be demonstrated with transabdominal ultrasonography. The venous blood plasma levels of thyroid-stimulating hormone, testosterone, prolactin and hemoglobin revealed no abnormalities. 


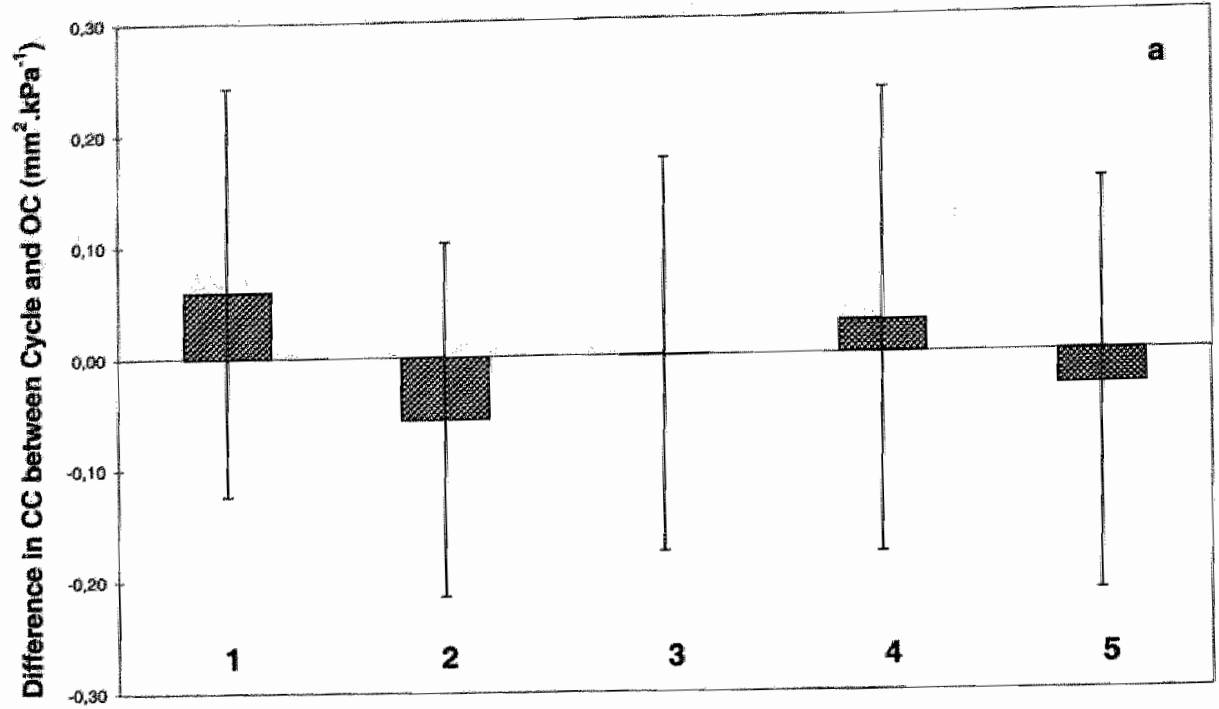

Phases of the menstrual and $O C$ cycles

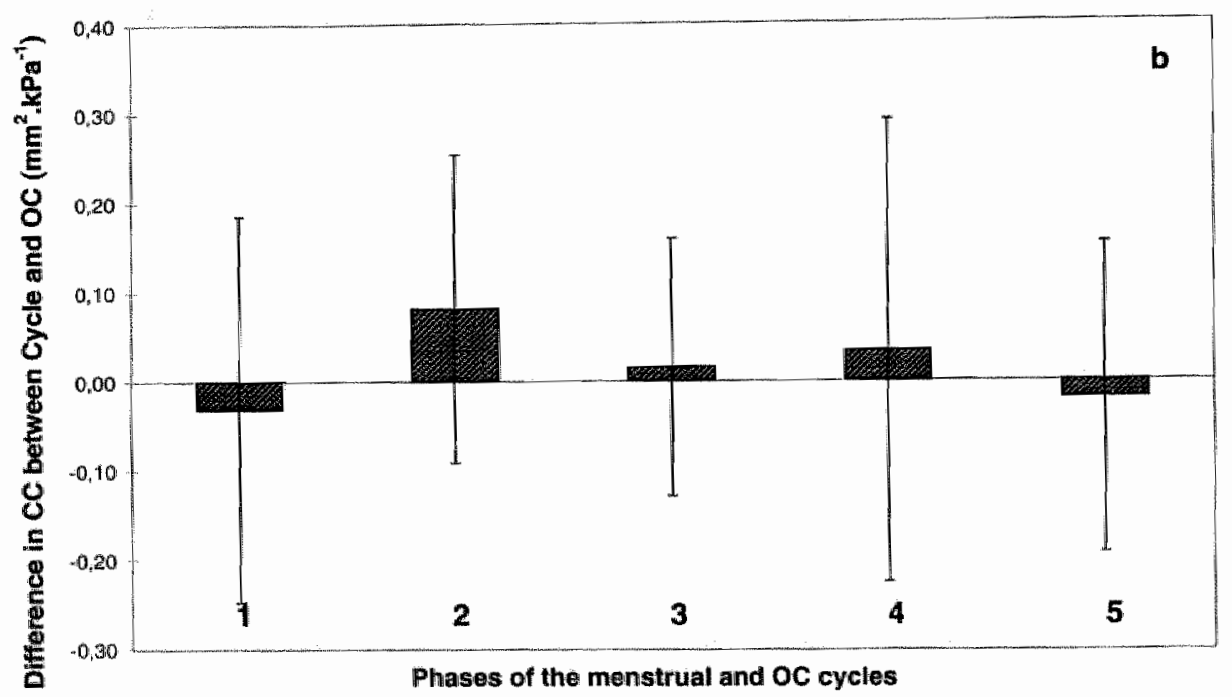

Figure 1. Dilference ( $t S D$ ) in compliance coeffictent (CC) of the right common carotid (a) and right common fenoral (b) arteries between the menstrual cycle (Cycle) and the corresponding phase during OC uso (OC). Five different phases are discerned (horizontal axis) according to the wenous plasma levels of $17 \beta$-oestradiol and progesterone of the spontaneous menstrual cycle, while the central ewent is considered to be the ovulation (Pluase 3). $1=$ menstrual and early follicular phases, $2=$ mid follicular phase, $3=$ periovulatory phase, $4=$ early luteal phase, $5=$ nidluteal phase. The $O C$ cycle is aligned in time, according to the same phases stating from the menstrual phase. 


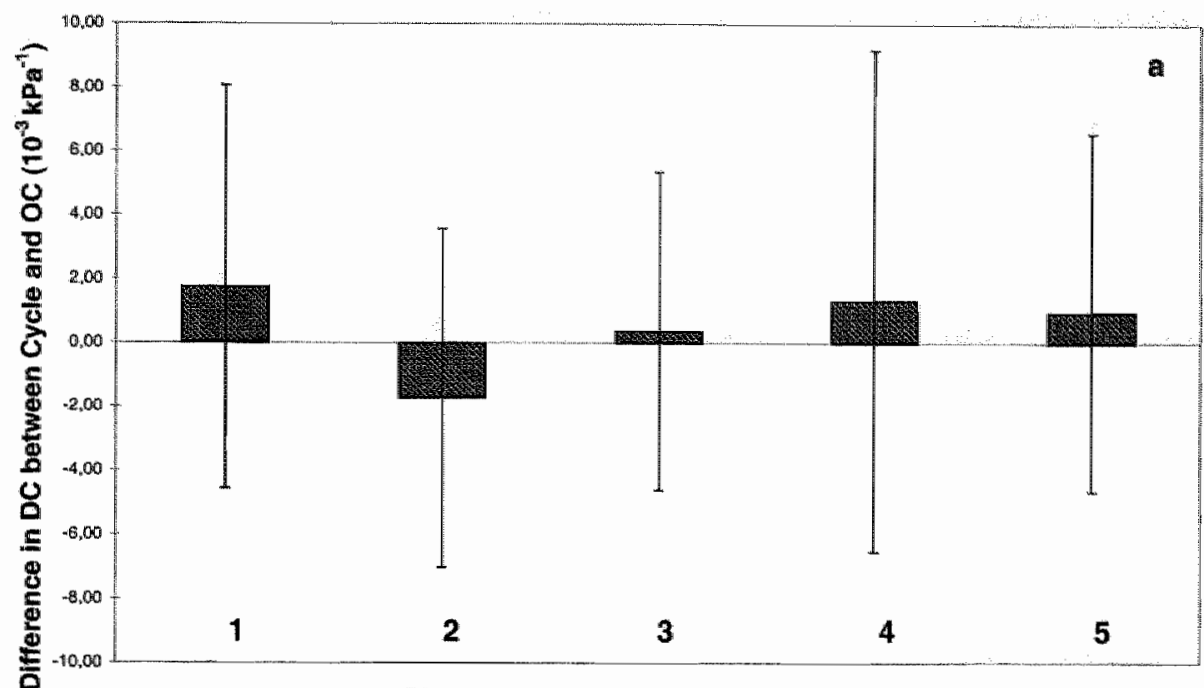

Phases of the menstrual and $O C$ cycles

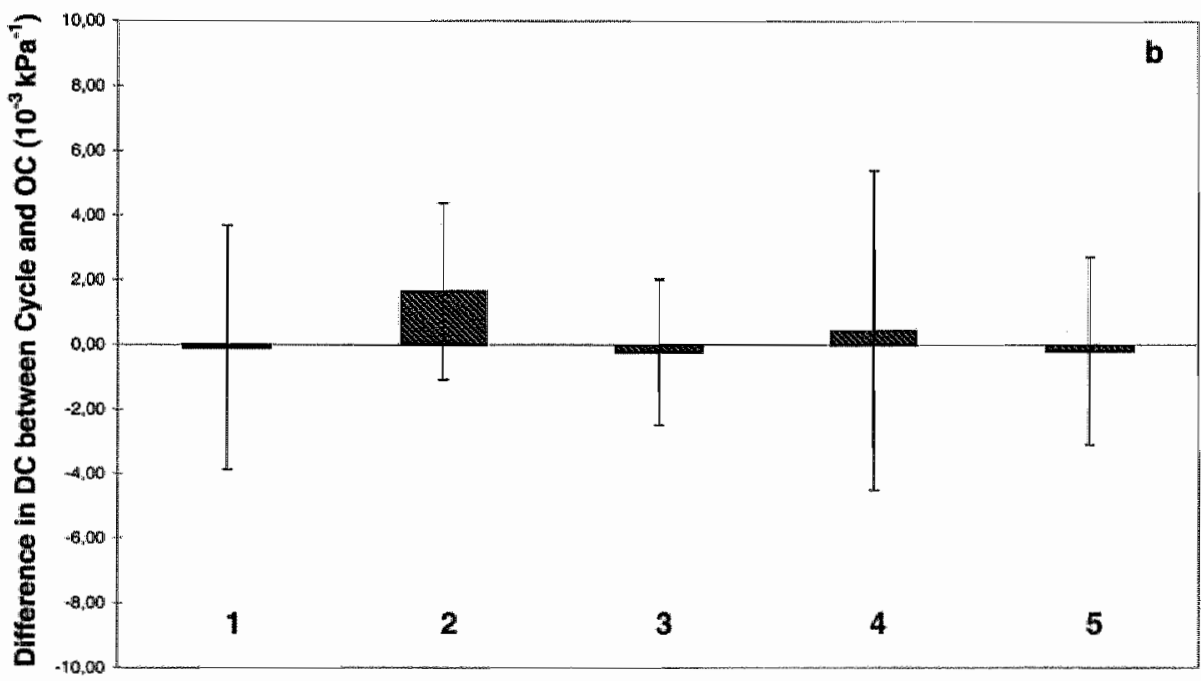

Phases of the menstrulal and $O C$ cycles

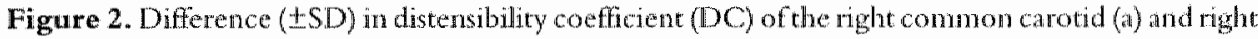
common femoral (b) arteries between the menstrual cycle (Cycle) and the corresponding phase during OC use (OC). Five different phases are discerned (horizontal axis) according to the venous plasma levels of 17 $\beta$-oestradiol and progesterone of the spontaneous menstrual cycle, while the central event is considered to be the ovulation (Phase 3). 1 = menstrual and early follicular phases, $2=$ mid follicular phase, $3=$ periovulatory phase, $4=$ early luteal phase, $5=$ midluteal phase. The $O C$ cycle is aligned in time, according to the same phases starting from the menstrual phase. 
$6 0 \longdiv { \text { Chapter } 4 }$

Table 1 , End-distralic dianeter (D) relatue distension (strain, $1 \mathrm{D} / \mathrm{D} \times 100 \%$ ), distenisibility coetGeient (OC) and compliance coefficient $(\mathrm{C}$ ) of the nght common carotid arter $(\mathrm{CCA})$ and the right common fenord artery (CFA) as heteninined in 14 presuned bealihy fenales.

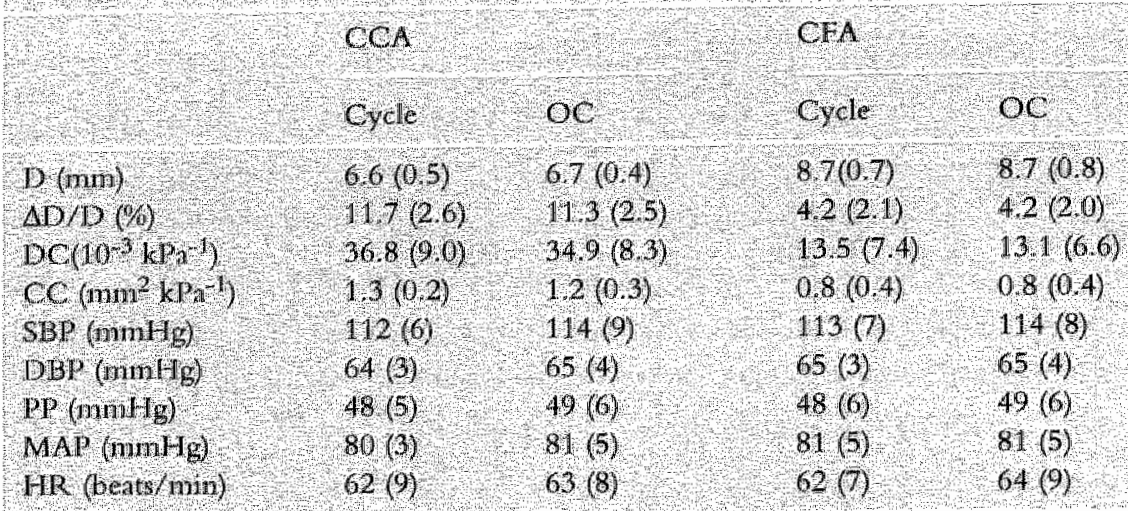

Syatolic (SBP) and distolic (DBP) arter 1 blood pressure, pulse pressire (DP), nean anterial blood

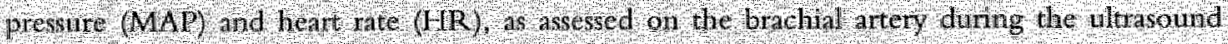

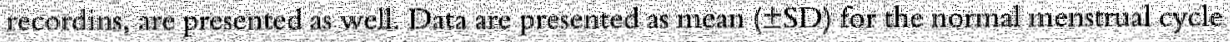
(Necording) ind after 3 noniths of oral connaceptive use $(O C$ )

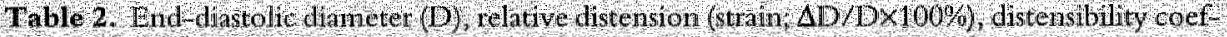
ficten (DC) and complintee coeffeient (CC) of the right common carotid antery (CCA) and the right comizon fenberal artery (CF A) a deternined in 13 presumed healthy fenales during and conGracentue use.

\begin{tabular}{|c|c|c|c|c|}
\hline & 00 & CREE & OC & FMEE \\
\hline $10(\mathrm{~mm})$ & $67(0.3)$ & $68(0,6)$ & $8.8(0.6)$ & $88(0.8)$ \\
\hline$\Delta 10 / 10$ & $117(2,7)$ & $10.6(2.8)$ & $42(2,2)$ & $4,3(2,1)$ \\
\hline $10 \mathrm{C}\left(10^{3} \mathrm{~km}, \mathrm{l}\right.$ & 35797 & $33.5(9.4)$ & $131(79)$ & 130066 \\
\hline $\mathrm{cc}\left(\mathrm{m}^{2} \mathrm{hl}+\mathrm{H}\right)$ & $12(13)$ & $12(0.3)$ & $08(05)$ & $08(0.4)$ \\
\hline $\operatorname{SBP}(\mathrm{ninh})[\mathrm{g})$ & $115(11)$ & $114(19)$ & $116(8)$ & 11609 \\
\hline DOP (GMMle) & $66(61$ & $66(5)$ & $66(8)$ & $66(5)$ \\
\hline PP (rum/g) & $60(8)$ & $48(7)$ & $50(7)$ & $50(8)$ \\
\hline MAP (nwm/g) & $82(7)$ & $82(6)$ & $83(7)$ & $83(6)$ \\
\hline 11 (bos ts $/ \mathrm{min}$ ) & $65(1)$ & $04(12)$ & $66(12)$ & $64(10)$ \\
\hline $\mathrm{E} 2(\mathrm{nnnol} / \mathrm{l})$ & $0.03(0.01)$ & $(0.08(703) \mathrm{x}$ & & \\
\hline 19 (muolll) & $0.9(0,5)$ & $100(0,6)$ & & \\
\hline
\end{tabular}

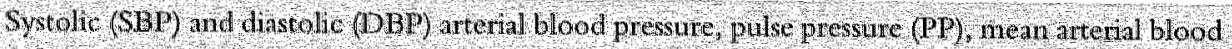

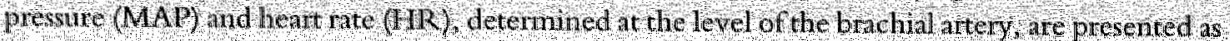
Well Data are piesented as mean ( $\$$ SD) at the end of the oral contraceptive cycle (OC Day $19-21$ )

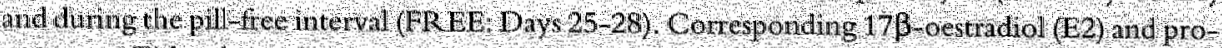

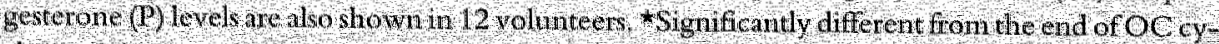
cle (p<O 005$)$ 


\section{Discussion}

The findings in the present study demonstrate that, in young presumed healthy females, 3 months use of a third-generation oral contraceptive does not affect artery wall properties, as compared to the spontaneous menstrual cycle.

The $\mathrm{OC}$ used here (30 $\mu \mathrm{g}$ ethinylestradiol and $75 \mu \mathrm{g}$ gestodene; Femodene) does not induce the vasopressor effect as observed with second-generation pills [11-14]. The relatively new progesterone component of this OC preparation is known for its low androgenic biophysical profile, which may explain the absence of a rise in blood pressure [30]. It could be argued that the duration of $O C$ use was too short to elucidate an increase in arterial blood pressure, but, with second-generation compositions, an increase in arterial blood pressure could be demonstrated already after 3 months.

Changes in artery wall properties are not necessarily related to changes in arterial blood pressure alone, because arterial distensibility and compliance of the elastic arteries were found to be substantially reduced in borderline hypertensives, despite the fact that, in these patients, blood pressure elevation is limited and noticeable only for part of the day $[5,15]$. In addition, in some forms of genetic hypertension, aortic distensibility and compliance are reduced before hypertension develops [16]. In this light, it cannot be excluded that $O C$ use of longer duration affects artery wall properties before influencing arterial blood pressure.

It may be concluded that neither the phase of the menstrual cycle [6] nor the use of oral contraceptives, at least in the combination used, can explain the differences in artery wall properties between males and females as observed in previous studies [1-5]. One should realize, however, that women tend to take OCs for years and changes in artery wall behaviour may only become apparent after longer periods of use.

In conclusion, 3 months use of a third-generation oral contraceptive does not influence the wall properties of peripheral arteries and cannot explain the observed difference between genders. The absence of a rise in blood pressure and the low androgenic profile of this specific oral contraceptive may have contributed to our findings.

\section{References}

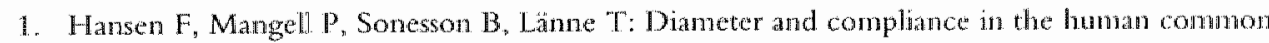
carotid artery - variations with age and sex. Ultrasound Med Biol. 1995;21(1):1-9.

2. François B: Alteration in arterial wall elasticity in the young. Clin Gen. 1983;24:287.

3. Laogun AA, Gosling RG: ln wivo arterial compliance in man. Clin Phys Plyysiol Mcas. $1982,3(3): 201-12$ 
4. Riley WA, Bames $\mathrm{R} W$, Schey HM: An approach to the non-invasive periodic assessment of arterial dasticity in the young. Prevent Med. 1984; 13:169-84.

5. van Merode T. Hick PJ, Hoek APG, Smeets FAM, Reneman R. Differences in carotid artery wall properties berween presumed-healthy mew and women. Ultrasound Med Biol. $1988,147) 571-4$

6. Willekes $\mathrm{C}$, Hoogland HJ, Keizer HA, Hows $A \mathrm{P}$, Reneman RS: The infuence of femalle sex hormones on artery wall properties during the nomal menstrual cycle. Clinical Science. 1997:92:487-91.

7. Stadel BV: Oral contraceptives and cardiovascular disease (frrst of two parts). N Engl J Med. $1981,305(1), 612-8$

8. Stadel BV: Oral contraceptives and cardiovascular disease (second of two parts). N Engl J Med. $1981 ; 305(12): 672-7$

9. Ory HW: Association between oral contraceptives and myocardial infarction: a review. IAMA. $1977 ; 237: 2619-22$.

10. Rosenbergr $\mathrm{L}$, Hennekens $\mathrm{CH}$, Rosner $\mathrm{B}$, al e: Oral contraceptive use in relation to mon-fatal myocandial infarction. Am J Epidemiol. 1980;111:59-66.

11. Mann J1, Vessey MP. Thorogood $\mathrm{M}$, Doll $\mathrm{R}$ : Myocardial infarction in women witly special reference to oral contraceptive practice. Br Med J. 1975;2:241-5.

12. Huppert LC: Vascular effects of homonal contraception. Clim Obstet Gynecol. 1981;24(3): 951-63.

13. Meade TW: Risks and mechanisms of cardiovascular events in users of oral contraceptives. Am J Obstet Gynecol. 1988;158(6 Pt 2):1646-52.

14. Weir JR. Blood pressure and the contraceptive pill. In: Bulpitt CJ, ed Handbook of Hypertension: Elsewer Science Publishers B.V.; 1985:289-300.

15. van Merode T, Brands PJ, Hocks APG, Reneman RS: Faster ageing of the carotid artery bifurcation in bonderline hypertensive subjects. J Hypertens. 1993;11(2):17》-6.

16. van Gorp AW, van Ingen Scherau DS, Hoeks APG, Struijker-Boudier HAJ, de Mey JGR, Reneman RS: Reduced aorta compliance precedes high blood pressure in spontaneously hypertensive rats (SHR). The FASEB Journal. 1996;10:A278, 1598.

17. Vollmann RF: "The menstrual cycle. Major Probl Obstet Gynecol. 1977;7:1-193.

18. Hoeks APG, Brands PJ, Smeets FAM, Reneman RS: Assessment of the distensibility of supencial arteries. Ultrasound Med Biol. 1990;16(2):121 1 8.

19. Hoeks APG, Arts TG, Brands PJ. Reneman RS: Comparison of the performance of the RF cross correlation and Dopplet autocorrelation technique to estimate the mean velocity of simulated ultrisound signals. Ultrasound Med Biol. 1993;19/9):727-40.

20. Ransing Mr: Noninvasive automatic determination of mean arterial pressure. Med Biol Eng Comput 1979:17:11-8. 21. Ramsay Mr: Blood pressure monitoring automated oscillometric devices. J Clin Monit. 1991;7;
$56-6 \%$.

22. Amoore JN, Geake WB. Scott DHT: Oscillonetric non-mvasive blood pressure meastrement: the influence of the make of instruments on readings? Med Biol Eng Comput. 1997,35:131-4.

23. Reneman RS, wan Merode T, Brands PJ. Hoeks APG: Inhomogeneities in arterial wall properties under nomal and pachological conditions. I Hypertens Suppl. 1992;10(6):S35-9.

24. Rencman RS, van Merode T, Hick P, Hocks APG: Cardiovascular applications of multi-gate pulsed Doppler systems. Ultrasound Med Biol. 1986;12(5):357-70.

25. Hoeks APG. Non-invasive study of the local mechanical arterial characteristics in lumms. In: Satar ME, OR ourke MF, eds. The arterial syotem in hypentensim. Dordrecht/Boston/London:
KLuwer Acadenic Publishers; 1993 . 
26. Reneman RS, Hoeks APG, Westerhof N: Non-inwasive assessment of artery wall properties in humans - methods and interpretations. J Vasc lnvest. 1996;2:53-64.

27. Kool MJ, wan Merode T, Reneman RS, Hoeks APG, Struiker Boudier HA, Van Bortel LM: Evaluation of reproducibiliry of a vessel wall movement detector system for assessment of large artery properties. Cardiovasc Res. 199:428(5):610-4.

28. W/Ilekes C. Hoogland H], Hoeks APG, Reneman RS: Bladder filling reduces femoral artery wall distension and strain: beware of a full bladder! Ulrasound Med Biol. 1998,24(6):803-7.

29. Fleiss JL. The Bonferroni correction for multiple comparisons. In: Shewart WA, Wils SS, eds. The design and andysis of dinical experintents. New York: John Whiley and Sons; 1986:103-7.

30. Wilde MI, Balfour JA: Gestodene. A review of its pharmacology, efficacy and tolerability in conbined contraceptive preparations. Drugs. 1995;50(2):364-95. 
Automated detection of local artery wall thickness based on M-line signal processing

\author{
Anold P.G. Hoeks!, Christine Willekes" , Pieme Boutouyrie", Peter J. Brands! \\ Jean M. Willigers. and Robert S. Reneman ${ }^{2}$ \\ Departments of Biophysics' and Physiology ${ }^{2}$, Cardiovascular Research Institute \\ Maastricht, Maastricht University, the Netherlands, and Department of Internal \\ Medicine ${ }^{3}$, INSERM U337, Broussais Hospital, Paris, France
}




\section{Abstract}

The Yonng's modulus of an anterial segnent, a measure of the elastic properties of the arterial wall, reguires the simultaneous and local assessment of pulse pressure, wall thickness, dimneter, and distensibility (relative increase in cross-sectional area per change in blood pressure). The dianeter and relative increase in cross-sectional area can be obtained with a wall track system, processing the radiofrequency (r.f) ultrasound signals received along a single line of observation (M-line processing). It will be demonstrated that it is feasible to combine, in a single measurement, the assessment of wall thickness and the (relative change in) diameter involving a minimum of user interaction. Phantom tests show a standard error of the estimate for intimamedia thickness measurements of less than $20 \mu \mathrm{n}$; in wyo registrations exhibit a wariation on the order of $45 \mu \mathrm{m}$. It is concluded that processing of the radiofrequency ultrasound signal, acquired along an M-line, provides an accurate and time-efficient alternative for videoprocessing of 2-dimensionat B-mode ultrasound intages to estinate artery wall thekness. 


\section{Introduction}

With the gradual improvement of display resolution of ultrasound echo systems, the assessment of dimensions of small structures (e.g., artery wall thickness) has become feasible [1-3]. Unfortunately, the internal hardware and software of commercial echo systems is less suited for the detection of small distances with a high accuracy. The processing linitations, caused by calipers with a limited resolution, are circumvented by digitizing a brightness mode ( $\mathrm{B}$-mode) image videotape and assessing intima-media thickness (IMT) off-line. To this end, an image is captured by a computer, equipped with a video frame grabber, in a preselected phase of the cardiac cycle allowing detailed analysis of the lumen-wall boundary region. It will be shown that analysis of 2-dimensional $\mathrm{B}$-mode images is complicated by the speckle pattern and preprocessing of the video-images [4]. Moreover, the additional off-line analysis increases processing complexity.

Phase interference of signals originating from reflectors, spaced at intervals less than the resolution of the echo system employed, will enhance or depress locally the B-mode signal level, causing the well-known speckle pattern in 2-dimensional ultrasound images $[5,6]$. At boundaries of structures, speckle may produce site-dependent variations in the slope and amplitude of the echo, resulting in an irregular outline. The outcome of a distance measurement will, therefore, vary with the location selected and the (subjective) amplitude or gradient threshold employed. Averaging allong the structure boundary is used to eliminate the influence of speckle, thereby assuming that the speckle pattern has a random spatial distribution. This works quite well, especially for those situations where intima and adventitia run parallel (i.e., the intima-media thickness does not vary locally). The site and length for averaging, usually 2 to $3 \mathrm{~cm}$, is then selected according to the dimensions of the fleld of view of the echo system in conjunction with the local anatomy of the artery of interest.

Averaging will reduce the influence of speckle on intima-media thickness measurements. To what extent averaging, indeed, ameliorates the results depends on the averaging strategy used. The most simple, but time-consuming, approach is based on manual tracing of the intima-blood and media-adventitia interfaces along a given vessel segment. Then intima-media thickness (IMT) is estimated by determining the average of wall thickness as measured at a few discrete points or along a continuous segment. Evidently, manual tracing puts emphasis on the position where the signal level crosses the display threshold, which makes the method susceptible of reflectivity of the structures, gain setting and compression characteristics of the ultrasound system. Automated averaging procedures open up the possibility of selecting the threshold according to the local characteristics of the non-linear B-mode signal in a direction perpendicular to the wall [7]. Clearly, the 
latter approach will objectivate and speed up the estimation procedure, although it still leaves the burden of capturing a $\mathrm{B}$-mode image at a timed moment with respect to the cardiac cycle. For proper imaging, the interfaces of interest should be oriented perpendicular to the ultrasound beam. For echo-systems, where the ultrasound probe is assumed to be positioned at the top (or the bottom) of the screen, imaging of peripheral arteries will result in interface boundaries parallel to the video lines. Averaging will then be effective only if the position within the region considered fluctuates more than the interspacing between video lines. Without interpolation schemes, the anticipated error in distance measurements will otherwise be governed by the video-line spacing, which is on the order of 0.1 $\mathrm{mm}$ for most echo-systems.

In addition to the problems associated with the interference of the beam and video line directions and the nonlinear display characteristics, the main disadvantage of the current B-mode image processing for media-intima wall thickness estimation is its high degree of user interaction. First, a B-mode image in a preselected phase of the cardiac cycle is captured by a computer, then the operator has to indicate the region of interest. Automated processing procedures as proposed by Selzer et al. [7] eases this procedure, will increase calculation speed, and makes the measurement more reproducible.

This paper describes an approach for estimating from radiofrequency ultrasound data, acquired in M-modle with a wall track system, the intima-media thickness of the posterior wall of an artery. First, the proposed method will be described in more detail. Then, its performance will be evaluated experimentally with a phantom. Finally, the reproducibility of measurements performed on the common carotid artery of healthy volunteers will be assessed.

\section{Processing algorithm}

The assessment of wall thickness contributes to the evaluation of the local mechanical characteristics of the vessel wall [3] as assessed with commercially available wall track systems [8]. The Young's modulus expresses the elasticity of an arterial segment as function of pulse pressure, wall thickness, lumen diameter and relative change in diameter [9]. In wall track systems, the received radiofrequency (r.f.) ultrasound signals along a single line of sight ( $M$-line) over a large number of observations are analyzed. To allow for proper identification of the vessel walls, the wall track system (Scanner 200, Pie Medical, Maastricht, the Netherlands) stores the r.f. signals over a few heart beats. The user has to identify the position of the vessel walls as part of the procedure to detect the displacement of vessel walls and, hence, the change in diameter as function of time $[8,10]$. Therefore, it requires only a minor modification to store the data within a window of $3 \mathrm{~mm}$ 
around the blood wall interface on the posterior side of the artery. After comple-tion of registrations of a large number of patients, all fles stored within a selected directory can then be processed with the same settings without further user interference. Possible speckle artifacts are reduced by temporal averaging of the envelope of the received signal over the first part of the cardiac cycle. Artery wall motion is corrected for by realigning the lines considered, based upon the observed change in position.

The assessment of artery wall thickness by means of ultrasound [1] is based upon the following conditions. The lumen-intima boundary has a low reflectivity, but a higher reflectivity than red blood cells. The boundary will be visible in B-mode (and predominantly at the posterior wall), especially at perpendicular incidence of the ultrasound beam. The media itself has a very low echogenicity. It is bounded by the weak reflections of the intima (narrow region) and the strong reflections of the media-adventitia transition. At the anterior wall, the trails of the high echo levels of the adventitia-media transition may obscure the low-level signals of the media and intima, even for high resolution echo systems (wide bandwidth), making wall thickness measurements at the near wall less accurate than at the far wall [11].

Wall thickness measurements are limited to the intima-media thickness (leading edge of lumen-intima to leading edge of media-adventitia interface at the posterior wall), because the outer boundary of the adventitia cannot be distinguished from surrounding tissue. The estimation procedure is applied to r.f. signals along a single line of view (spot measurement), eliminating nonlinear processing characteristics of echo-systems (Figure 1a). Processing a single line of observation is inadequate because speckle may modify the local envelope, as can be observed in the upslope of the media-adventitia reflection in Figure 1b. Averaging the power distribution over time along a line will reduce the speckle artifacts, provided that there is some variation in the interspacing of the echoes due to arterial wall motion and associated wall compression during the cardiac cycle (Figure 1c). Wall motion will improve the quality of the signals, but complicate processing, because echo signals will be displaced over time along the line of view. To avoid the latter complication, the r.f. signals are aligned in phase prior to averaging based upon the detected displacement in between observations as provided by the wall track system algorithm. To reduce possible time skew, the response time of the displacement estimation technique is made as short as possible ( 2 subsequent lines), necessitaring a longer processing window in depth to achieve an acceptable displacement resolution [12]. The length of the processing window can be varied under software control from its full length to (the last) $50 \%$ of the data window covering $3 \mathrm{~mm}$.

The averaging process will enhance signals from wall interfaces exhibiting similar displacements between observations and smooth secondary echo signals (e.g., reverberations) with a different displacement behavior (Figure 1c). Wall 
signals can be distinguished from other signals (or background) by considering the derivative of the mean amplitude distribution with respect to depth. Only for the leading edge of distinct echoes the derivative will have a high (positive) value. To avoid problems with gain settings, the threshold for the derivative is expressed as a percentage of the peak amplitude within the data window. Initial experiments indicate that $2 \%$ is a suitable value, but this may depend on the r.f. sample frequency with respect to the maximal frequency of the envelope (half the bandwidth of the r.f. signal). The derivative is only used to identify the regions containing relevant leading echo edges (the region where the derivative exceeds the threshold). To obtain an accurate position, the amplitude distribution within the region is reexamined. The position where the instantaneous amplitude is halfway the amplitude range within the region is considered as the location of the intima edge. This detection procedure is repeated for the next region (possibly the media-adventitia edge) where the derivative exceeds the threshold. To avoid introduction of false edges within the range of intima and adventitia, especially for a large wall thickness, the maximum of the adventitia signal should be at least a preset multiple of the intima maximum. If a detected edge does not meet this requirement, the observed edge is ignored and the search for the next edge is continued. After acceptance of two edges, indicated by triangles on the baseline in Figure $1 c$, the search procedure is aborted.

Because it will be impractical to maintain a steady measurement condition, the averaging of echo power distribution is repeated for each cardiac cycle. Subsequent cardiac cycles will then give new, but highly dependent, estimates of wall thickness. On the other hand, some position instability will contribute to the suppression of speckle artifacts. For the present estimation procedure, this unsteadiness is introduced by the displacement of the posterior wall due to the local change in blood pressure. Because pressure changes are most pronounced in the early phase of the cardiac cycle, processing is restricted to $500 \mathrm{~ms}$ from the R-peak of the ECG. Although, for r.f. line alignment each r.f. line acquired at a sample rate exceeding $500 \mathrm{~Hz}$, has to be processed, amplitude averaging is indicated at a much lower time spacing because of the low speed of tissue displacement. To reduce computational complexity, averaging is only executed at intervals of $50 \mathrm{~ms}$, whereas displacement detection is performed for each line.

The resolution for wall thickness detection, applied to the averaged amplitude distribution at the end of the 500-ms time segment, will be limited by the r.f. sample frequency (at $20 \mathrm{MHz}$ approximately $0.040 \mathrm{~mm}$ ). A linear amplitude interpolation procedure is employed to Jocate the edge position at a much finer scale. The resulting resolution highly depends on the reproducibility of the selection of signal segments. The lower limit for the intima-media wall thickness is at least the 


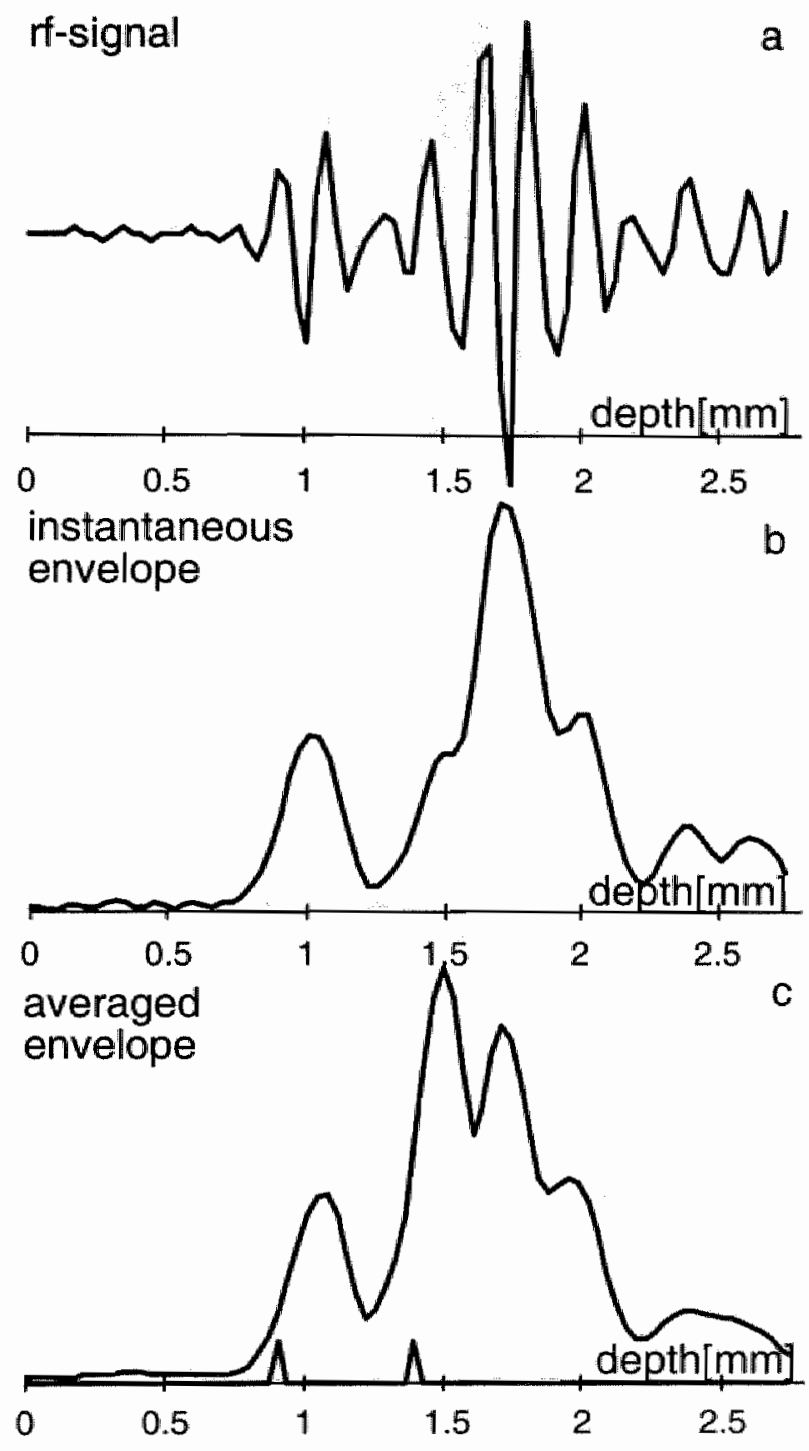

Figure 1. (a) Radiofrequency (rf) signal covering posterior wallIumen interface, (b) instantaneous amplicude distribution; and $(c)$ time-averaged mean. The triangles at the baseline of (c) indicate the position of the detected adges. 


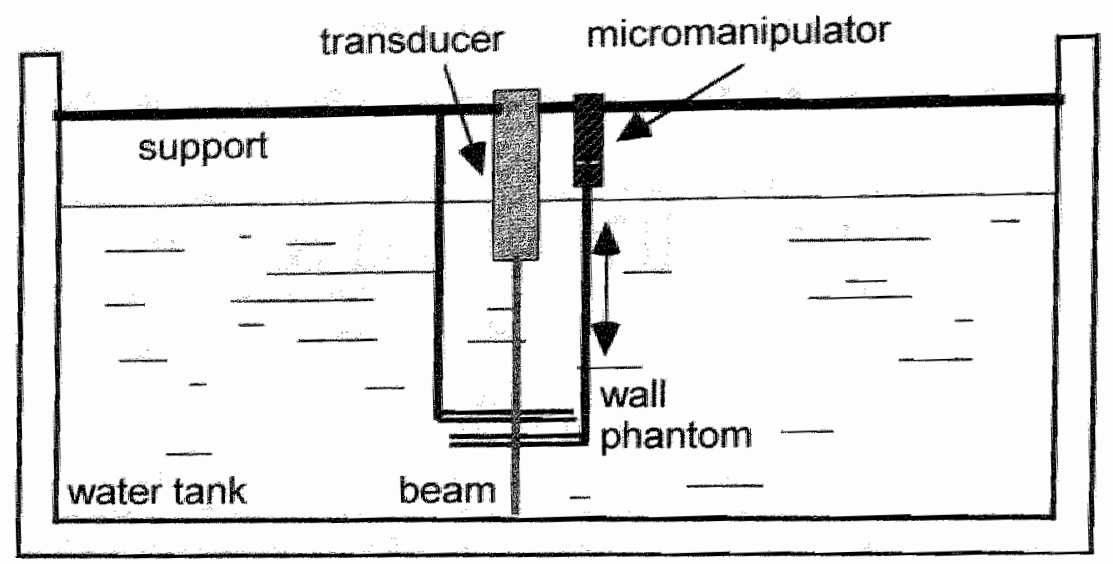

Figure 2. Test configutation for wall thickness detection. With the micromanipulator a double-layered reflector can be moved in vertical direction, thereby changing the distance to a second similar reflector which has a fixed position with respect to the transducer.

axial resolution of the echo-system employed, usually on the order of $0.3 \mathrm{~mm}$ for ultrasound systems for transcutaneous application.

\section{Phantom configuration}

To verify if the proposed signal processing procedure, indeed, produces an accurate and reproducible estimate of the distance between 2 reflections, a phantom was constructed (Figure 2 shows a vertical cross-section). A thin-walled latex tube (wall thickness $0.15 \mathrm{~mm}$, circumference $50 \mathrm{~mm}$ ) was dragged over a U-shaped support wire (wire thickness $4.0 \mathrm{~mm}$ ) with a distance between both legs of $5 \mathrm{~cm}$, providing two parallel reflector planes at a fixed distance of 4.0 mm. Because of stretching and conservation of mass, the wall thickness is reduced to about 0.075 mm. The construction was mounted on a support arm in a water tank and was displaced in the vertical direction with a micromanipulator (one revolution equivalent to a displacement of $0.5 \mathrm{~mm}$ ). A similar construction, containing a double reflector configuration, was mounted on the same support bar, together with a 7.5 MHz Jinear array probe of a Pie 200 scanner (Pie Medical, Mastricht, the Nether-
lands).

The whole construction resulted in 4 parallel reflector planes, with the first pair located at a fixed distance of $15 \mathrm{~mm}$ from the transducer surface (Figure 2). The initial distance between the second and third reflector plane was $10 \mathrm{~mm}$. The focal 
position of the echo system was set at $20 \mathrm{~mm}$ and maintained at that range during the experiment.

The distance measured, based upon a sampled r.f. line, depends on both the speed of sound in the medium and the sample frequency of the r.f. signal $(22.1$ $\mathrm{MHz}$ ). The known distance between a pair of reflector planes $(4.0 \mathrm{~mm}$ ) allows calibration of the distance measurements in terms of $\mu m$ per sample interval, without separate measurements of the speed of sound in water and the r.f. sample frequency. Employing the calibration distance, the distance between both sets of reflectors was first set at $1.0 \mathrm{~mm}$ and then reduced to $0.4 \mathrm{~mm}$ by counting revolutions of the micromanipulator. Starting from this base value recordings were made at intervals of $0.05 \mathrm{~mm}$ up to $1.1 \mathrm{~mm}$. The whole procedure was repeated once, eventually giving two series of estimated wall thicknesses as function of the imposed distance.

\section{In vivo evaluation}

The subject population consisted of 11 young $(20-30$ y) normotensive females without any evidence of cardiovascular disorders. The study was approved by the joint medical-ethical committee of the Maastricht University and the Academic Hospital Maastricht. All subjects gave informed written consent.

All measurements, with the subjects in a supine position, were performed in the morning in a climatized room $\left(20-22^{\circ} \mathrm{C}\right)$ after an acclimatization period of 15 minutes to normalize cardiovascular function. First, the common carotid artery and the carotid artery bifurcation were screened for possible vascular disease with the same 7.5-MHz Pie 200 linear array echo system (Pie Medical) as used for the phantom measurements, after which an $M$-line was positioned perpendicular to the common carotid artery $2-3 \mathrm{~cm}$ proximal to the carotid artery bifurcation. Subsequently, the system was switched to $\mathrm{M}$-mode and, starting synchronously with a trigger derived from the R-peak of the ECG, rf data were collected in the data-acquisition memory of the wall track system at a sample frequency of 22.1 $\mathrm{MHz}$ and an $\mathrm{M}$-line update frequency of 500 for a period of 4 seconds. After r.t. data acquisition, the first r.f. line was displayed on a personal computer screen, allowing identification of a window of $3 \mathrm{~mm}$, covering the posterior lumen-wall-transition. Data from this window over time were then stored on hard disk for further off-line processing. The above procedure for positioning of the $\mathrm{M}$-line and for data acquisition was repeated in the same session 3 times by the same investigator.

After completion of data acquisition for all subjects, the recorded files were processed employing the wall thickness program. The threshold for the derivative was maintained at 0.025 . Each heart beat within a recording resulted in an estimate 


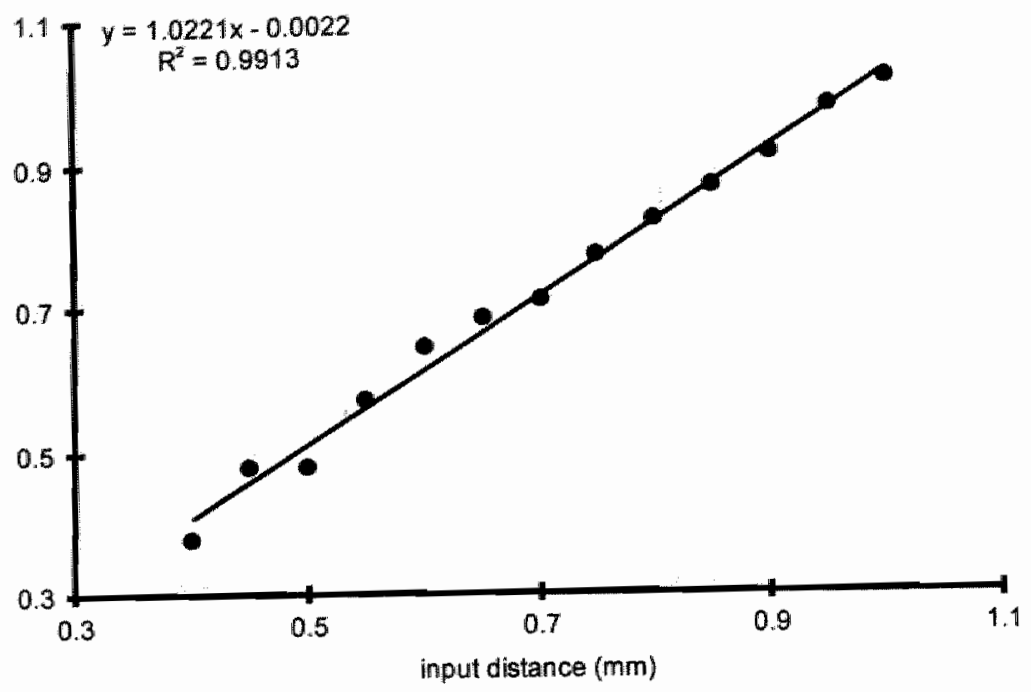

Figure 3. Estimation of wall thickness as function of imposed distance between parallel reflector planes.

of wall thickness; the median of the estimates per recording was used for further evaluation. Based upon the 3 subsequent recordings per subject, the mean and the standard deviation of the estimate was computed, allowing calculation of the intrasession intraobserver intrasubject variation [1.3].

\section{Results}

The phantom meastrement procedure was executed twice, resulting in two series of estimated wall thicknesses as function of the imposed distance. Figure 3 gives the result of the first run. The linear regression line through the data points is expressed as $y=1.022 \mathrm{x}-0.002$ with an $\mathrm{R}^{2}=0.991$. Based on the difference between the observed value and the corresponding point on the linear regression line, the standard error of the estimate is $0.019 \mathrm{~mm}$ with a bias of $-0.012 \mathrm{~mm}$. For the second run, a similar result was obcained: $y=0.994 x-0.006$ with $R^{2}=0.993$ with a standard error of the estimate of $0.017 \mathrm{~mm}$ (bias is $0.0 \mathrm{~mm}$ ).

Because the test population consisted of young, presumably healthy, volunteers, the wall thickness is expected to fall in a narrow range. The in vivo reproducibility results are given in Figure 4 , depicting the difference between the 3 consecutive measurements per subject and the subject mean. The standard devi- 


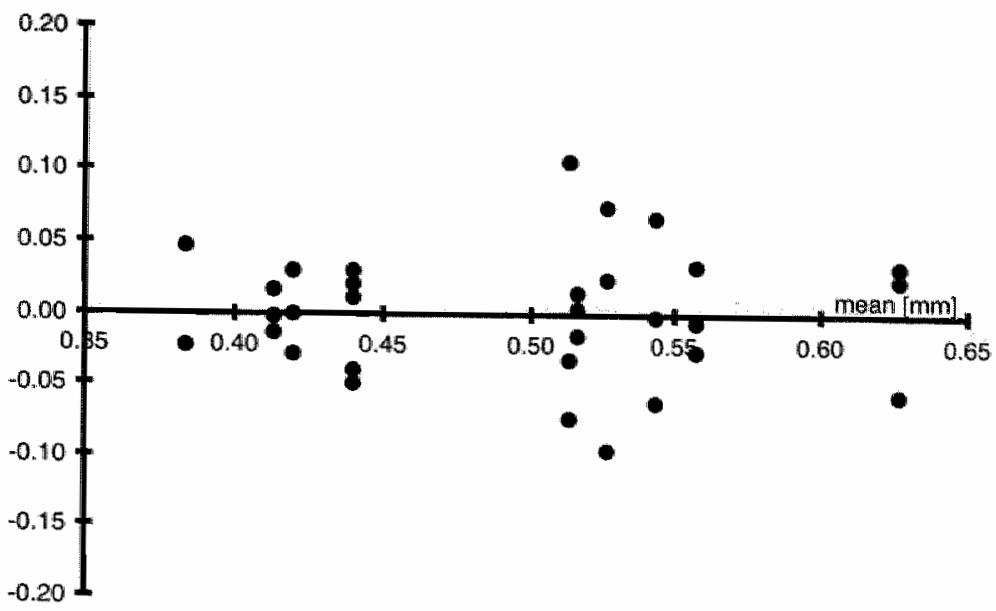

Figure 4. Error in repeated measurements of common carotid artery wall thickness in a population of 11 young heathy women. The dots represent the difference between measurement and subject mean.

ation, averaged over all subjects, was $0.044 \mathrm{~mm}$. For the range studied, the observed error does not depend on wall thickness.

\section{Discussion}

Based upon the in vino and phantom test results, it may be concluded that intima-media wall thickness (IMT) can be measured accurately and reliably with a good resolution by means of automated r.f. processing. The observed standard deviation of the estimate in 3 repeated independent measurements in the common carotid artery of 11 young women is only $0.044 \mathrm{~mm}$. This compares favorably with methods based on $\mathrm{B}$-mode video image processing $[1,4,14]$. Although averaging is performed in the time domain, rather than in the scan plan, the results are the same as obtained with automated B-mode processing [7]. Computer processing of $r$.f. signals acquired along an $\mathrm{M}$-line has some distinct advantages. The radiofrequency signal, considered for processing, has not yet been subjected to nonlinear processing common to $\mathrm{B}$-mode images, like signal rectification followed by lowpass filtering (spatial smoothing), and amplitude compression. In the proposed r.f. method, the amplitude as function of depth is obtained after conversion to a quadrature signal, allowing detection of the instantaneous amplitude without subsequent smoothing, thereby retaining the spatial resolution. The 
measurement of local wall thickness can be combined with distensibility assessm ment, thereby considerably reducing user interference and processing complexity.

The signals acquired in the phantom test configuration do not fully reflect the characteristics of in vivo signals. The reflectors are thin homogeneous parallel planes. Moreover, the measurement condition is fully static (i.e., no change in phase between different reflections occurs within a measurement). That is why averaging of the estimated wall thickness does not improve the result. The highly predictable outcome is confimed by the similarity of the regression lines for 2 subsequent runs. Only a minor difference in the $y$-intersect can be noted, which can be attributed to the accuracy of repositioning of the reflector. The other difference between in wivo and phantom r.f. signals is in the relative levels of the signals returned by the "lumen-intima" and "media-adventitia" interface. For the phantoms, both are equal in amplitude because attenuation of ultrasound by water can be ignored, and both interfaces exhibit the same transition in acoustic impedance. Because the lumen-intima reflection is quite large, it will take some time (depth) until the amplitude is reduced to a neglible level with respect to the level of the next signal originating from the media-adventitia transition. This interaction of "intima" and "adventitia" reflections at a short interspacing is clearly visible in Figure 3: the magnitude of the fuctuations around the regression lines increases for a shorter interspacing. For realistic signals, the intima reflections would have an amplitude on the order of $10 \%$ of the adventitia reflection (see Figure 1). Henceforth, in vito, it would take a shorter time (distance) until the trailing edge of the intima reflection can be ignored. As a consequence of the shortcomings of the phantom configuration (no effective averaging, relative large intma amplitude) the test results are not directly comparable with those obtained in an in vivo measurement situation. Despite these shortcomings, the observed low standard error of the estimate (less than $0.020 \mathrm{~mm}$ ) justifies the expectation that the algorithin will function properly for realistic signals.

The averaging procedure relies on the expected change in wall thickness over a cardiac cycle. Because of conservation of mass, distension of an artery due to the pulse pressure causes a similar reduction in wall thickness. This should affect the phase interaction (speckle) of $\mathbf{r}$. signals retumed from reflectors spaced at intervals smaller than the resolution of the echo system. Indeed, it can be concluded from Figure 1 that incidental peaks in the instantaneous envelope are removed by the averaging process, resulting in a much smoother envelope as function of depth.

Averaging of envelopes with a different interspacing of reflectors also has a negative aspect, because the observed wall thickness will be related to mean wall thickness rather than to the end-diastolic value. For young healthy volunteers, the relative change in diameter due to pulse pressure in an elastic artery will be about 10\%. This will give an underestimation of wall thickness on the order of $5 \%$. For 
an artery with an intima-media thickness of $0.5 \mathrm{~mm}$, the expected bias will be $0.025 \mathrm{~mm}$. In older subjects and patients, the wall thickness will increase but, concomitantly, the relative distension will decrease, mantaining the bias at the same value. Because the expected bias is linked to the distensibility of the artery and to wall thickness, and both parameters change only gradually over time, it will not affect subject evaluation.

In addition to the influence of deformation of the arterial wall on the observed wall thickness during the measurement, averaging over time has another side effect. The detection of displacement and alignment of reflections is based upon cross-correlation of 2 subsequent observations over a large window (3 mm). A large window in depth is necessary to allow for a short window in time [12]. Restricting averaging over time to only one cross-correlation pair avoids a phase lag between the detected displacement and the current r.f. signal. The thickness of the arterial wall varies during a cardiac cycle and the associated change in interspacing of reflections will cause decorrelation. The latter reduces the accuracy of displacement detection [15]. Again, a short time window for averaging will suppress this secondary effect. The main contribution to the cross-correlation originates from the adventitia, producing the strongest signal, which can be found in the last part of the data window; the other part contains low level signals from lumen, intima and media.

The in vivo results show a standard error $(0.044 \mathrm{~mm})$ of the estimate for repeated and independent measurements twice as large as the results obtained with the phantom (less than $0.020 \mathrm{~mm}$ ). The phantom distances, however, tanged from 0.4 to $1.0 \mathrm{~mm}$ where the error was predominantly observed for values below 0.6 mm. This is exactly the range of wall thickness in the subject population. Moreover, the consecutive measurements were independent in the sense that the ultrasound probe was repositioned between measurements, contributing to the intrasession variability. Figure 4 includes 2 subjects with a substantially larger deviation (in excess of $0.05 \mathrm{~mm}$ ). This larger deviation may be due to local itregularities in the arterial wall and/or different phase interaction. To reduce the contribution to the error of the estimate, it is suggested to consider the median of three consecutive measurements rather than the result of a single observation. This will improve the relevance of wall thickness measurements in longitudinal studies, where a high resolution and reproducibility is required.

For both the phantom and the in vivo evaluation the threshold for the derivative was set at 0.025. A substantially higher threshold may cause loss of edges, while a much lower value will give rise to edges related to noise. It is oun observation that, for the given r.f. sample frequency, the observed wall thickness is not influenced by thresholds within a range from 0.015 to 0.030 . For a higher r.f. sample frequency with respect to the r.f. frequency bandwidth, the threshold 
should be proportionally decreased. Because, within the window considered, all r.f. data are scaled with respect to the peak amplitude of the adventitia reflection, the threshold will be independent of gan setting and/or attenuation of the wltratsound signal by intervening tissue.

Presently, the processing procedure still follows a 2-step approach. First, data (from a number of subjects) are gathered and stored on hard disk. Whille the recording is made, the position of both arterial walls has to be identified to allow for the assessment of the initial artery diameter and the change in diameter as function of time (distension waveform). Only the r.f. data covering the posterior lumen-wall region are retained for further processing. After having made a large number of registrations, all recordings are automatically processed (with the same settings) to extract the intima-media thickness. The estimates per heart beat, together with the median over the heart beats considered, are retained in a log file. Obviously, this procedure has some disadvantages. Storing r.f. data on a disk requires a large memory and a good registration protocol for different users. Moreover, the result will become available after some delay. The off-line processing approach was followed only to retain control over the processing sequence. Now, the procedure is evaluated; the next step would be a full integration with distension measurements, involving adjustment of the input and output protocol. Simultaneous local assessment of artery diameter, distension and wall thickness along the same line of observation provides a distinct advantage, because studies have shown that changes in arterial distensibility are inhomogeneous along arterial bifurcations, some sites being more affected than others [9]. Therefore, to adequately describe changes in arterial function under these circumstances, one has to be informed of artery wall properties locally.

\section{Acknowledgement}

This work was supported by Biomed grant CT94.1121 of the European Union.

\section{References}

1. Pignoli P. Tremoli I, Poli A, Oreste P, Paoletti R: Intimal plus nedial thickness of the arterind wall: a direct measurenent with ultrasound imaging. Circulation. 1986;74(6):1399-406.

2. Bond GM, Bames RW, Riley WA, Wilmoth SK, Chambless LE, Howard G, Owens B: The ARIC Study Group. High-resolution B-mode ultrasound scanning methods in the atherosclerosis risk in communities study (ARIC). J Neuromag. 1991;1(2):68-73. 
3. Riley WA, Barnes RW, Evans GW, Burke GL: Ultasonic measurement of the elastic nodulus of the common carotid artery - the Arherosclerosis Risk in Communiries (ARIC) study. Srroke. $1992 ; 23(7): 952-6$.

4. Easton JD: Accuracy of high-resolution nltrasound inaging for quantitative assessment of early carotid atherosclerosis. Cerebrovase Dis. $1994 ; 4: 109-113$.

5. Wells $\mathrm{PNT}$, Hailiwel $\mathrm{M}$ : Speckle in utrasonic imaging. Ulrasonics. 1981;19:225-9.

6. Burckhardt CB: Speckle in ultrasound B-mode scans. IEEE Trans Son Ultrason. 1978;25:1-6.

7. Selzer RH, Hodis HN, Kwong Fu H, Mack WJ, Lee PL, Lin CR, Liu CH: Evaluation of computerized edge tracking for quantifying intima-media thickness of the common canotid artery from B-mode ultrasound images. Atherosclerosis. 1994;111(1):1-11.

8. Hoeks APG. Non-invasive study of the local mechanical arterial characteristics in humans. In: Safar ME, O'Rourke MF, eds. The artevial system in hypentension. Dordrecht/Boston/London: Kluwer Academic Publishers; 1993.

9. Reneman RS, Hoeks APG, Westerhof N: Non-invasive assessment of artery wall properties in humans - methods and interpretations. J Vasc Invest. 1996:2:53-64.

10. Hoeks APG, Brands PJ, Smeets FAM, Reneman RS: Assessment of the distensibility of superficial arteries. Ultrasound Med Biol. 1990;16(2):121-8.

11. Wong $M$, Edelstein J, Wollman J, Bond $M G$ : Ultrasonic-pathological comparison of the laman arterial wall. Verification of intima-media thickness. Arterioseler Tinomb. 1993;13(4):482-6.

12. Hoeks APG, Arts TG, Brands PJ, Reneman RS: Comparison of the perfomance of the RF: cross correlation and Doppler autocorrelation technique to estmate the mean velocity of simulated ultrasound signals. Ultrasound Med Biol. 1993;19(9):727-40.

13. Bland JM, Altman DG: Statistical methods for assessing agreement between two methods of clinical measurement. Lancet. 1986;1 (8476):307-10.

14. Riley WA, Barnes RW, Applegate WB, Dempsey R, Hartwell T, Davis VG, Bond MG, Furberg $\mathrm{CD}$ : Reproducibility of noninvasive ultrasonic measurement of carotid atherosclerosis. The Asymptomatic Carotid Artery Plaque Study. Stroke. 1992;23(8):1062-8.

15. Varghese T, Ophir J, Céspedes I: Noise reduction in elastograms using temporal stretching with multicompression imaging. Ultrasound Med. Biol. 1996;22:1043-52. 
Evaluation of off-line automated

intima-media thickness detection of the common carotid artery based on M-line signal processing

Christine Willekes ${ }^{1}$, Arnold P.G. Hoeks', Michiel L. Bots ${ }^{3}$, Peter J. Brands ${ }^{2}$, Jean M. Willigers ${ }^{2}$, Robert S. Reneman ${ }^{1}$.

Deparments of Physiology and Bioplyysics ${ }^{3}$, Cardiovascular Research Institute Maastricht, Maastricht University, Maastricht, and Department of Epidemiology \& Biostatistics ${ }^{3}$, Erasmus University Medical School Rotterdam, Rotterdam, The Netherlands. 


\begin{abstract}
Intima-media thickness (IMT) measurements have gained increasing sattention, because IMT is assumed to represent the endothelial adaptive response to physiological and pathophysiological processes. The main aim of the present study was to assess the intrasubject intrasession variability of a new off-line automated radio-frequency (RE) IMT method in comparison with an already established off-line manual B-mode IMT method. IMT was also assessed by means of an on-line manual B-mode and an on-line manual RF IMT method. We investigated posterior wall IMT $0-1 \mathrm{~cm}$ proximal to the bulb in both common carotid arteries of 16 young (20-31 y; mean: 25 y) female and male and 13 elderly ( $51-65 y$; mean: $56 y$ ) femalle volunteers. Two commercially available ultrasound devices (Pie Medical Scanner 200 and Ultramark 9) were used to assess the effects of signal processing on the off-Ine autonated RF IMT method. Intrasubject intrasession variability was decermined using the standard deviation to evaluate and compare the various methods. Speaman rank correlation coefficients and Bland and Alman bias and limits of agreement were calculated to objectivate the comparability between the various methods. Intrasubject intrasession variation of IMT estimates was not statistically different between any of the methods. We observed a good comparability between the commonly used off-line manual B-mode $I M T$ method and the off-line automated RF IMT method at the level of the common carotid artery.
\end{abstract}




\section{Introduction}

In the past decade, the intima-media thickness (IMT) of the artery wall has gained increasing attention, because it is assumed to represent the endothelial adaptive response to physiological and pathophysiological processes, such as those seen in ageing and hypertension [1-5]. A variety of MT measurement protocols, based on different ultrasound methods, have been developed and improved in order to obtain reliable and reproducible results $[5-11]$.

In 1984, it was shown, using calipers, that in witro artery wall thickness can be assessed reliably and accurately by $B$-mode imaging, and the results obtaned correlated well with histological examinations [12]. In 1986, it was demonstrated that IMT can also be assessed in viwo, and that it indeed represents the true intima-media complex as confimed by histological recognition [8]. "The method, however, shows a considerable variation. This is partly atributed to the limited axial resolution and a relatively poor magnification of the $B$-mode magers at that time. Thanks to technical improvements in displaying the received B-mode signal and better zoom possibilities, the current ultrasound devices are capable of disceming intima-media complexes more accurately with a precision of $0.1 \mathrm{~mm}$ [13].

One of the other methods to measure IMT uses automated digitization of the B-mode image, after capturing it in a preselected phase of the cardiac cycle with a frame grabber, and subsequent off-line analysis [9,14]. Aside from the high user interactivity, the speckle pattern and the signal preprocessing in the ultrasound scanner system prior to video presentation are important restrictions of this method. To delineate the different boundaries of the intima and media, markers have to be placed manually on the video image[14,15]. This is timemconsuming and introduced some subjectivity, dependent on the reflectivity of the stuctures and the gain setting and signal compression characteristics of the ultrasound system. The process was improved and made quicker by automated interpolation of the intima-media complex after simple identification by the observer $[16,17]$. This improved the reproducibility of the procedure and rendered it more user independent. Additionally, automated spatial averaging procedures circumvented the dependence of the outcome on the threshold level by adjusting the threshold according to the local characteristics of the nonlinear $B$-mode signal $[11,18]$. "The off-line manual as well as off-line automated B-mode IMT methods provide a mean IMT over a length of $10 \mathrm{~mm}$.

The $B$ - and $M$-mode signals displayed on the ultrasound monitor are derived from the received raw radiofrequent (RF) signals. These RF signals have, among others, been used to assess artery wall displacement with a wall track system (WTS) [19]. The RF signals also can be used to measure IMT Jocally by manually placing 
841 Chapter 6

markers on amplitude signals of the blood-intima interface and the mediaadventitia interface as induced by the end-diastolic RF line. The off-line automated RF IMT measurement method uses temporal averaging of the RF signals received over the cardiac cycle, rather than spatial averaging of the echo-signal [6] to reduce the incidental infuence of speckle. Considiering the median value of the IMT estimates, obtained over a few subsequent cardiac cycles, will improve the precision of the IMT estimate. The automated procedure is more time-efficient than the prewiously mentioned manual $B$-mode methods and rather user-independent. It calculates mean IMT locally over a cardiac cycle instead of mean IMT over a $10 \mathrm{~mm}$ segment at end-diastole. The reproducibility of this method is good, as published previously [6].

The aim of the present study was to evaluate the intrasubject intrasession variability and comparability of the various procedures to estimate IMT (manual on-line and automated off-line B-mode and RF processing), using two different commercially available ultrasound systems (Ultramark 9 and Pie Medical Scanner 200). No on-line manual B-mode IMT measurements were performed on the Pie Medical Scanner 200 , because of the absence of adequate zoom magnification. The on-line manual RF IMT method was performed only on the first RF-line of the Pie Medical Scanner 200 , because of its use in combination with the WTS. To investigate whether our RF IMT method measured the same as the B-mode IMT method, the results of both methods were compared. The measurements were performed on the left and right common carotid arteries of volunteers of different ages.

\section{Material and methods}

\section{Subjects}

The study was performed on 16 presumed healthy male and female volunteers (20-31 y; mean $25 \mathrm{y}$ ) and equally divided over both genders, and an additional group of 13 presumed healthy females $(51-62 \mathrm{y}$; mean $56 \mathrm{y})$. Bottl young and elderly volunteers were used to obtain an adequate range of IMT values as ageing induces a physiological and consistent increase in IMT. The study was approved by the joint Medical Ethics Committee of the Maastricht University and the Academic Hospital Mastricht. All volunteers gave their written consent after receiving detailed information before entering the study. 


\section{Ultrasound systems}

The IMT measurements were performed using two different commercially available ultrasound devices. The Pie Medical Scanner 200 (Pie Medical, Maastricht, The Netherlands) has a linear array transducer of $7.5 \mathrm{MHz}$. The measured puise length at $-6 \mathrm{~dB}$ as received from a tissue target at a distance of $20 \mathrm{~mm}$ is $0.35 \mu \mathrm{s}$, corresponding to an axial resolution of approximately $0.26 \mathrm{~mm}$. This scanner has an electrocardiographic (ECG) modality to start data collection at the end of diastole. The Ultramark 9 (ATL, Bothell, Washington, USA) has a linear array transducer of $6-10 \mathrm{MHz}$. The measured pulse length at $-6 \mathrm{~dB}$ is $0.31 \mu$ s, corresponding to an axial resolution of approximately $0.22 \mathrm{~mm}$. The device contains a cine-loop function to review stored images over one to two cardiac cycles together with the recorded ECG trace so that the selection of a specific phase of the cardiac cycle can be performed manually. A built-in super VHS video recorder allows storage of the obtained images for off-line assessment of IMT, according to spatial B-mode averaging.

\section{Intima-media thickness measurement protocol}

We measured the IMT of both the left and the right common carotid artery at 0-1 cm proximal to the bulb in the plane of the bifurcation (Figure 1). Only the posterior wall was investigated, because here the reflections from the blood-intima and media-adventitia transition are distinctly visible, whereas, at the anterior wall, the trailing edge of the adventitia reflections may obscure the media and intima signal. We compared five different methods in use to assess IMT. All measurements were performed by one single investigator (C.W.). The reading of the stored end-diastolic B-mode images was performed in Rotterdan by an experienced ulttrasonographer.

\section{Image analysis}

\section{Off-line automated RF technique}

First, we measured local IMT 0 and $1 \mathrm{~cm}$ proximal to the bulb by means of the off-line automated RF IMT method based on M-line signal processing as described in detail previously [6], using the Ultramark 9. The off-line automated RF IMT method was based on the following procedure. A B-mode image was obtained of the common carotid artery in a longitudinal plane after which an $\mathrm{M}$-line was positioned perpendicular to the posterior wall, showing a clear intima-media complex. Subsequently, the system was switched to M-mode and after ECG triggering, RF signal collection started in the data acquisition memory 


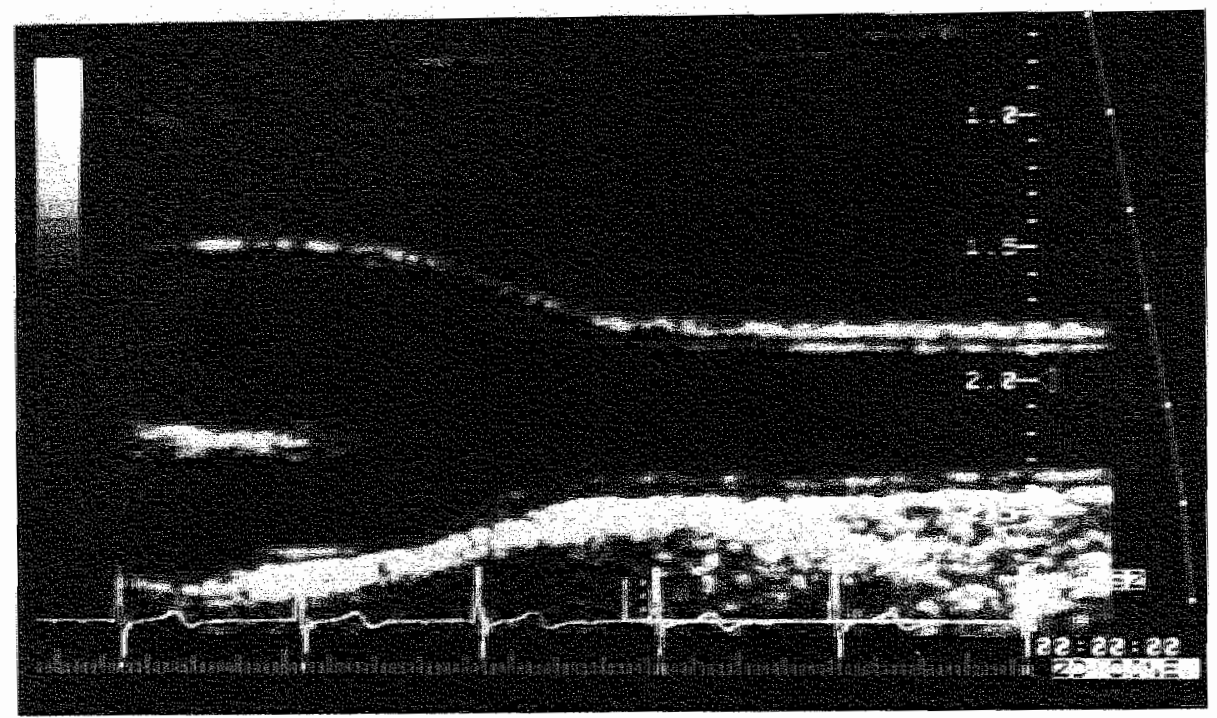

Figure 1. B-mode photogtaphy of the vight common carotid artery of a 52-y-old healthy volunter obtained using the Ultwamark 9. The intima media complex clearly is visible at the posterior and anterior common carotid artery wall over a distance of at least $1 \mathrm{~cm}$. At the left, the widening of the bub is used as a landmark for intma-media thickness measurements.

of the WTS at a sample frequency of $20 \mathrm{MHz}$ and an $\mathrm{M}$-line update frequency of $400 \mathrm{~Hz}$ for a period of $4 \mathrm{~s}$. Consecutively, the first RF line was displayed on the computer monitor, allowing identification and selection of a window of $3 \mathrm{~mm}$, covering the posterior intima-media complex. Data from this window over time were stored on hard disk for additional off-line processing. At the end of the measurement protocol the recorded files were processed using the wall thickness program. The system settings were held constant, with a threshold of the derivative of the amplitude at 0.02 (2\% of peak amplitude adventita per sample distance; approximately $35 \mu \mathrm{m}$. "The RF signals were aligned in phase prior to averaging based on the detected displacement between observations, as provided with the WTS algorithm. Averaging over the systolic phase of a heart beat enhanced signals from wall interfaces exhbiting similar displacements between observations and smoothed secondary echo signals (e.g., reverberations) with a different displace ment behaviour. For each theart beat, the derivative of the averaged amplitude distribution was considered with respect to depth to distinguish wall signals from other signals. Only the leading edge of distinct echoes exceeding the threshold for the derivative was used to identify relevant regions. The position where the instantaneous amplitude was halfway in the amplitude nange within the region was considered the location of the intima edge. This detection procedure was repeated. 
for the next region (possibly the media-adventitia edge), where the derivative exceeded the threshold. Each heart beat within a recording resulted in an estimate of IMT. The ratio of intima to adventitia was at least 1.0 , to suppress detection of false edges. The resolution for wall thickness detection was approximately $40 \mu \mathrm{m}$ [6]. The lower limit for intima-media wall thickness was determined by the axial resolution of the ultrasound device used. Measurements were repeated three times at both 0 and $1 \mathrm{~cm}$ proximal to the bulb in the common carotid artery. The average of the median values obtained at both locations was taken as a representative IMT value.

Second, we used the Pie Medical Scanner 200 in combination with the off-line automated RF IMT method to evaluate the effect of system characteristics on the estimated IMT. The Pie Medical Scanner 200 uses a sample frequency of 22.1 $\mathrm{MHz}$ and an M-line update frequency of $500 \mathrm{~Hz}$.

\section{Off-line manual B-mode technique}

Third, we used the off-line manual B-mode approach. The B-mode images obtained with the Ultramark 9 were frozen at the $\mathbb{R}$ wave of the ECG ( $\sim$ end diastolic phase). Clearly visible intima-media complexes of the common carotid artery more than $1 \mathrm{~cm}$ from the bulb were selected. The frozen images were expanded maximally to attain maximum detail (zoom), stored on super VHS videotapes, and sent to an analysis center for additional analysis. The videotapes were read according to a standardized procedure described in detail before [13]. Briefly, the frozen images from the videotape were digitized and displayed on the screen of a personal computer using additional dedicated software [15]. The lumen-adventitia and media-adventitia interfaces of the distal common carotid were marked with a cursor over a length of $10 \mathrm{~mm}$. The beginning of the dilatation of the common carotid artery (bulb) served as a reference point for the start of the measurements. The mean value of the end-diastolic intima-media thickness of the corresponding segment was calculated. This procedure was repeated for three different images obtained at both sides, and the average of the three measurements was taken as a representative for comparison.

\section{On-line manual B-mode fedmique}

Fourth, the same Uitramark $9 \mathrm{~B}$-mode image was used to assess IMT on-line with the aid of calipers of the Ultramark 9, which can be moved with a precision of 0.1 mm. Each image was analyzed instantaneously at two places in the common carotid artery ( 0 and $1 \mathrm{~cm}$ proximal to the widening of the bulb) at consistent gain and zoom settings. Three different measurements were performed at each site, and the average of both locations was taken as the reading. 
RF-line WTS Ple Medical Scanner 200

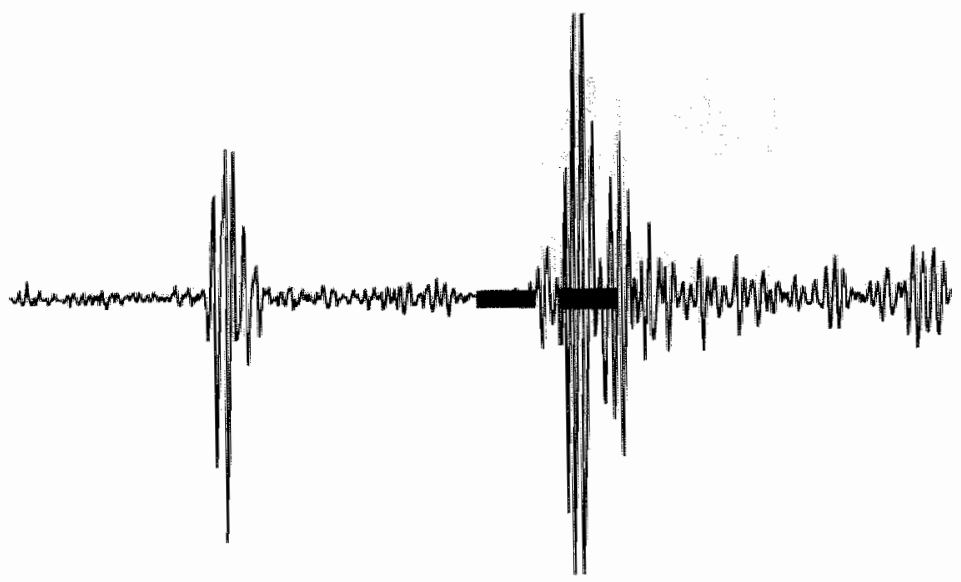

$=$ sample volume

Figure 2. Sample wolumes (black boxes) positioned on the frist radiofrequent (RF) line received from the Pie Medical Scanner 200 at end-diastole are used to estumate intima-media thickness. The right side of the left sample volume is placed in the beginning of the lumen-intima reflection, and the left side of the right samle volume is placed in the beginning of the media-adventitia transition of the posterior wall. "The distance between both edges of the sample volumes is presented with a precision of two decimals. WTS = wall track system.

\section{On-line manual RF technique}

Filth, we used the Pie Medical Scanner 200 manually to place sample volumes on the first RF line obtained at end-diastole. This end-diastolic RF line was displayed on the computer monitor for assessment of Jocal artery wall movement according to the method of Hoeks et al. [19]. The placement of sample volumes at the posterior blood-intima interface and media-adventitia interface (Figure 2) mimics partially the off-line automated RF IMT protocol, albeit that only the end-diastolic artery wall thickness is considered and that speckle interference on the raw RF-signal is not reduced by averaging over the cardiac cycle. Data are presented (in $\mathrm{mm}$ ) on the computer monitor with accuracy to two decimal precise, whereas the RF-line is discretized in steps of $35 \mu \mathrm{m}$. For documentation, a printout of the screen was made. Three measurements were performed at the same locations in the common carotid artery as mentioned in the automated RF 
method, and again the average of both locations was used as representative of ench side in the artery.

Two different ultrasound devices were used in the protocol because we wanted to establish the influence of ultrasound signal processing on the outcome of the automated RF IMT technique. Also, the zoom capacities of the Pie Medical Scanner 200 were limited such that we were unable to attain proper end-diatolic B-mode images for analysis by the on-line and off-line B-mode techniques. Finally, we already had used the Pie Medical Scanner 200 in combination with the WTS and wanted to establish the possibility to assess IMT based solely on the end-diastolic $\mathbb{R E}$ line presented on the nonitor during the WTS measurement protocol.

\section{Statistical analysis}

Difference in intramethod intrasession variability was assessed by means of the Wilcoxon non-parametric signed rank test for statistical significant difference in standard deviations (SDs) between the various methods (Table 1). SPSS packages were used to calculate the Speaman Rank correlation coefficient between various methods. We determined the corresponding measurement agreement by assessing the bias (mean difference $[d]$ ) and limits of agreement $(=d \pm 2$ SD) as described by Bland and Alman [20]. After acknowledging the normal distribution of mean differences in IMT between left and right common carotid artery with each method and the relative small bias between both sites (min. -31 . $\mathrm{m}$, max. $11 \mu \mathrm{m}$ : not statistically significantly different), IMT measurements of both common carotid arteries were included as independent values in the statistical analysis for each method. In case of one missing value, the average of the remaining two values was taken. On one occasion, two values were missing, when using the automated IMT method. The one remaining value was taken as the subject's reading.

\section{Results}

The intrasubject intrasession variation of IMT-estimates was not statistically significantly different between the various methods (Table 1). No significant differences between left and right common carotid arteries were observed by means of paired t-tests using SPSS sofware packages. The on-line ruanual placing of calipers on the enlarged B-mode image of the artery gave as good results as any of the other methods (SD range for young subjects: $27-64 \mu \mathrm{m}$ ). 
$9 0 \longdiv { \text { Chapuer } 6 }$

\begin{tabular}{|c|c|c|c|c|}
\hline & Young & & Elderly & \\
\hline Micthod & Left & Iught & Left & Right \\
\hline Sn-Jne $\mathrm{B}$ monode & $483(27)$ & $494(31)$ & $714(43)$ & $708(6)$ \\
\hline $001 \mathrm{lne} \mathrm{B}$-1 norde & $492(30)$ & $522(26)$ & $704(35)$ & $693(3)$ \\
\hline On-linc RA line & $494(30)$ & $514(25)$ & $682(46)$ & $669(44)$ \\
\hline Orthne R F OM 9 & $494(45)$ & $513(64)$ & $713(46)$ & $133(69)$ \\
\hline OrOlne R F Plo & $523(46)$ & $549(42)$ & $739(7)$ & $730(61)$ \\
\hline
\end{tabular}

The correlations between the off-line manual B-mode IMT method and our off-line automated RF IMT method for both systems are shown in Figures 3 and 4. The correlation coefficients are satisfactory and highly significant $(\mathrm{r}=0.86$ and $r=0.87$, respectively; both $p<0.0001$ ). The measurement agreements as depicted in Figures 5 and 6 for either comparison are good, with a bias of $31 \mu \mathrm{m}$ (off-line automated RF IMT Pie Medical minus off-line manual B-mode IMT Ultramark 9) and $13 \mu \mathrm{m}$ (off-line automated RF IMT Ultramark 9 minus off-line manual B-mode IMT Ultramark 9) and with limits of agreement of $-109 \mu \mathrm{m}$ to $+171 \mu \mathrm{m}$ and $-125 \mu \mathrm{m}$ to $+151 \mu \mathrm{m}$, respectively. In nearly all cases (98\% off-line antomated RF method; 92\% off-line manual B-mode IMT method), values were obtained. Both the on-line manual RF and B-mode IMT methods showed a fair association with the off-line manual B-mode IMT method $(\mathrm{r}=0.83$ and $\mathrm{r}=0.90$, Figures 7 and 8 , respectively). This is confirmed by the mean differences $(-12 \mu \mathrm{m}$ and $-5 \mu \mathrm{m}$, respectively) and limits of agreement as seen in the corresponding Bland-Altman figures $(-152 \mu \mathrm{m}$ to $+128 \mu \mathrm{m}$, Figure 9 ; and $-119 \mu \mathrm{m}$ to $+109 \mu \mathrm{m}$. Figures 9 and 10, respectively). 

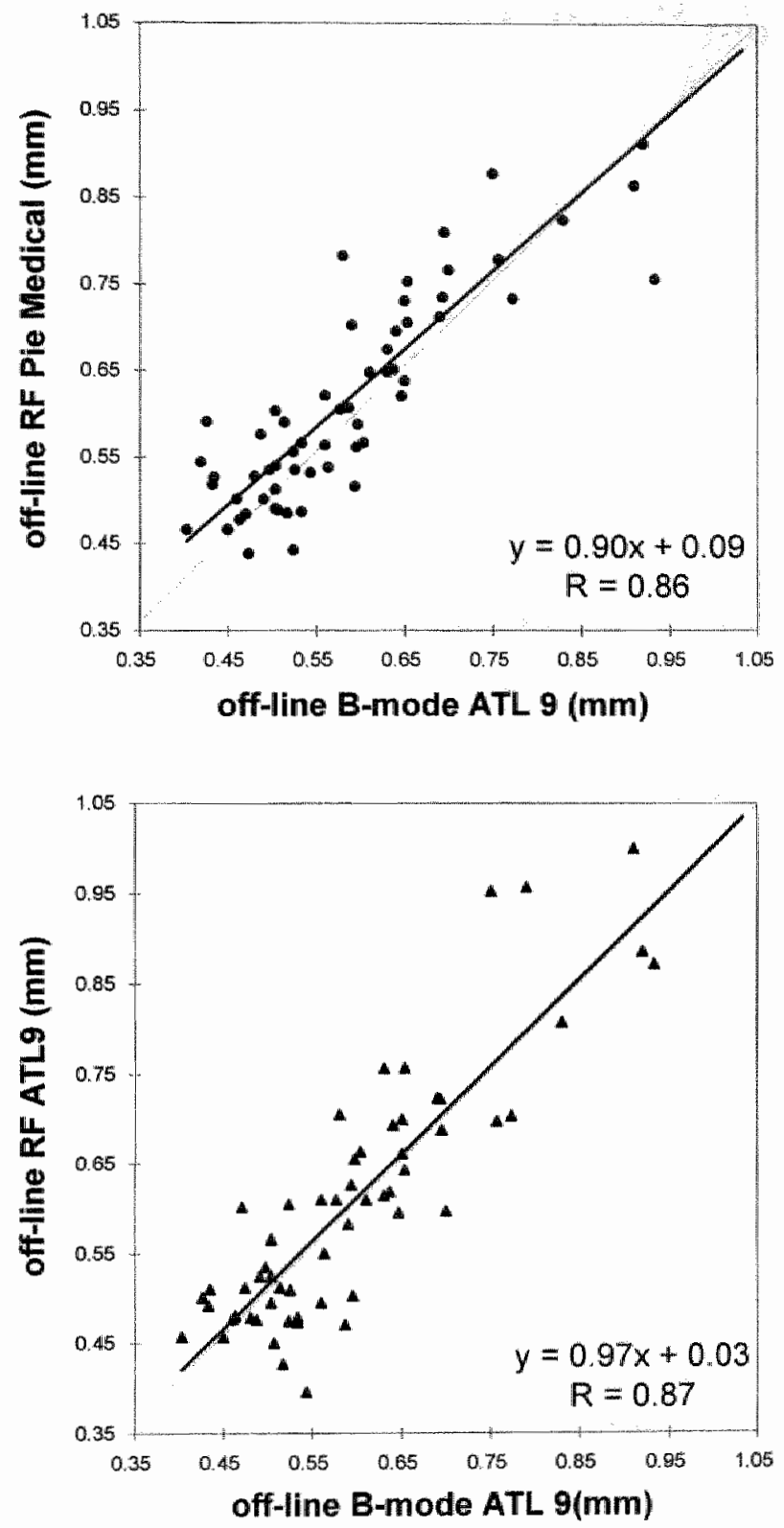

Figure 3 (top) and figure 4 (bottom). Intima-media thickness (IMT) results obtained with the offline automated radio frequency (RF) IMT method using the Pie Medical Scanner 200 (top) and the Ulramark 9 (bottom) compared with the off-line manual B-mode ATL IMT results. 
IMT off-line RF Pie Medical vs. off-line B-mode ATL 9

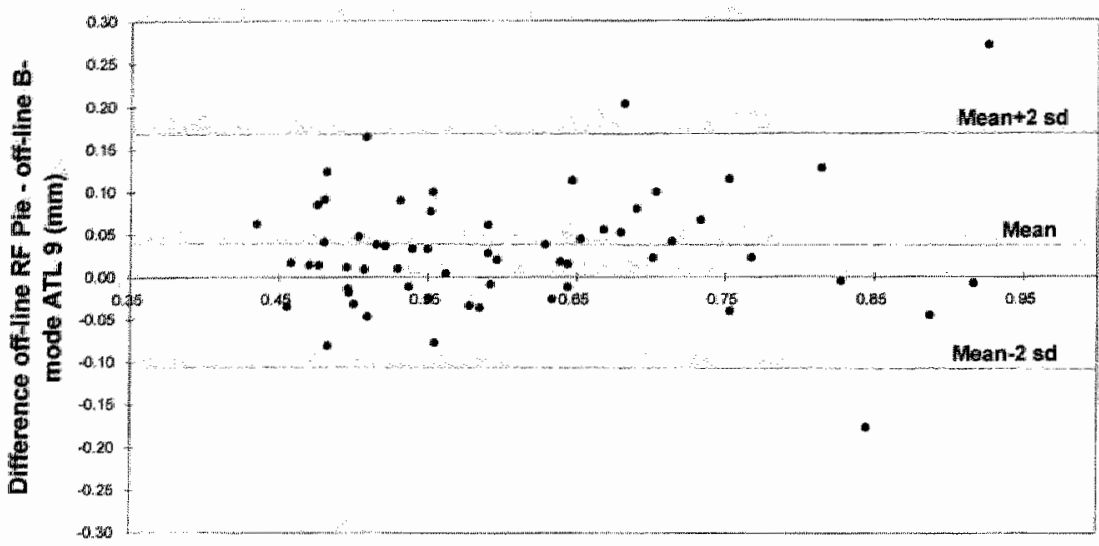

Average off-line RF Pie Medical * off-line B-mode ATL 9 (mm)

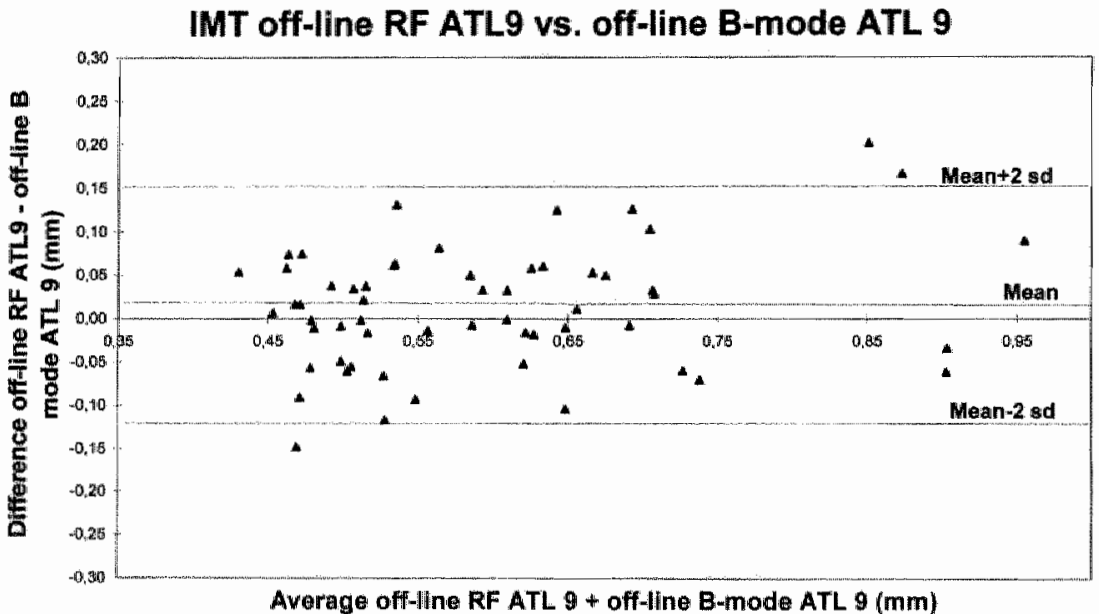

Figure 5 (top) and figure 6 (bottom). Bland-Altman comparison between the off-line autonated radio-frequency (RF) intima-media thickness (IMT) walues obtained with the Pie Medical Scanner 200 (top) and Ultramark 9 (bottom) and the on-line nanual B-mode IMT values, 

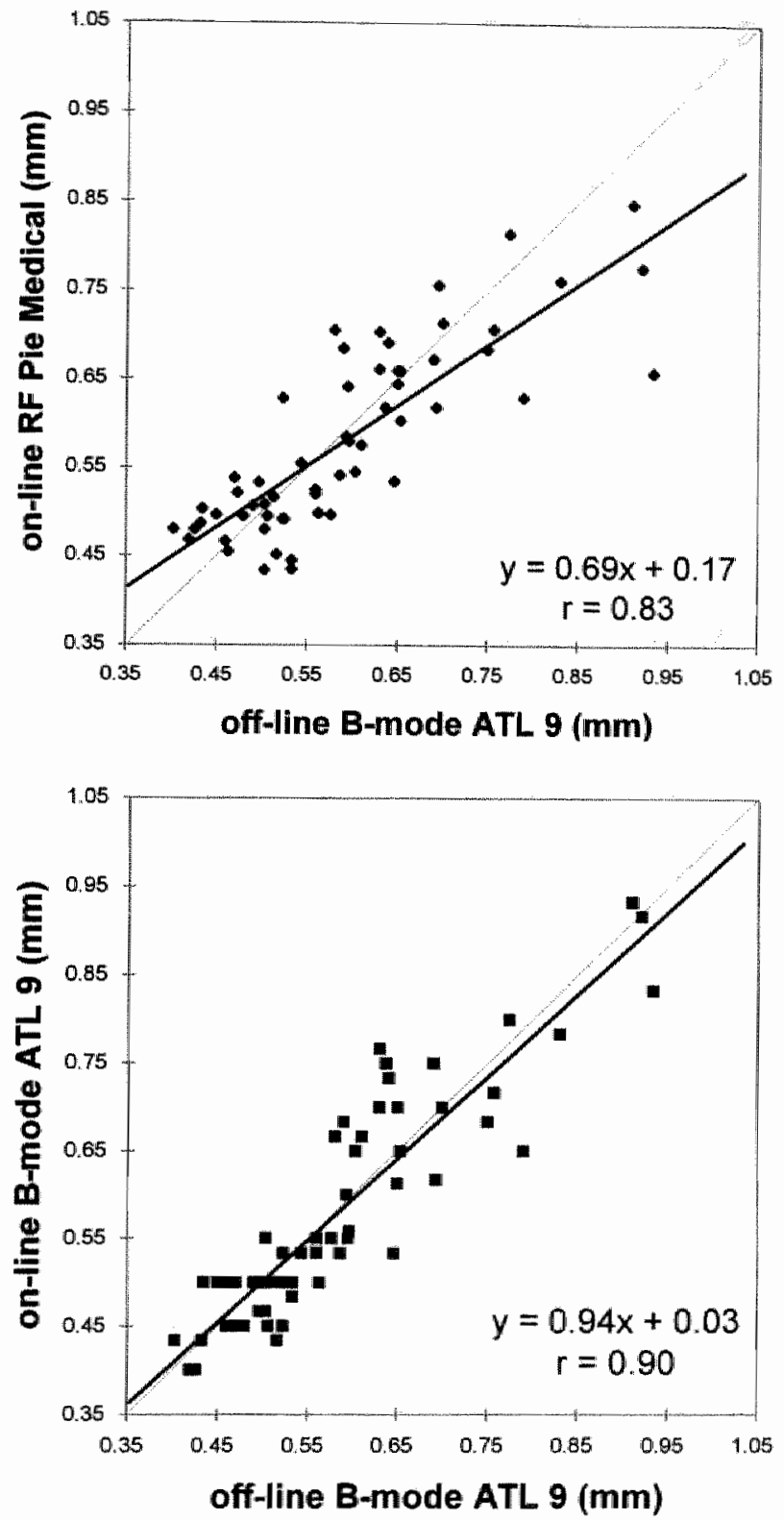

Figure 7 (top) and figure 8 (bottom). Intima-media thickness (IMT) results obtaned with the off-line manual B-node IMT method as compared with the on-line manual RF IMT" method (top) and on-line manual $\mathrm{B}$-node IMT method (bottom). 
94 Chapuer 6

IMT on-line RF Ple Medical vs. off-line B-mode ATL 9

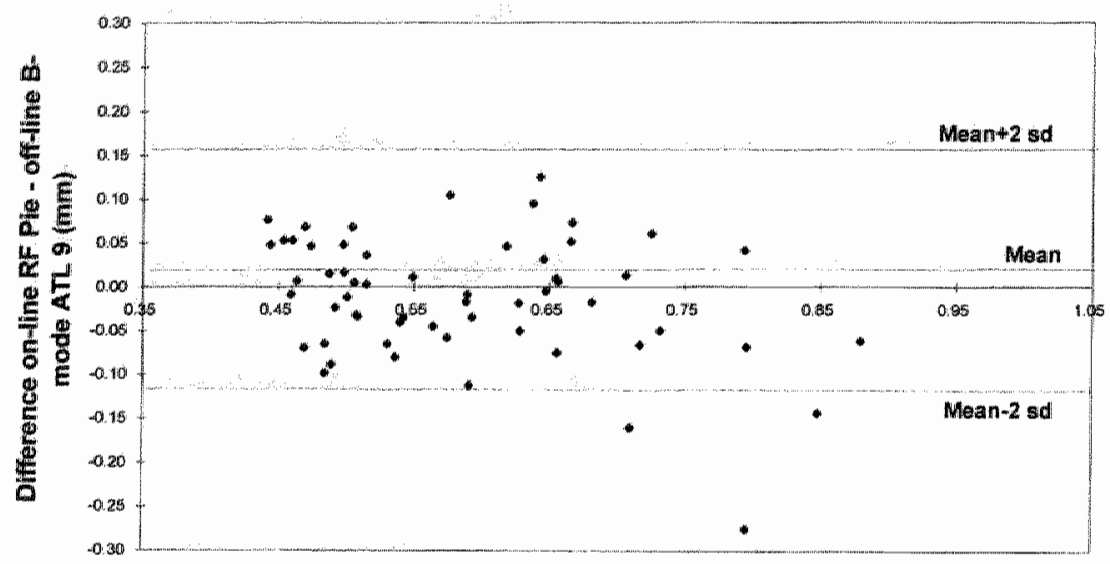

Average on-line RF Pie Medical + off-line B-mode ATL 9 (mm)

IMT on-line B-mode vs. off-line B-mode ATL 9

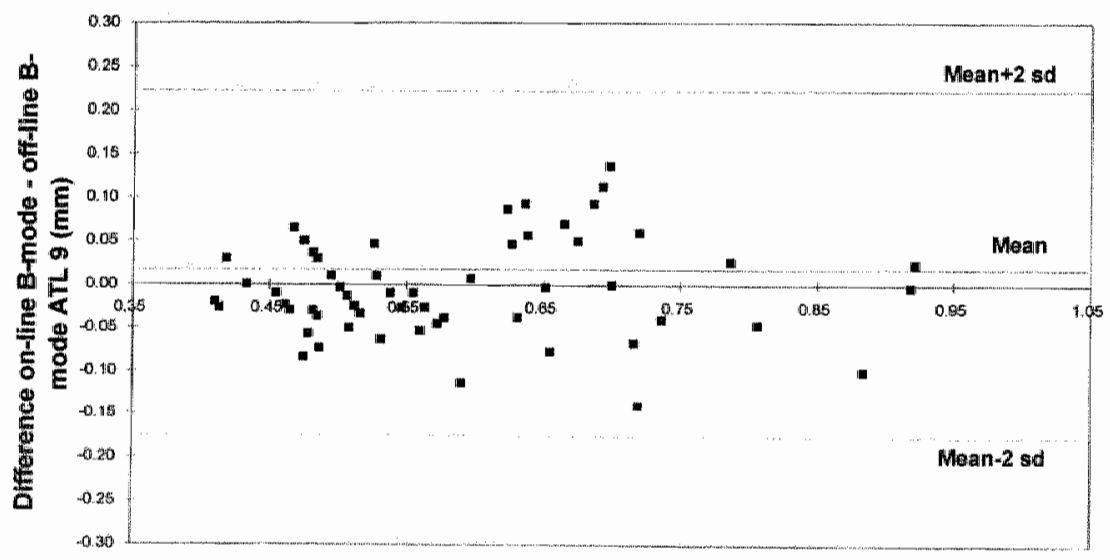

Average on-line B-mode + off-line B-mode ATL 9 (mm)

Figure 9 (top) and figure 10 (bottom). Bland-Altman comparison between the off-line manual B-mode intima-media thickness (IMT) values and the on-line manual radio frequency (RF) IMT method (top) and the on-line manual B-mode IMT method (bottom). 


\section{Discussion}

In the present study, we determined the intrasubject intrasession variability and comparability of various manual and automated B-mode and RF processing methods used to estimate common carotid IMT. We observed a good correlation and measurement agreement between the formerly established and commonly used off-line manual B-mode IMT $[5,9,13-16,18]$ and our recently developed off-line automated RF IMT method based on M-line signal processing [6].

The intrasubject intrasession variability is acceptable and comparable in all methods used (Table 1). The manual B-mode method performs equally well as the off-line methods, which might lead to the conclusion to skip the latter methods in favour of the former when considering time-efficiency. One should realize, however, that the manual $\mathrm{B}$-mode method is subjective in nature. It is impossible to perform IMT measurements in a blinded way with this method, making it less suitable for longitudinal studies. Even when using the automated edge detecting system of Selzer et al. [18], the ultrasonographer still may influence the measurements, depending on the study design. It is important to note that both the success rate and the limits of agreement of IMT estimates in the present study are better in comparison to previous evaluation studies [21]. This can be attributed partly to the subject population (healthy volunteers) studied.

The advantage of the off-line automated RF IMT method is that it is not only reliable, but also less time-consuming and less user dependent than previously described methods. Another advantage of the RF method is that the same signal leads to simultaneous assessment of the local (relative) change in artery diameter over time and local IMT. With the parameters obtained and the local pulse pressure, the Young's modulus, the best parameter to describe the intrinsic elastic arterial properties, can be determined locally in an artery $[22,23]$. This is an asset in improving insight into arterial adaptation in processes such as ageing and hypertension.

We would like to emphasize the need to measure IMT locally, because of heterogeneity of intima thickening allong an artery segment. This is especially important when studying the relation between IMT on the one hand and, for example, wall shear rate [24], artery strain or distension on the other hand. When interested in IMT as an indicator of a specific disorder, it may be more appropriate to average over a certain segment.

The off-line automated RF IMT results obtained with the Ultramark 9 and the Pie Medical Scanner 200 were comparable in outcome. This illustrates the insensitivity of the method for the ultrasound system characteristics.

The assessment of IMT averaged over the cardiac cycle instead of at the end-diastole, as formerly in the off-line manual B-mode IMT method, induces a systematic measurement error. The maximum bias in IMT will be on the order of 
$8 \%-10 \%$ in young volunteers and is dependent on the relative increase in diameter per heart beat (systolic-diastolic phase). This would explain an underestimation of $40-50 \mu \mathrm{m}$, for a mean IMT of $500 \mu \mathrm{m}$ by the RF IMT method as compared to $\mathrm{B}$-mode. In elderly volunteers, the relative increase in diameter decreases with age whereas the IMT increases, thereby leading approximately to the same absolute difference in IMT $( \pm 5 \%-6 \%$ of $750 \mu \mathrm{m}= \pm 37.5-45 \mu \mathrm{m})$. However, a smaller estimate of the off-line manual B-mode IMT was observed compared to the off-line automated RF method using the Ultramark 9 as well as the Pie Medical Scanner 200 , especially in the older age group (Table 1). A possible explanation for the observed difference could be underestimation by the B-mode method due to either the delayed detection of the lumen-intima transition in $\mathbb{B}$-mode (absolute value rather than a relative one) or the earlier detection of the media-adventitia transition due to compression characteristics [25]. Differences between the reader of the images using the off-line manual $\mathrm{B}$-mode in Rotterdam and the other methods performed in Maastricht also cannot be excluded.

In summary, we conclude that the off-line automated RF IMT method is a feasible method to assess IMT at the posterior wall of the common carotid artery as compared to the established off-line manual B-mode IMT method. One of the major advantages of this new automated procedure is that it is less user dependent and less time consuming than previously developed methods. Also, artery wall distensibility can be measured simultaneously at the same location, facilitating detailed study of the intrinsic wall characteristics.

\section{References}

1. O'Leary DH, Polak JE, Kronmal RA, Savage PJ, Borhani NO, Kittner SJ. Tracy R, Gardin JM, Price TR, Furberg CD: Thickening of the carotid wall. A market for atherosderosis in the elderly? Cardiovascular Health Study Collaborative Research Group. Stroke. 1996;27(2): 224-31.

2. Terson J, Formgren J Israelsson B, Berglund $G$. Ultrasound-determined intima-media thickness and atherosclerosis. Ditect and indirect validation. Atterioscler Thromb. 1994:14(2):261-4.

3. Salonen R, Salonen J"T: Progression of carotid atherosclerosis and it determinants: a population-based ultrasonography study. Atherosclerosis. 1990;81(1):33-40.

4. Salonen JT, Salonen R. Ultanonogmaphically assessed carotid morphology and the risk of coronary heart disease. Arterioscler 'Thromb. 1991;11(5):1245-9.

5. Wong M, Edelstein J, Wollman J, Bond MG: Ultrasonic-pathological comparison of the human arterial wall. Verification of intima-media thickness. Arterioscler Thromb. 1993;13(4):482-6.

6. Hoeks APG, Willekes C. Boutouyrie P, Brands PJ, Willigers JM, Reneman RS: Automated detection of local artery wall thickness based on M-line signal processing. Ultrasound Med Biol. $1997 ; 23(7): 1017-23$

7. Persson J, Stavenow L, Wikstrand J, Israelsson B, Formgren J, Berglund G: Noninvasive quantification of atherosclerotic lesions. Reproducibility of ultrasonographic measurement of arterial wall thickness and plaque size. Arterioscler Thromb. 1992;12(2):261-6. 
8. Pignoli $P$. Trenoli $E$, poli $A$, Oreste P. Paoleti $R$ : Intimal plus medial thickness of the arterial wall: a direct measurement with ultrasound inaging. Circulation. 1986;74(6):1399-406.

9. Riley WA, Banes $R W$, Applegate WB, Dempsey $R$, Hartwell $T$, Dawis VG, Bond MG, Furberg CD: Reproducibility of noninvasive ultrasonic measurement of carotid atherosdenosis. The Asymptomatic Carotid Artery Plaque Study. Stroke. 1992;23(8):1062-8.

10. Salonen R, Haapanen A, Salonen JT: Meastrement of intima-nuedia thickness of common carotid arteries with high-resolution. B-node ultrasonography; inter-and intra-observer variability. Ulrasound Med Biol. 1991;17(3):225-30.

11. Wendelhag I, Liang $Q$, Gustavsson $T$, Wikstrand J: A new automated computerized analyzing system simplifies readings and reduces the variability in ultrasound measurement of intina-nedia thickness. Stroke. 1997;28(11):21.95-200.

12. Pignoli P: Ultrasound B-mode imaging for arterial wall thickness measurement. Atherosder Rev. 1984:12:177-84.

13. Bots ML, Mulder PG, Hofman A, van Es GA, Grobbee DE: Reproducibility of catotid vessel wall thickness measurements. The Rotterdam Study. J Clin Epidemiol. 1994;47(8):921-30.

14. Bond GM, Barnes RW, Riley WA, Wilmodn SK, Chambless LE, Howand G, Owens B: The ARIC Study Group. High-resolution B-mode ultrasound scaming methods in the atherosclerosis risk in communities study (ARIC). J Neuroinag. 1991;1 (2):68-73.

15. Wendellhag I, Gustavsson T, Surkula M, Berglund G, Wikstrand J: Ultrasound measurement of wall thickness in the carotid artery: fundamental principles and description of a computerized analysing system. Clin Physiol. 1991;11(6):565-77.

16. Chambless LE, Zhong MM, Arnett D, Folsom AR, Riley WA, Heiss G: Variability in B-mode ultrasound measurements in the atherosclerosis risk in communities (ARIC) study. Ultrasound Med Biol. 1996;22(5):545-54.

17. Riley WA, Craven T, Romont $A$, Furberg CD: Assessment of temponal bias in longitudinal measurements of carotid intimal-medial thickness in the Asymptomatic Carotid Artery Progression Study (ACAPS). ACAPS Research Group. Ultrasound Med Biol. 1996;22(4): 405-11.

18. Selzer RH, Hodis HN, Kwong Fu H, Mack WJ, Lee PL, Liu CR, Liu CH: Evaluation of computerized edge tracking for quantifying intima-media thickness of the common carotid artery from B-mode ultrasound images. Atherosclerosis. 1994;111(1):1-11.

19. Hoeks APG, Brands PJ. Sneets FAM, Reneman RS: Assessment of the distensibility of superficial arteries. Ultrasound Med Biol. 1990;16(2):121-8.

20. Bland JM. Alman DG: Statistical methods for assessing agreement between two nuethods of clinical measurement. Lancet 1986;1(8476):307-10.

21. Montauban van Swijndregt AD, The SH, Gussenhoven EJ, Lancee CT, Rijsterboryl H, de Groot E, van der Steen AF, Bom N, Ackerstaff RG: An in witro evaluation of the line pattern of the near and far walls of carotid arteries using B-mode utrasound. Ulerasound Med Biol. $1996 ; 22(8): 1007-15$

22. Reneman RS, Hoeks APG. Westerhof $N$ : Non-invasive assessment of artery wall properties in humans - methods and interpretations. J Vasc Invest. 1996,253-64.

23. Hoeks APG, Reneman RS: Biophysical principles of vascular diagnofis. I Clin Ultrasound. $1995 ; 23(2): 71-9$

24. Komet L, Lambregts JAC, Hoeks APG, Reneman RS: Differences in near-wall shear wate in the carotid artery within subjects are associated with different intima-media thicknesses. Arterioscler Thromb Vasc Biol. 1998;18(12): 1877-84.

25. Easton JD: Accuracy of high-resolution ulltrasound imaging for quantitative assessment of early carotid atherosclerosis. Cerebrowasc Dis. 1994:4:109-113. 


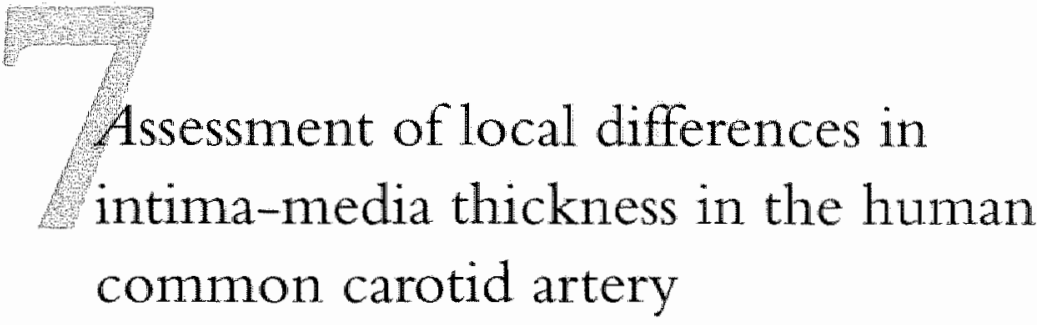

Chnistine Willekes ${ }^{\prime}$ Peter J. Brands ${ }^{2}$, Jean M. Willigers ${ }^{2}$, Amold P.G. Hoeks ${ }^{2}$ and Robert S, Reneman

Departments of Physiology', and Biophysics" Cardiovascular Research Institute Maastricht, Maastricht University, The Netherlands. 


\begin{abstract}
:
Intimal thickening may be focal in nature and is especially found in areas with low shear rate. To be able to study the relation between intima-media thickness (IMT) and wall shear rate appropriately, a method to assess IM"I" locally is required. It was the aim of the present study to investigate the ability of a recently developed automated method to assess local differences in $\mathrm{MMT}^{\mathrm{T}}$, if any, in relatively short arterial segments. Therefore, intrasession interlocation differences in IMT were assessed at the posterior wall of the common carotid artery close to the bulb $(0 \mathrm{~mm})$ and 10 and $20 \mathrm{~mm}$ more apstrean in terms of mean difference \pm 2 standard deviations. Prior to this study we investigated the ability of the systen to reproducibly assess IMT locally (intersession intralocation) in terms of repeatability coefficient ( $=2$ standard deviations). The measurements were performed in the common carotid artery $20 \mathrm{~mm}$ proximal to the bulb. The study was performed on young and older subjects presumed to be healthy. The intersession intralocation repeatability coefficient was $0.07 \mathrm{~mm}$ in the young group and $0.11 \mathrm{~mm}$ in the older group. The IMT close to the bulb (0 mm) was significantly larger $( \pm 0.050-0.065 \mathrm{~mm})$ than that at the other loca thons in both age groups. We condude that local IMT can be assessed reproducibly and local in short arterial segments can be studied reliably.
\end{abstract}




\section{Introduction}

Previous studies have shown that intimal thickening may occur locally and preferentially at sites subjected to low shear rate, as observed near branch points opposite to the flow divider, rather than high shear rate or shear stress [1-3]. Therefore, to be able to study the relation between intima-media thickness (IMT) and wall shear rate in humans properly a technique to assess IMT locally is required.

The method most frequently used to measure IMT, however, measures IMT averaged over about $1 \mathrm{~cm}$ in the artery of interest, based on automated processing of ultrasound B-mode images $[4,5]$. The method also provides the maximum IMT without further specification of the exact localisation within the $1 \mathrm{~cm}$ segment. The main disadvantage of this IMT method is the spatial averaging, thereby obscuring local variations in IMT and the exact location of the site of assessment, making it less suitable for studies investigating its relation with, for example, wall shear rate. Recently, we developed a non-invasive teclunique to assess IMT locally along the arterial tree that compares favourably with the automated $\mathrm{B}$-mode technique commonly used to determine IMT, when the measurements are averaged over arterial segments of about $1 \mathrm{~cm}[6]$.

It was the aim of the present study to evaluate whether local differences in IMT, if any, in relatively short arterial segments could be assessed by means of this newly developed ultrasound technique. Prior to this study, we investigated the ability of the system to reproducibly assess IMT locally Reproducibility was determined as intersession intralocation variability in terms of repeatability coefficient $(=2$ standard deviations) according to Bland and Altman [7]. Possible differences in local IMT' were determined by comparing IMT at various sites in the common carotid artery in one session (intrasession interlocation study) in terms of mean difference and corresponding standard deviations. The IMT measurements were performed in the common carotid artery of presumed healthy volunteers of varying ages.

\section{Material and methods}

\section{Subjects}

The intersession intralocation study was performed in a group of 12 young (mean age 25 years) and 11 older female volunteers (mean age 56 years). The intrasession interlocation study to assess local differences in IMT was performed in 16 male and female volunteers of 20-31 years of age (young age group: mean age 25 years; 8 males and 8 females) and a group of 13 females of 51-62 years of age (older age group: mean age 56 years), again both groups presumed to be healthy. The study 
Was approved by the joint Medical Ethics Commitee of the Mastricht University and the Academic Hospital Mastricht. All volunteers gave their informed consent after having received detaled information before entering the study.

\section{IMT measurewent protocol}

In both age groups, the intersession intralocation reproducibility study was perfomed at the posterior wall of the right common carotid artery, approximately $20 \mathrm{~mm}$ proximal to the carotid artery bulb. This part of the study was limited to the posterior wall, because here the reflections from the blood-intima and media-adventitia transition are distinctly visible, while at the anterior wall the trailing edge of the adventitia may obscure the media and intima signals. More-over, at the posterior wall the leading edges of the ultrasound reflections from the lumen-intima and media-adventitia interfaces are taken, while at the anterior wall the trailing edges of the ultrasound envelope, which may be composed of several partly overlapping reflections, have to be considered. The average time intervall between both sessions was approximately 1 week in both age groups. Three independent measurements, each being the median value of the IMT as assessed during 3-5 consecutive heart beats, were obtained during each session. These three measurements were averaged. The same procedure was followed in both age groups (see 'Statistical analysis").

The intrasession interlocation differences were assessed by comparing the IMT values as obtained in the common carotid artery 0,10 and $20 \mathrm{~mm}$ proximal to the widening of the bulb (Figure 1; see 'Statistical analysis'). This part of the study was performed on both the right and left common carotid artery. In all examinations again only the posterior wall was investigated (see above). At each location three independent measurements were performed, removing the ultrasound probe from the skin in between measurements. The average of the three measurements, each being the median $\| M T^{\prime}$ value as assessed during 3-5 consecutive heart beats, was taken as a representative value.

During the investigations the head was tilted to the contralateral side at an angle of $45^{\circ}$. All examinations were performed with the jugular vein in front of the carotid artery, thereby enhancing the ultrasound signal from the underlying structures. The received ultrasound signal was consequently considered in the same range after positioning of the posterior wall at the same depth as much as possible in all volunteers, keeping the ultrasound system at constant gain and dynamic range settings. All these precautions made the IMT values recorded at the specified locations comparable on a performer basis. Therefore, the residual variation in IMT can be considered to be real differences based on (patho)physiological processes. 


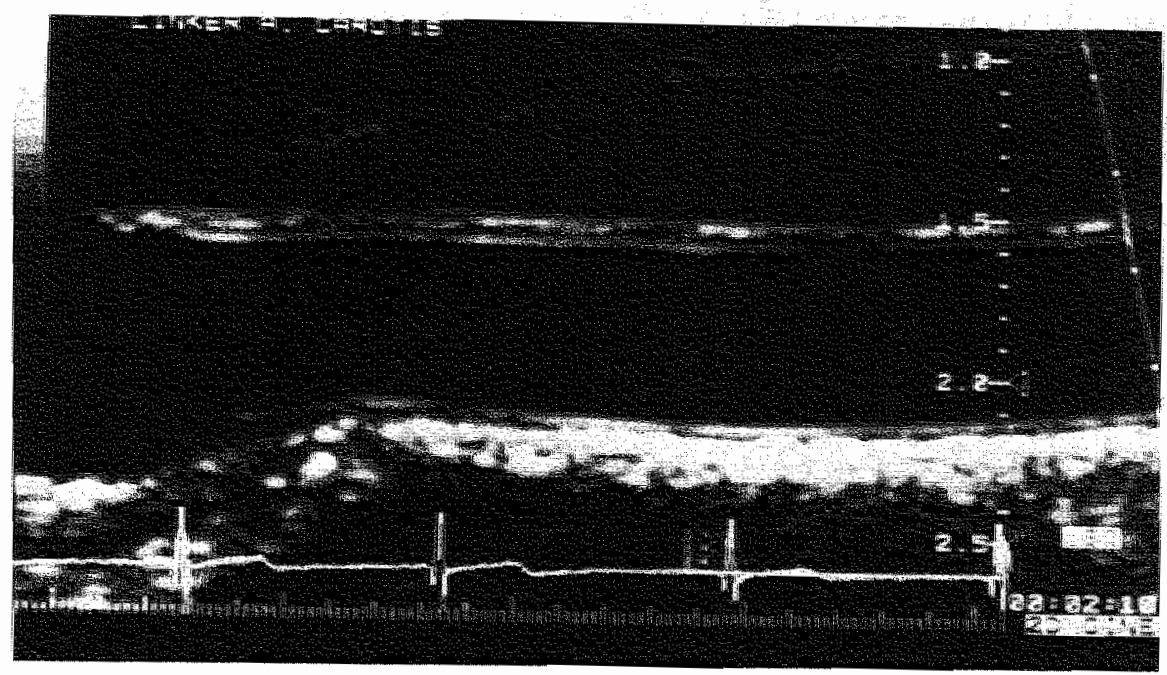

Figure 1. B-mode image of the right conmon carotid artery of a 25 -year-old volunteen obtained with the Ultamark 9, ATL. The intima-media complex is clearly visible at the posterior wall of the common carotid artery over a distance of at least $10 \mathrm{~mm}$.

\section{IMT measurement principle}

The IMT measurements were performed using an Ultramark 9 (Ultramark 9 High Definition Imaging, ATL, Bothell, Wash., USA) with a linear array transducer of $7.5 \mathrm{MHz}$. The measured pulse length at $-6 \mathrm{~dB}$ received from a target at a distance of $20 \mathrm{~mm}$ is $310 \mathrm{~ns}$, corresponding to an axial resolution of approximately $220 \mu \mathrm{m}$. The scanner has an ECG modality to trigger the data collection.

Our automated radiofrequency (RF) method to assess IMT has been described in detail before [8]. In short, a B-mode image was obtained from the common carotid artery in a longitudinal section just before the widening of the bulb in the bifurcation. An $\mathrm{M}$-line was positioned perpendicular to the posterior wall at the site of interest showing a clear intima-media complex during the whole registration. Subsequently, the system was switched to M-mode and, after ECG triggering, RF data collection started in the data acquisition memory of the wall track system as developed by Hoeks et al. [9] at a sample frequency of $20 \mathrm{MHz}$, an $\mathrm{M}$ line update frequency of $400 \mathrm{~Hz}$ and for a duration of 4 seconds corresponding to 3-5 heart beats. Consecutively, the first RF line was displayed on the computer monitor, allowing identification of the arterial walls with a window of $3 \mathrm{~mm}$, covering the posterior intima-media complex during the cardiac cycle. Data from this window over time were stored on hard-disk for further off-line processing. At the end of the measurement protocol all recorded files were processed employing 
the wall thickness program. The instantaneous envelope of the amplitude of the RF signals was detemined and, after phase alignment of the RF signals, the envelope of the amplitude distribution was tine-averaged [8]. Averaging over the systolic phase of a heart beat enhanced signals from wall interfaces exhibiting similar displacements between observations and smoothed secondary echo signals (e.g., reverberations) with a different displacement behaviour. For each heart beat the derivative with respect to depth of the averaged normalized amplitude distribution, exceeding a threshold set at 0.020 , was considered to distinguish wall signals from other signals. Only the leading edge of distinct echoes exceeding the threshold for the derivative was used to identify relevant regions. The position where the instantaneous amplitude within this region reached the $50 \%$ level was considered as the location of the intima edge. This detection procedure was repeated for the next region (the media-adventitia edge) where the derivative exceeded the threshold. The required ratio of intima and adventitia amplitude was at least 1.0 to avoid detection of false edges. Each heart beat within a recording provided an estimate of IMT. The resolution for wall thickness detection is related to the RF sample frequency $(20 \mathrm{MHz})$ and is approximately $40 \mu \mathrm{m}$ [8]. The lower limit for the wall IMT was selected according the axial resolution of the ultrasound system used and set at $300 \mu \mathrm{m}$.

\section{Statistical analysis}

The intersession intralocation reproducibility was determined using the repeatability coefficient between session 1 and 2 as defined by Bland and Altman [7]. The repeatability coefficient is equal to 2 standard deviations under the assumption of a normal distribution.

For both age groups the intrasession interlocation differences were based on intrasubject differences averaged over the group (Table 1). The intrasession interlocation differences were compared by means of a Friedman non-parametric test using SPSS software packages. In this part of the study the left and right common carotid arteries were considered as two different sites of measurement. Young and older age groups were analysed separately to assess age influences on intima-media thickening. The mean difference and standard deviations were assessed between the different locations [7]. In the statistical analysis of the older age group two pairs of IMT estimates were excluded for the comparison of different locations, because one of each pair of IMT values was missing. 
Table 1. Lintralocation and incellocation varability

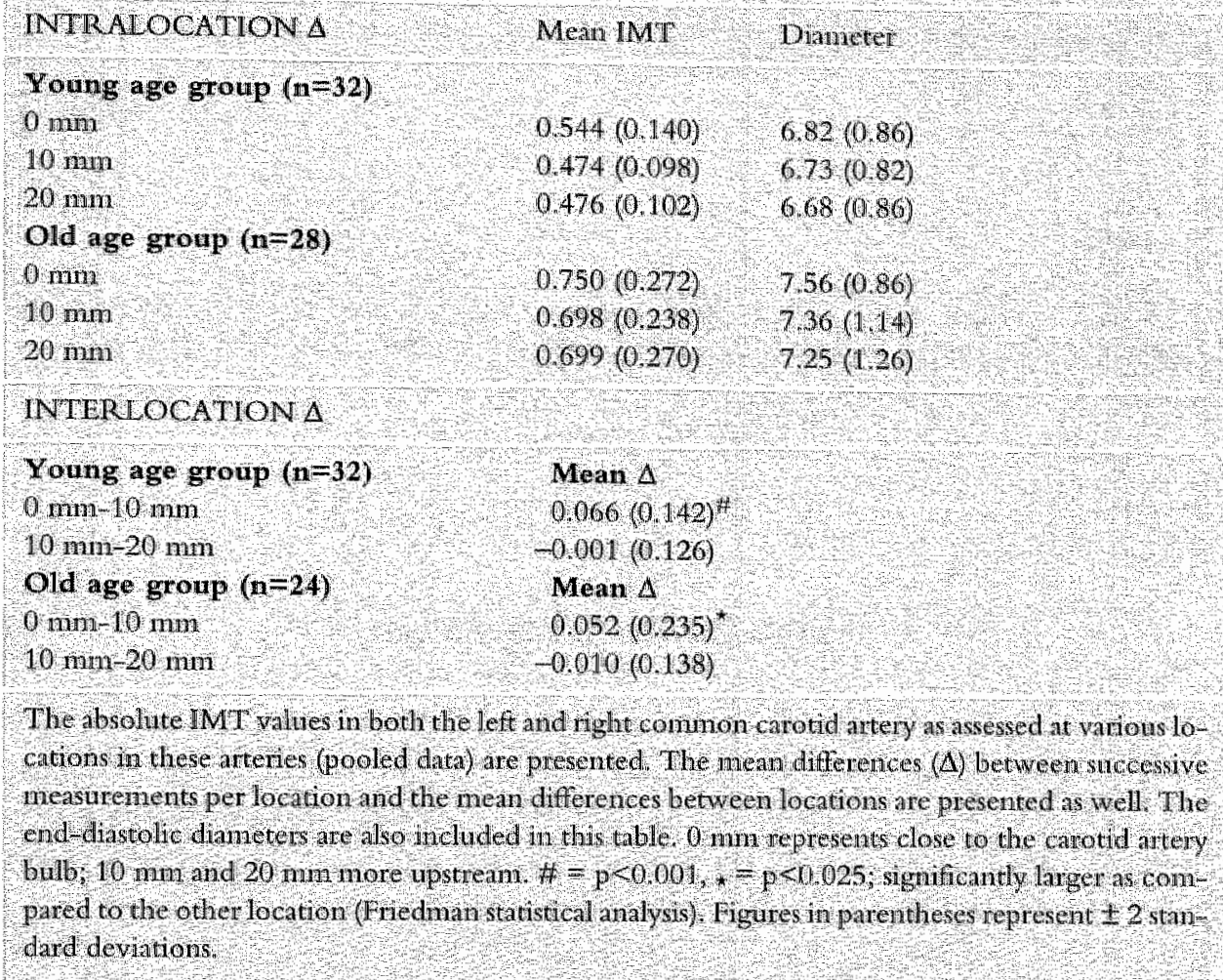

\section{Results}

The intersession intralocation repeatability coefficient was acceptable in both age groups: $0.069 \mathrm{~mm}$ in the young group, and $0.109 \mathrm{~mm}$ in the older group (Figure 2). Because no significant differences in IMT could be detected between males and females, the data were pooled for further analysis (Table 1)

A statistically significant positive difference was observed between location 0 $\mathrm{mm}$ on the one hand and locations $10 \mathrm{~mm}$ and $20 \mathrm{~mm}$ on the other for both the young and the older age group (Table 1). In the young age group 28 out of 32 observations and in the older age group 18 out of 26 observations showed a larger IMT at location $0 \mathrm{~mm}$ than more upstream (Figure 2) The absolute mean difference was $0.065 \mathrm{~mm}$ in the young age group $(p<0.001)$ and $0.050 \mathrm{~mm}$ in the older age group ( $p<0.025$ ). The largest IMT was consistently found at location $0 \mathrm{~mm}$ in both age groups (Friedman statistical analysis using SPSS packages; $p<0.001$ and $p<0.025$, respectively). The absolute IMT was significantly smaller (range: 


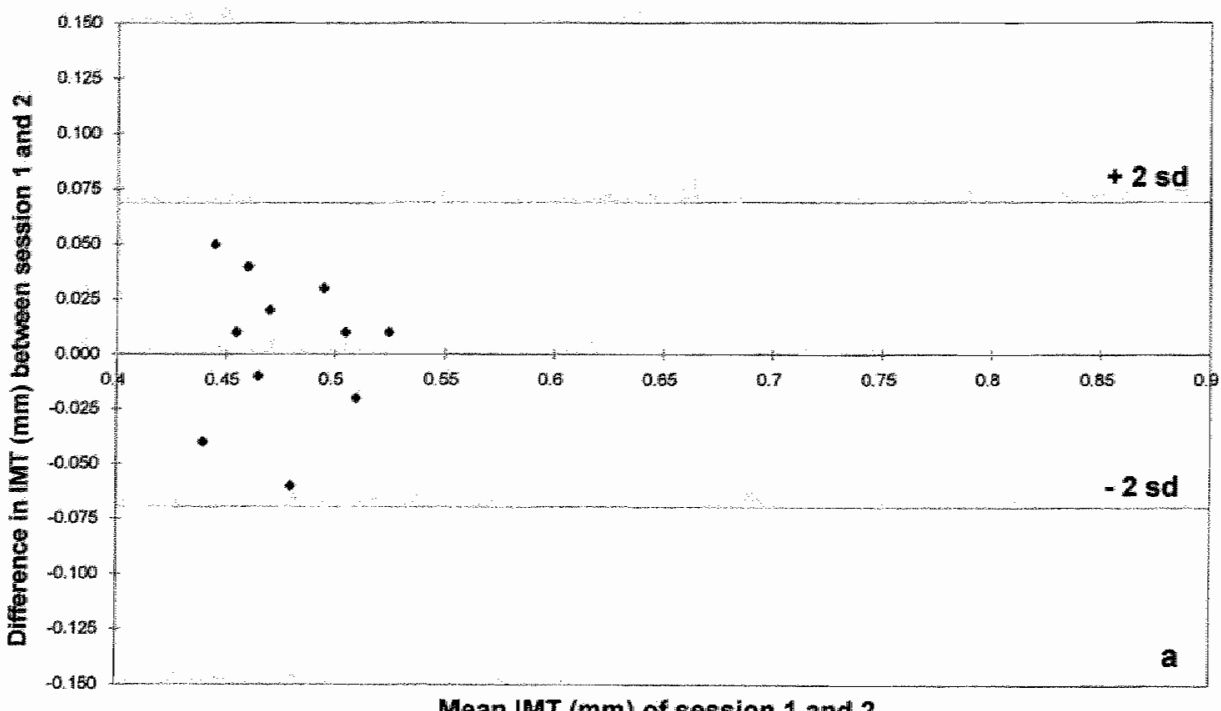

Mean IMT (mm) of session 1 and 2

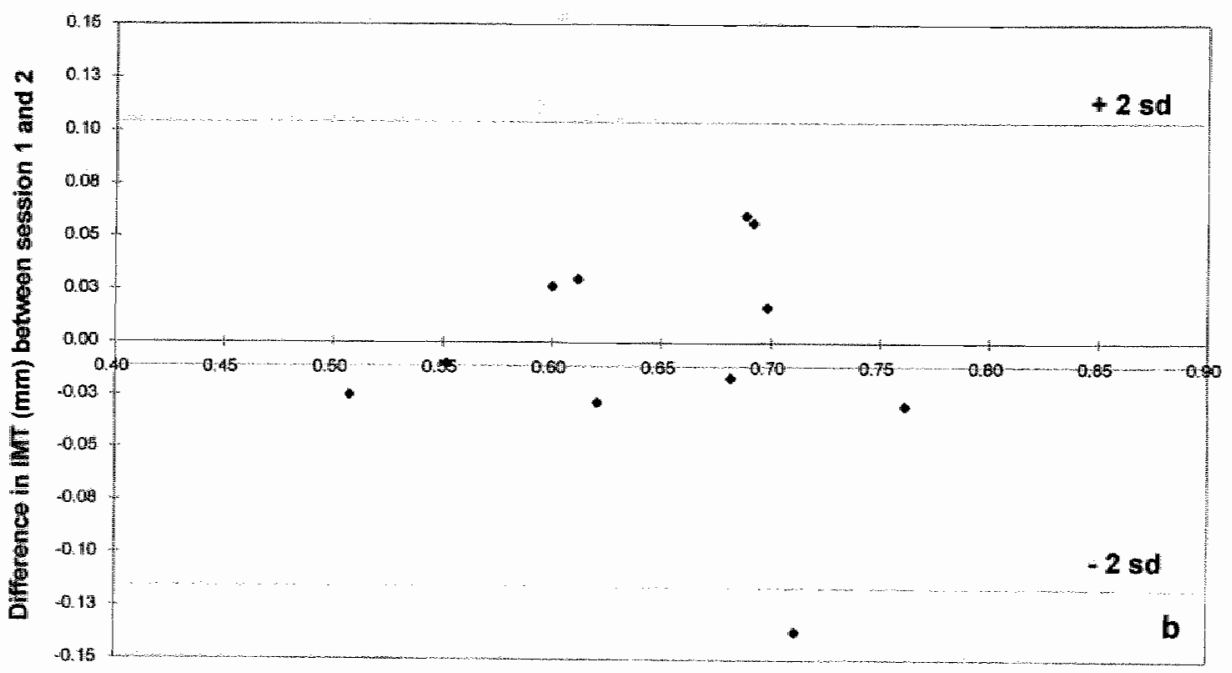

Mean IMT ( $\mathrm{mm}$ ) of session 1 and 2

Figure 2. Relation between mean IMT and difference in IMT of session 1 and 2 in young (a) and older subjects (b) in the common carotid arery. The mean difference \pm 2 standard deviations are depicted as dotted lines. 


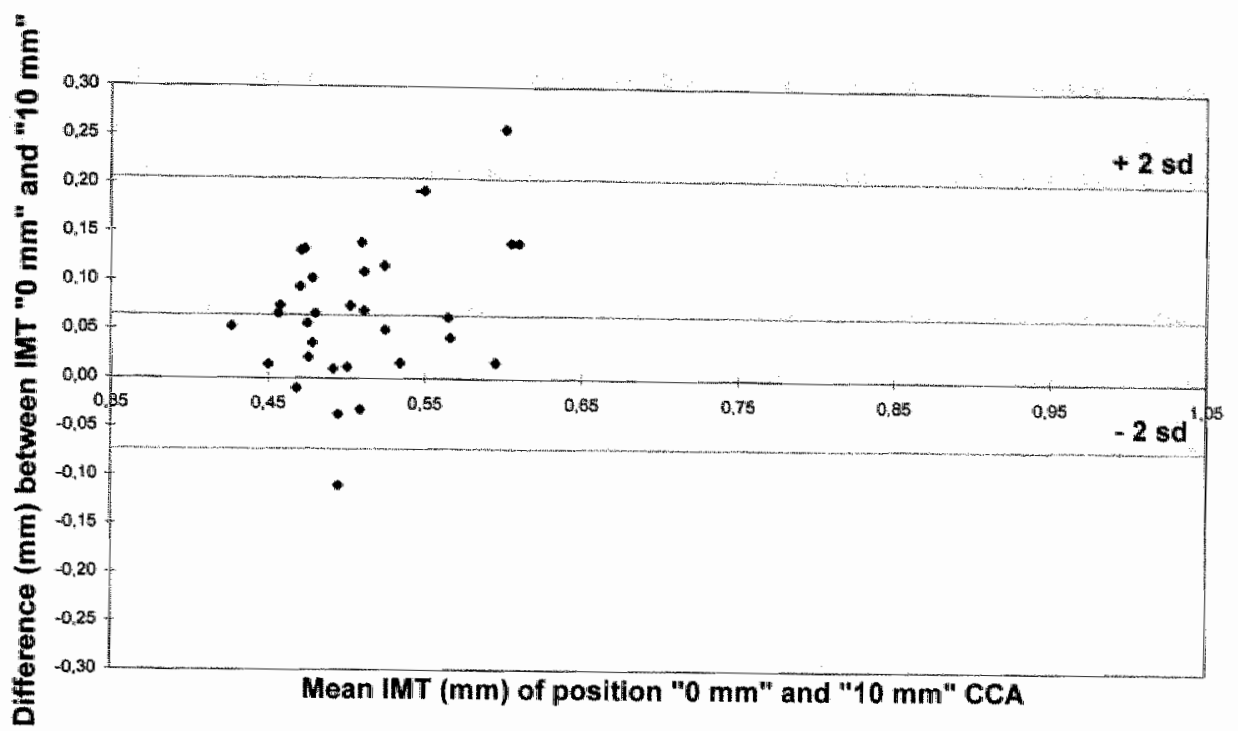

Figure 3 Relation between mean IMT and difference in $1 \mathrm{MT}$ in the young age group in the common carotid artery (CCA) at locations 0 and $10 \mathrm{~mm}$. The mean difference \pm 2 standard deviations are depicted as dotted lines.

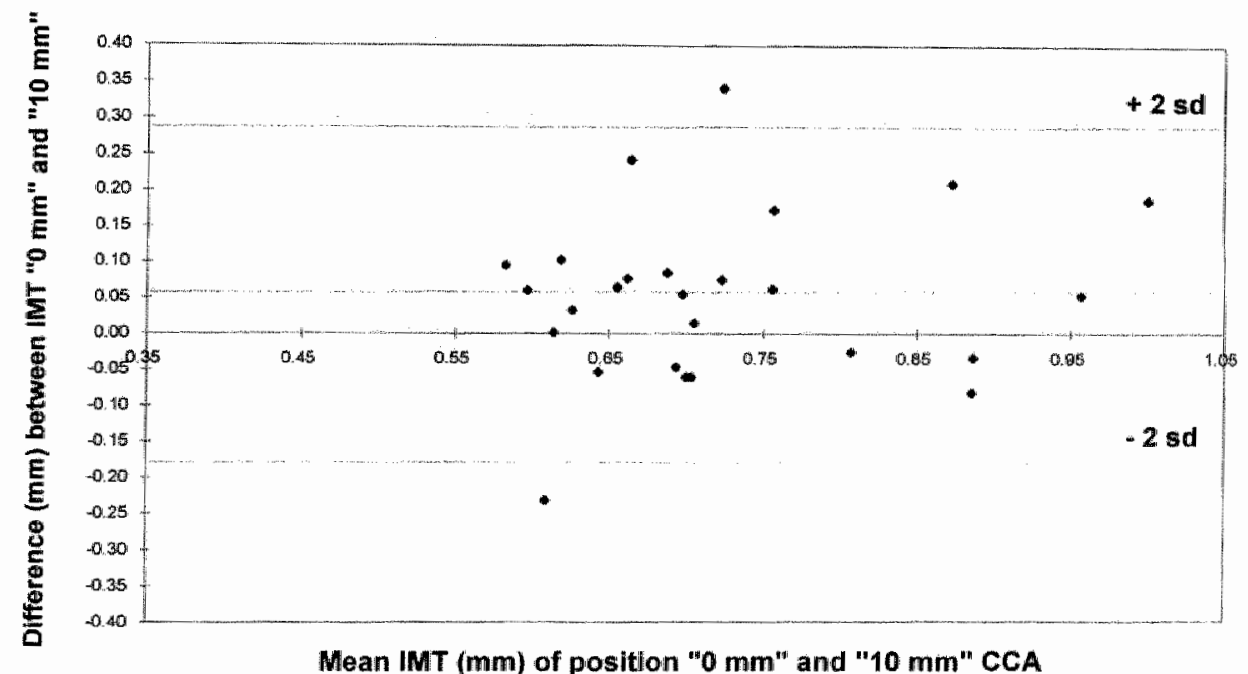

Figure 4. Relation between nean IMT and difference in IMT in the older age group in the common carotid artery (CCA) at locations 0 and $10 \mathrm{~mm}$. The mean difference \pm 2 standard deviations are depicted as dotted lines. 
$0.476-0.540 \mathrm{~mm}$ ) in the young than in the older age group (range: 0.698-0.750 mm). There was a significant trend towards larger standard deviations in case of larger IMTs resulting in a nearly constant coefficient of variation. The mean difference and standard deviations between location 0 and $10 \mathrm{~mm}$ were $0.066 \mathrm{~mm}$ $(2 \mathrm{SD}=0.143 \mathrm{~mm})$ for the young age category and $0.052 \mathrm{~mm}(2 \mathrm{SD}=0.236 \mathrm{~mm})$ for the older age category. As expected, the end-diastolic diameter tended to be larger near the carotid artery bulb than more upstream $(p<0.001$ and $p=0.069$ for the old and young age group, respectively; Friedman test). It may be concluded that $n$ measurements allow the detection of a difference of $2 \mathrm{SD} / \sqrt{ }[7]$. Therefore in one single young person in one session 2 repeated measurements and in one single old person 6 repeated measurements have to be performed to conclude that IMT" is larger near the bulb than $10 \mathrm{~mm}$ upstream. To detect a true difference in a group of, for example, $0.1 \mathrm{~mm}$ with $90 \%$ power, at least 6 young volunteers or 15 older volunteers should have one artery examined [10].

\section{Discussion}

The findings in this study show that local IMT' can be assessed reproducibly at the posterior wall of the common carotid artery in both young and older healthy female volunteers with a time interval of approximately 1 week. Significantly larger IMTs were found at the posterior wall of the common carotid artery close to the bulb than more upstream, irrespective of right or \eft carotid artery. This was observed in both the young and the older age group, despite significantly larger IMTs in the latter age group, most likely due to ageing. The larger IMTs were measured with larger standard deviations. The standard deviations relative to the absolute IMTs, however, were comparable in both age groups as well as at all locations. The larger IMT closer to the carotid artery bulb than more upstream can likely be explained by differences in wall shear rate at these sites. Near the bulb the linger IMT was associated with a locally lower shear rate than upstream [2].

It is of importance to note the swift change in IMT from close to the carotid artery bulb to more upstream in the common carotid artery and that significant differences in IMT can be observed at such short distances from each other. Because of the larger IMT close to the bulb, it is recommended that in future longitudinal studies IMT measurements based on B-mode spatial averaging should only be performed at least $10-20 \mathrm{~mm}$ proximal to the carotid artery bulb.

This study also documents the acceptable intersession reproducibility needed to perform longitudinal studies at a specific location in the common carotid artery. Our automated non-invasive technique to assess IMT locally along the arterial tree compares favourably with the B-mode technique commonly used to determine 
IMT [6]. The intrabserver intersession reproducibility of our technique, based upon the mean IMT of the far wall of the common carotid artery is better than of the B-mode techniques (standard deviation of mean difference of repeated measurements: $0.051-0.064 \mathrm{~mm}$ vs. $0.080-0.110 \mathrm{mun})$ [11,13]. The reproducibility of $\mathrm{B}$-mode techniques, based upon automated edge detection algorithms using sub-pixel interpolation, was found to be in the same range as that of the automated RF method $[14,15]$.

A great advantage of the automated RF IMT method is that simultaneous with local IMT the local end-diastolic diameter and the relative diameter increase per heart cycle (=strain) can be determined by means of the wall track system as developed by Hoeks et al. [9]. With these values and the local pulse pressure we can calculate the intrinsic elastic properties of the artery wall by assessing the Young's modulus [16].

This study demonstrates that in a relatively healthy group of young and older volunteers even minor (in the order of 0.050-0.065 mm) local differences in IMT can be assessed reliably. Whether the same holds for patients with specific accelerated vessel wall anomalies due to (a combination of) risk factors needs further investigation. In any case the RF IMT method discussed here is a step forward in the understanding of local (patho)physiological processes of artery wall adaptation to a variety of atherogenic stimuli, especially when combining the IMT and wall dynamic measurements with local wall shear stress assessment.

\section{Acknowledgement}

We would like to thank H.A.J. Schouten for his excellent statistical contribution to this study.

\section{References}

1. Friedman MH, Deters OJ Mark FF, Brent Bargeron C, Hutchins GM: Arterial geometry affects hemodynamics. A potential risk factor for atherosclerosis. Atherosclerosis. 1983;46:225-31.

2. Komet L, Lambregts JAC, Hoeks APG, Reneman RS: Differences in near-wall shear rate in the carotid antery within subjects are associated with differcue intina-media thicknesses. Arterioscler Thromb Vasc Biol. 1998; 18(12):1877-84.

3. Zarins CK, Giddens DP, Bharadvaj BK. Sottiurai VS, Mabon RF, Glagov S: Carotid bifurcation atherosclerosis. Quantitarive correlation of plaque localization with flow velocity profiles and wall shear stress. Circ Res. 1983;53:502-14.

4. Riley WA, Barnes RW, Applegate WB, Dempsey R, Harwell T, Davis VG, Bond MG, Furberg $\mathrm{CD}$ : Reproducibility of noninvasive ultasonic measurement of carotid atherosclcrosis. The Asymptomatic Carotid Artery Plaque Study. Srroke. 1992;23(8):1062-8. 
5. Bond GM, Bames RW, Riley WA, Wimoth $S K$, Chambless LE, Howard $G$, Owens $B$ : The ARIC Situdy Group. Highwesolution B-mode ultrasound scaming methods in the atherosclerosis risk in communities study (ARIC). J Neuromag. 1991;1(2):68-73.

6. Willekes C, Bots ML, Brands PJ, Willigers JM, Hoeks APG, Reneman RS: Evaluation of off-line auromated intima-media thickness detection of the common carotid artery based on M-line signal processing. Ultrasound Med Biol. 1999;25(1);7-64.

7. Bland JM, Alman DG: Statistical methods for assessing agreement between two methods of Clincal measurement. Lancet. 1986,1(8476):307-10.

8. Hoeks APG, Willeke C. Boutouyrie P, Brands PJ, Willigers JM, Reneman RS: Automated detection of Jocal artery wall thickness based on $\mathrm{M}$-line signal processing. Ultrasound Med Biol. $1997 ; 23(7): 1017-23$

9. Hoeks APG, Brands PJ, Smeets FAM, Reneman RS: Assessment of the distensibility of superficial arteries. Ultrasound Med Biol. 1990;16(2);121-8.

10. Kirkwood BR. Essentials of nedical statistics Oxford, London, Edingburgh, Boston, Palo Alto, Melboume: Blackwell Scientific Publications; 1988.

11. Persson J. Stavenow L, Wikstrand J, Israelsson B, Formgren J, Berglund G: Nonimwasive quantification of atherosclerotic lesions. Reproducibility of ultrasonographic measurement of arterial wall thickness and plaque size. Arterioscler Thromb, 1992;12(2):261-6.

12. Salomen $R$, Haapanery $A$, Salonen IT: Measurement of intima-media thickness of conmon carorid arteries with high-resolution $\mathrm{B}$-mode ultrasonography: inter- and intra-observer variability. Ultrasound Med Biol. 1991;17(3):225-30.

13. Wendelhag $\mathrm{I}$, Wiklund $O$, Wikstrand $\mathrm{J}$ : Arterial wall thickness in farnilial hypercholesterolemia. Ultrasound measurement of intimamedia thickness in the common carotid artery. Arterioscler Thromb. 1992;12(1):70-7.

14. Selzer RH, Hodis HN, Kwong Fu H, Mack WJ, Lee PL, Liu CR, Liu CH: Evaluation of computerized edge tracking for quantifying intima-media thickness of the common carotid artery from B-mode ultwasound images. Atherosclerosis. 1994;111(1):1-11.

15. Wendelhag I, Liang Q. Gustavsson T, Wikstrand J: A new antomated computerized analyzing system simplifies readings and reduces the variabilicy in ultrasound measurement of intimamedia thickness. Stroke. 1997;28(11):2195-200.

16. Reneman RS, Hoeks APG: Diameter and compliance in the human arta - variations with age and sex. Ultrasound Med Biol. 1996;22:271-2. 
Hormone replacement therapy in postmenopausal women increases absolute and relative distension of the common carotid artery and beneficially affects the lipid profile

Christine Willekes', Marga M. Illand ${ }^{2}$, Henk J. Hoogland ${ }^{2}$, Arnold P.G. Hoeks ${ }^{3}$, Robert.S. Reneman'

Departments of Physiology ${ }^{1}$, Gynaecology ${ }^{2}$, and Biophysics ${ }^{3}$. Cardiovascular Research Institute Maastricht, Maastricht University and Academic Hospital Maastricht, Masstricht, The Netherlands. 


\begin{abstract}
After menopause, women tend to catch up with men regarding the risk of cardiovascular disease. Substitution with female sex hormones decreases this risk substantially. We investigated the effect of hormone replacement therapy (HRT) on artery wall properties and lipid profile in postmenopausal women. The dynamic and structural wall properties of the elastic common carotid and the muscular common fenoral artery were investigated with a specially designed ultrasound wall tracking system and automated non-inwasive arterial blood pressure measurements. The pulsatility index (Pl) of the uterine artery was assessed as well by means of a color flow inager. Fourteen postmenopatasal women were examined before and repetirively during a two year combined cyclic regime of HRT (2 ng micronised oestradiol and 25-50 Hg gestodene). A group of 11 postmenopausal voluntecrs served as controls to eliminate ageing effects. Absolute and relative distension (strain) of the common carotid atery increased significantly in the HRT group, as did mean arterial pressure $(p<0.05)$. HRT did not affect these parameters in the common femoral artery. PI showed a significant decrease only in the oestrogen-only phase of the first cycle. Total cholesterol and LDL decreased significanty in the HRT group whereas HDL showed an increase, which just did not reach the level of significance. The LDL/HDL atio was significandy lower in the HRT group. No significant effect on intima-media thickness could be observed in this study. These findings indicate that HR T beneficially affects distension and strain of the elastic common carotid artery and the lipid profile, although an effect of blood pressure on antery wall propertias cannor be excluded.
\end{abstract}




\section{Introduction}

Women tend to catch up with men after menopause regarding the risk of cardiovascular disease [1]. This higher risk has been ascribed to loss of ovarian function after the menopausal transition, because (exogenous) female sex hormones have been shown to beneficially affect the lipid profile $[2,3]$ and arterial wall processes related to atherogenesis $[4,5]$. For example, in experimental models of atherosclerosis oestrogen prevents the formation of atherosclerotic plaques [6] and reduces the deposition of cholesterol in the intima [7,8]. Moreover, in experimental studies oestrogens were found to reduce the amount of collagen in the media $[9,10]$, vascular tone and arterial impedance [11]. The latter observation may lead to less stiff elastic arteries, and, hence, to a reduced work load on the heart.

Several studies were directed on the effect of hormone replacement therapy on large elastic central and muscular peripheral arteries showing decreased arterial stiffness in the former and increased vasodilatation in the latter [12-19]. Most of these studies were cross-sectional in nature. To the best of our knowledge, the influence of homone replacement therapy (HRT) on local dynamic artery wall properties, intima-media thickness, and uterine artery impedance in relation to lipid profile has not yet been investigated in a prospective longitudinal way.

Therefore, in the present study we investigated whether HRT during about two years improved the dynamic properties and structure of the arterial wall of the common carotid and common femoral arteries and the lipid profile of postmenopausal, presumed healthy volunteers. Local vascular effects of HRT were investigated by measuring the pulsatility index (PI) in the uterine artery. Untreated and presumed healthy volunteers matched for age- and postmenopausal-duration served as controls.

\section{Material and methods}

\section{Study group}

The study was performed on 14 postmenopausal, presumed healthy volunteers in the age of 45-58 years (mean 52 years) and a postmenopausal duration of 31-72 months (average 32 months). A group of 11 presumed healthy untreated age- and postmenopausal-duration matched volunteers, not taking any medication, served as controls to exclude ageing effects on the arterial system. All volunteers were subjected to extensive physical examination as well as laboratory investigation of kidney, liver and renal function before entering the study. Blood plasma levels of $17 \beta$-oestradiol and follicle stimulating hormone (FSH) were assessed to confirm 
the postmenopausal status. None of the volunteers was hypertensive at the beginning of the study protocol. The study was approved by the joint Medical Ethics Committec of the Maastricht University and the Academic Hospital Maastricht. Informed consent was obtained from all volunteers before entering the study.

\section{Study protocol}

The examinations were performed in a quiet room with an average temperature of $23 \pm 2^{\circ} \mathrm{C}$. Measurements were made at the same moment of the day, to avoid diumal variations, and started after a 10-15 minute supine rest to stabilize blood pressure levels. Volunteers were asked to refrain from smoking and the consumption of alcohol-, caffeine- or quinine-containing beverages at least three hours prior to the examination.

After screening, one baseline measurement was performed before starting HRT. The HRT regime consisted of $2 \mathrm{mg}$ micronised oestradiol daily (day $1-16$ ) in combination with cyclic $25-50 \mu \mathrm{g}$ gestodene daily during day 17-28 (Schering, Berlin, Germany). The HRT subjects were seen after 2, 4, 12, 22, 24, 48, 72 and 96 weeks of therapy. In weeks 2 and 22, subjects were seen during oestradiol-only therapy, while measurements in weeks $4,12,24,48,72$ and 96 were performed during oestradiol- and gestodene-combined therapy. The comparison between oestradiol-only and oestradiol-and gestodene-combined weeks was perfomed to assess possible negating effects of gestodene administration. The control volunteers were investigated after $24,48,72$ and 96 weeks. During each visit ultrasonic vascular examinations were performed at the level of the right common carotid artery and the right common femoral artery. The PI in the left uterine artery was investigated in the HRT group as a representative of impedance to flow downstream of the point of measurement [20]. The control group did not participate in this part of the vascular investigation, because some of the volunteers were not willing to be submitted to the intravaginal examination. Blood pressure was measured at the level of the right brachial artery by means of an automated oscillometric blood pressure measurement device. Venous plasma lipid profiles of HRT and control subjects were assessed in weeks 48 and 96 .

\section{Ultrasonic vascular examinations}

The ultrasonic vessel wall tracking system (WTS) to determine artery wall properties has been described in detail before [21]. In short, the instrument consists of a conventional ultrasound imaging system with a $7.5 \mathrm{MHz}$ linear array probe (Pie Medical, Maastricht, The Netherlands) and a data-acquisition system connected to a personal computer. The measured pulse length at $-6 \mathrm{~dB}$ received from a target at 
a distance of $20 \mathrm{~mm}$ is $350 \mathrm{~ns}$, corresponding to an axial resolution of approximately $260 \mu \mathrm{m}$. During the vascular examination the artery of interest was imaged in B-mode in a longitudinal section, $2 \mathrm{~cm}$ proximal to the bifurcation (flow divider), whereafter an $\mathrm{M}$-line was positioned perpendicular to the vessel wall. The ultrasound system was switched to M-mode and synchronous with the ECG, data were collected during a period of about 4 seconds, covering 3-5 heart beats. The raw radiofrequency (RF) data were temporarily stored in an 1 MByte large memory. The anterior and posterior walls of the artery were identified manually by placing sample volumes on the wall reflections as seen in the first captured RF-line, displayed on the computer monitor. Consecutively, the data were transferred line by line to the computer. A cross-correlation algorithm calculated the cumulative change in phase between corresponding segments of successive RF lines for both walls, hereby continuously following the artery walls during motion (tracking). Eventually, the displacement of the anterior and the posterior wall was shown simultaneously with the difference between these displacements, representing the change in diameter during the cardiac cycle (distension). The arterial end-diastolic diameter (D) and the change in diameter from diastole to systole $(\Delta D)$ for each captured heart beat were provided as well. Simultaneously arterial blood pressure measurements were obtained every three minutes at the level of the brachial artery by means of a semi-automated oscillometric device (DINAMAP; Criticon, Tampa, FL, USA). Pulse pressure (PP), defined as systolic minus diastolic blood pressure, was determined by averaging the three measurements nearest to the distension measurements. In previous studies, the pulse pressure in the brachial artery has been shown to correlate well with the carotid artery pulse pressure [22].

From $D, \triangle D$ and $P P$, the arterial cross-sectional distensibility (DC) and compliance (CC) coefficients were calculated according to the following equations [23]:

$$
\begin{aligned}
& \mathrm{DC}=(2 \Delta \mathrm{D} / \mathrm{D}) / \mathrm{PP} \\
& \mathrm{CC}=\pi \mathrm{D} \Delta \mathrm{D} /(2 \mathrm{PP})
\end{aligned}
$$

With the wall-tracking system, displacements of a few micrometers can be resolved and $\mathrm{D}, \Delta \mathrm{D}, \Delta \mathrm{D} / \mathrm{D}, \mathrm{DC}$ and $\mathrm{CC}$ can be assessed reliably [24]. The artery wall properties, as determined in this way, reflect a combination of passive elastic characteristics of the wall and active components induced by smooth-muscle cells. Therefore, we investigated the elastic common carotid artery and the muscular common femoral artery. To save time only the right common carotid and the right common femoral artery were investigated. This is allowed because in previous studies the wall properties of the right and left common carotid arteries as 
well as the right and left common femoral arteries were found to be not significantly different (C. Willekes, M.J. Kool, A.P.G. Hoeks, R.S. Reneman, unpublished results). All examinations were performed with an empty bladder, because recent studies in our institute have shown that a full bladder affects artery wall properties of the common femoral artery [25].

In both groups, intima-media thickness (IMT) was measured on the posterior wall of the right common carotid artery, approximately $2 \mathrm{~cm}$ proximal to the carotid artery bulb. The posterior wall was chosen, because here the reflections from the blood-intima and media-adventitia transition are distinctly visible, while at the anterior wall the trailing edge of the hyperechoic adventitia may obscure the media and intima signals. Our automated RF method to assess IMT has been described in detail before [26]. In short, the same radiofrequency (RF) data as mentioned above, collected at a sample frequency of $20 \mathrm{MHz}$, an $\mathrm{M}$-line update frequency of $400 \mathrm{~Hz}$ and a duration of 4 seconds corresponding to $3-5$ heart beats, were used. On the first RF-line displayed on the computer monitor a window of $3 \mathrm{~mm}$ covering the posterior intima-media complex was identified. Data from this window over time were stored on hard-disk for further off-line processing. At the end of the measurement protocol all recorded files were processed employing the wall thickness program. The instantaneous envelope of the amplitudle of the RF signals was determined and, after phase alignment of the RF signals, using the assessed motion of the posterior wall (see distension movements), the envelope of the amplitude distribution was time-averaged. Averaging over the systolic phase of a heart beat enhanced signals from wall interfaces exhibiting similar displacements between observations and smoothed secondary echo signals (e.g., reverberations) with a different displacement behavior. For each heart beat the derivative with respect to depth of the averaged normalized amplitude distribution, exceeding a threshold of 0.020 , was considered to distinguish wall signals from other signals. Only the leading edge of distinct echoes exceeding the threshold for the derivative was used to identify relevant regions. The position where the instantaneous amplitude within this region reached the $50 \%$ level was considered as the location of the intima edge. This detection procedure was repeated for the next region (presumably the media-adventitia edge) where the derivative exceeded the threshold. The required minimal ratio of intima and adventitia amplitude was set to 1.0 to avoid inclusion of false edges. Each heart beat within a recording provided an estimate of IMT. Three independent measurements, each being the median value of the IMT as assessed during 3-5 consecutive heart beats, were used to calculate the mean IMT. The resolution for wall thickness detection is related to the RF sample frequency $(20 \mathrm{MHz}$ ) and is approximately $40 \mu \mathrm{m}$ [26]. The lower limit for the intima-media wall thickness was selected according to the axial resolution of the ultrasound system used and set at $300 \mu \mathrm{m}$. 
From IMT, D and DC, the Young's modulus (E) was calculated according to the following formula [27]:

$$
\mathrm{E}=(\mathrm{D} / \mathrm{IMT}) / \mathrm{DC}
$$

The Young's modulus describes the intrinsic elastic properties of the artery wall and compliance the functional aspects of the artery wall.

\section{Assessment of pulsatility index}

This part of the study was carried out with a color flow imaging (ATL HDI, Ultramark 9, Bothell, Washington, USA) system with a $7.5 \mathrm{MHz}$ phased transducer. The vascularization of the uterus was visualized by means of the color Doppler mode, and blood flow velocity waveforms were recorded by placing the Doppler gate over the coloured areas and activating the pulsed Doppler function. We examined the ascending branch of the left uterine artery lateral from the cervix at the level of the internal os. The highest achievable signals were sought for in each vessel examined. "The maximum Doppler frequency shift was automatically traced and recorded on super VHS tape during at least 4 good quality consecutive heartbeats. The automatic calculation of the PI used the following equation: $\mathrm{PI}=$ peak systolic frequency shift minus the end diastolic frequency shift divided by the mean frequency shift over the cardiac cycle. After the examination, data were analysed off-line by the same examiner (C.W.), averaging at least 4 repeatible heartbeats, and using the average PI to compare data in time. The actual value of the PI for a particular artery depends on such mechanical factors, as the artery diameter and distensibility and the effective resistance and distensibility of the peripheral vascular beds supplied by the artery [28].

\section{Serum lipid investigations}

At the beginning of each examination blood was drawn from an antecubital vein and serum lipid parameters were determined in the Academic Hospital laboratory according to standard procedures. In order to obtain comparable results for each subject all investigations were performed at the same moment of the day (preferably at the same moment in the morning and after an overnight fast). Total cholesterol, Low Density Lipoproteins (LDL), High Density Lipoproteins (HDL) and triglycerides were determined according to local laboratory standard protocols. The LDL and HDL levels were used to calculate the $\mathrm{LDL} / \mathrm{HDL}$ ratio $(=\mathrm{LDL} / \mathrm{HDL} \times 100 \%$. Differences between baseline and consecutive measurements were calculated and used for statistical analysis. The interassay coefficient of 
variation (=100xstandard deviation/mean, in percent) of total cholesterol, LDL, HDL and triglycendes was $2.4 \%, 6.5 \%, 7.3 \%$ and $3.2 \%$, respectively.

\section{Statistical andysis}

SPSS-software packages were used to perform non-parametric statistical analysis. Differences between baseline and $2,4,12,22,24,48,72$ and 96 weeks in the HRT group were tested for statistical significance by means of the Wilcoxon non-parametric signed rank test. In the HRT group week 2 vs 4 and week 22 vs 24 were separately evaluated for significant differences by means of Wilcoxon signed rank test to assess possible effects of gestodene after short (week $2 \mathrm{vs}$. 4) and long periods of treatment (week 22 vs 24). Bonferroni correction was applied for repeated analysis $\{\mathrm{p}<0.05 / \mathrm{g}(\mathrm{g}-1) / 2]$, where $\mathrm{g}$ is the number of pairwise comparisons \} [29]. For the PI a level of $p<0.005$ was considered to be statistically signifcant. Differences between the HRT and the control group after 96 weeks and corrected for baseline values were tested for statistical significance using the Mann-Whitney $U$-test in order to assess any effects of HRT independent of age. Here, a level of $p<0.05$ was considered to be statistically significant.

\section{Results}

At baseline the HRT and control group were not significantly different concerning their age, menopausal status, vascular status, lipid profile and blood pressure. In both groups, the distribution of length, height, body mass index and smoking status was comparable. Three HRT subjects dropped out of the study at 3,11 and 18 month of therapy due to different circumstances not related to HRT use. One subject had high endocrine oestradiol levels and aberrant bleeding, most likely due to still functioning ovaries. The second dropout wished to discontinue the medication protocoll for personal reasons. The last volunteer developed. complaints of leg atherosclerosis, in retrospect already present at the beginning of the study protocol. No volunteer in the control group dropped out during the follow-up period.

\section{Vascular parameters}

No significant differences in compliance and distensibility were found between oestradiol-only and oestradiol and gestodene-combined periods in both the common carotid and the common femoral artery, after either short 2 respectively 4 weeks) or long ( 22 respectively 24 weeks) term treatment. The distensibility and compliance of the common carotid as well as the common femoral artery did not 
change significantly in time in both the HRT group and the control group. No significant differences in compliance and distensibility of the common carotid and the common femoral artery could be detected between the HRT and the control group at the end of the study, when corrected for baseline values (Table 1). The absolute and relative distension (strain) of the common carotid artery as well as the mean arterial pressure were significantly higher in the HRT group than in the control group at the end of the study, when corrected for baseline values (Figure 1). HRT had no significant effect on the absolute and relative distension of the common femoral artery (Table 2). The intima-media thickness and the Young"s modulus of the carotid artery did not change significantly during the experimental period in both the HRT and the control group. Corrected for baseline values both parameters were not significantly different between the HRT and the control group after 96 weeks. The PI of the left uterine artery, examined in the HRT group only, showed a short-term significant decrease, reaching a minimum after the first two weeks of oestradiol-only therapy. This effect was reduced during the next two weeks of combined oestradiol-and gestodene-therapy. From 3 weeks of HRT onward, no significant effect could be detected anymore, although the absolute values remained below baseline levels (Figure 2).

\section{Lipid parameters}

Total cholesterol and LDL content were significantly decreased at the end of the experimental period in the HRT group, but not in the control group (Table 3). As compared to control at the end of HRT, HDL content tended to increase, but this difference did not reach the level of significance. As a consequence, at the end of the study period the LDL/HDL-ratio was significantly lower in the HRT than in the control group $(\mathrm{p}<0.016)$. 
$120 \prod^{\text {Chapter } 8}$

\section{Difference between control-and HRT-group after 96 weeks}

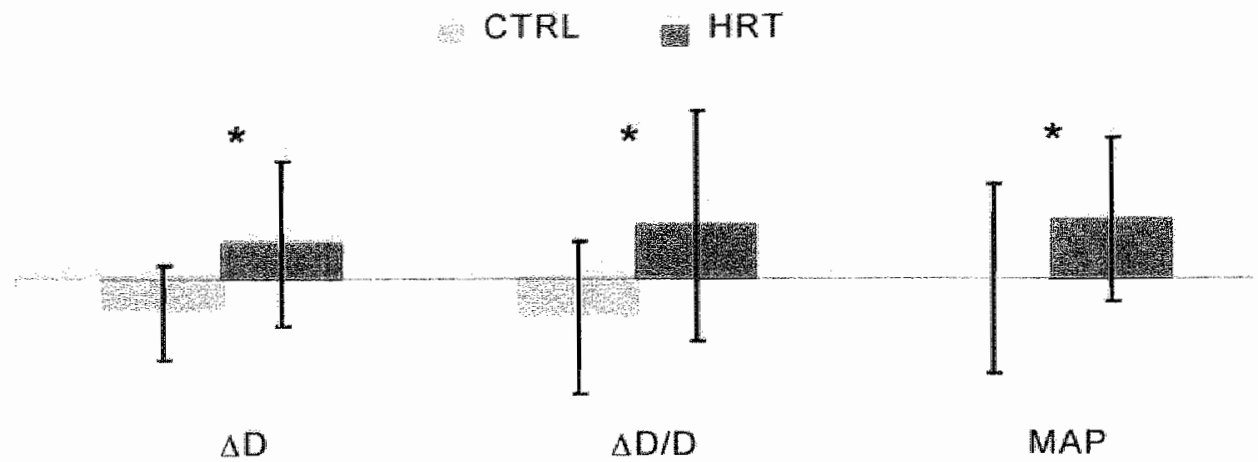

Figure 1. Differences $(* 0<0.05)$ in absolute $(\Delta D)$ and relative distension $(\Delta D / D)$ and mean arterial pressure (MAP) between control- (CTRI) and HRT group (HRT) after 96 weeks.

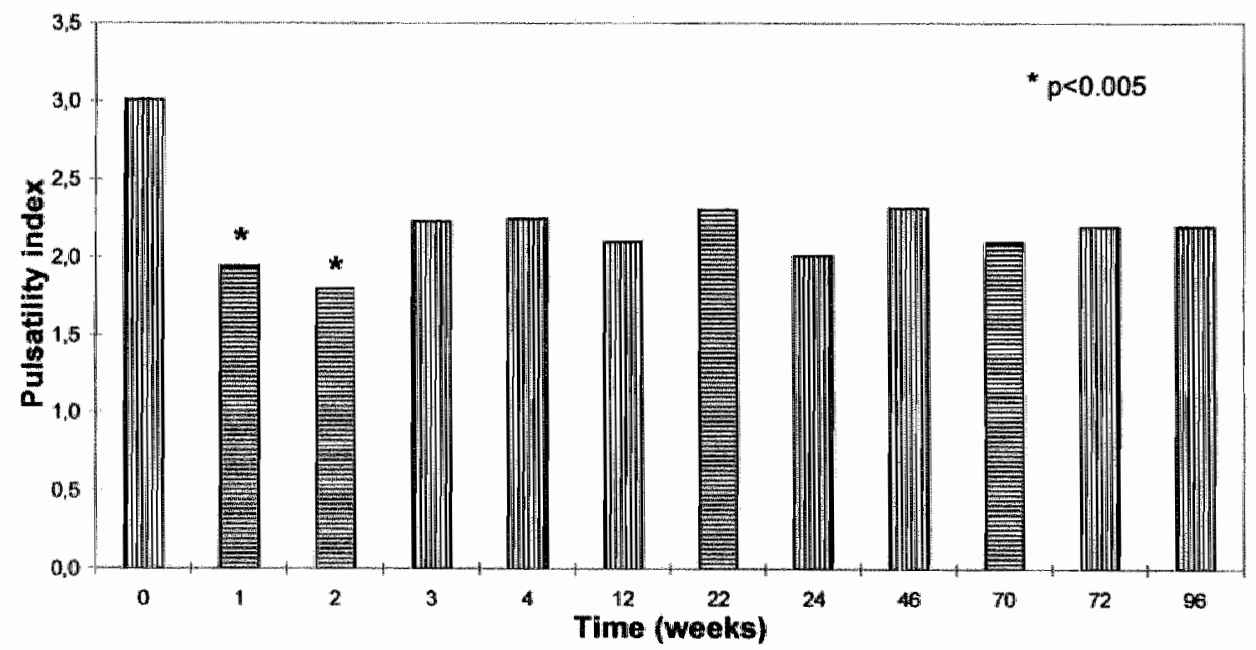

Figure 2. Effect of HRT on pulsatility index of the left uterine artery as a function of time. Horizontal bars mark the oestratiol-only sample points. Vertical bars mark the oestradiol-gestodene combined sample points $*=p<0.005$. 
Trable 1. Carond antery paramater and blow presture a baseline (B) and hfer 96 weeks in the HRT and control (CTRI) group The differences (A) between biseline and 96 weeks are depicted as wel. Mean values and standard devations are presented $t=\mathrm{BO} 0.05$.

\begin{tabular}{|c|c|c|c|c|c|c|}
\hline & B HRT & $\mathrm{B}(\mathrm{TM})$ & $96 \mathrm{WINT}$ & $96 \mathrm{WCTR}$ & $\triangle \mathrm{HRT}$ & $\triangle C \mathrm{ML}$ \\
\hline & 710.41 & $7 \times(06)$ & $70(04)$ & $2,4(0.6)$ & $0.06(0,3)$ & $-0,02(0) 4$ \\
\hline (nta) & $10,5(0.09)$ & $0.39(0.13)$ & $0,38(0,12)$ & $0,36(6.13)$ & $0.03(000) *$ & $-0.03004)$ \\
\hline$\Delta \mathrm{O} / \mathrm{O}$ ) & $50(15)$ & $52(1,6)$ & $54(19)$ & $48(6)$ & $0.4(10)^{*}$ & $034(0,6 \%)$ \\
\hline $\mathrm{CC}\left(\mathrm{min}^{2} \mathrm{LP}\right)$ & $0,50(0,13)$ & $0.65(0.26)$ & $056(015)$ & $0,59(0.23)$ & $40 \%(0,13)$ & non $(0,09)$ \\
\hline $\mathrm{DC}\left(10^{\circ} \mathrm{kP}\right)$ & $15,(4,1)$ & $1490(5,15)$ & $14.6(4.0)$ & $13.62(4.35)$ & $0.55(3,9)$ & $-135 / 2,10$ \\
\hline$(\mathrm{P}) \mathrm{P}+4$ & $794(211)$ & $832(451)$ & $812(185)$ & $926(600)$ & $16(2+2)$ & $24(135)$ \\
\hline MT (num) & $0640099)$ & $0770,11)$ & $0.04(0110)$ & $106008)$ & 1000006 & 00030,081 \\
\hline $\mathrm{SBP}(\mathrm{mm} H \mathrm{~g})$ & $123(1)$ & $131(12)$ & $131,16)^{2}$ & $133(13)$ & $8(14)$ & $2(13)$ \\
\hline (numilla) & $72(6)$ & 780 & $75(8)$ & $76(7)$ & $3(6)$ & $-2(8)$ \\
\hline 2 (nninge) & 527 & $53(10)$ & $56(11)$ & $57(13)$ & $5(9)$ & 4(1) \\
\hline $\mathrm{AP}$ (nim) $\mathrm{g})$ & $89(7)$ & $96(8)$ & $94(10)$ & 9507 & $50)^{\circ}$ & $0(1)$ \\
\hline
\end{tabular}

$\mathrm{D}=\mathrm{end}$ - liastolic dianeter, $\mathrm{DD}$ - absolute distonsion, $\Delta \mathrm{D} \mathrm{DD}$ - relatike distension, $\mathrm{CC}=\mathrm{compl}$ ance coefficient, DC - disterisibility coefictent, $\mathrm{D}-\mathrm{Y}$ oung's modulus, $1 \mathrm{MT}$ - matha-media thicknes, $\mathrm{SBP}=$ systolic blood pressure $\mathrm{DBP}=$ diastolic blood presure, $\mathrm{PP}=$ pulse pressure. $\mathrm{MAP}=$ mean arterial pressure.

Table 2. Femoral artery parameters and blood pressure at baseline (B) and after 96 week in the IIR 1 and control groups (CTRL) The difference ( 4 ) between baseline and 96 week rare depicied as well Mean values and standard devinions are presented

\begin{tabular}{|c|c|c|c|c|c|c|}
\hline & $1 \mathrm{HAT}$ & BCTA & $96 \mathrm{~N} 11 \mathrm{~N} T$ & 96 w CTRL & $\triangle \mathrm{HRT}$ & $\triangle$ GrRL \\
\hline $\mathrm{P}(\mathrm{nmm})$ & $94(10)$ & $90 / 10$ & $92(1,3)$ & 9,4088 & $0.3(0.6)$ & $0+(0.6)$ \\
\hline$\Delta D(n m)$ & $0.19(0.07)$ & $0.19(0,08)$ & $0.21(0.08)$ & $0.17(0,06)$ & 0026004 & $003(0.08)$ \\
\hline$\Delta \mathrm{B} \triangle \mathrm{B}(\%)^{\circ}$ & $20,0.7$ & $2,2(0.8)$ & $22(0,9)$ & $179(0,7)$ & $0,2(0,5)$ & $0043(0.8)$ \\
\hline $\mathrm{CC}(\mathrm{mm} / \mathrm{kP})$ & $0.43(0.21)$ & $0.40(0,16)$ & $0.44(0,3)$ & $0,3,(0,14)$ & $0010009)$ & $-0.07(0.13)$ \\
\hline $\mathrm{DO}(10 \mathrm{se})$ & $5,94(2,3)$ & $635(2,3)$ & $5.85(2.9)$ & $493(2,39)$ & $4709(1)$, & I, $42(1.82)$ \\
\hline $\operatorname{SBP}(\mathrm{min} / \mathrm{lg})$ ) & 1260 & $126(16)$ & $135(17)$ & $131(15)$ & $6(12)$ & $3(15)$ \\
\hline DBP (minH & $76(7)$ & $76(7)$ & $76,9)$ & 760 & $2(1)$ & $0(9)$ \\
\hline MP (nnHlg) & $62(6)$ & $53(12)$ & $58(10)$ & $56(11)$ & 60 & 300 \\
\hline $\mathrm{MAP}$ (minm $\mathrm{Hg})$ & $92(1)$ & $94(10)$ & $96(1)$ & $94(10)$ & $4(9)$ & $1(9)$ \\
\hline
\end{tabular}

$\mathrm{D}=$ end-diastolic dianeter $\mathrm{DD}=$ absolute distension, $\mathrm{AD} / \mathrm{D}-\mathrm{relative}$ distension, $\mathrm{CC}=\mathrm{compli}-$

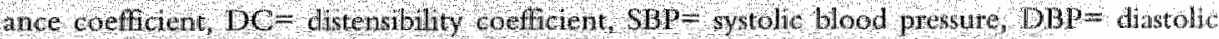
blood pressure, $\mathrm{PP}=$ pulse pressure, $\mathrm{MAP}=$ nuen artenal pressure. 


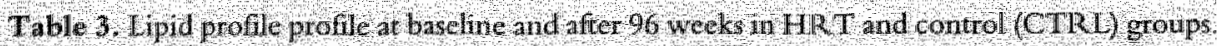
The difference becween baseline and 96 weeks are depicted as well Mean values and standard de valions are presented

\begin{tabular}{|c|c|c|c|c|c|c|}
\hline & $\begin{array}{l}\mathrm{Bass} \text { ) } \\
\mathrm{CPT}\end{array}$ & 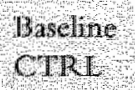 & $\begin{array}{l}96 \text { weeks } \\
\text { rint }\end{array}$ & $\begin{array}{l}96 \text { weeks } \\
\text { culdL }\end{array}$ & $\triangle M R T$ & $\triangle \mathrm{OTRI}$ \\
\hline C (nmold) & $67 .(1,1)$ & $6,3(6,8)$ & $58(6.8)$ & $6701)$ & $-0.9(0.8)^{* t}$ & 0.310. \\
\hline 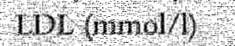 & $3.6(1,4)$ & $4.3(0.9)$ & 3500 & $4.5(1.3)$ & $-11(1,0) * x$ & $0.2(0,9)$ \\
\hline HDI (minol/h) & $14(16)$ & $15(0,4)$ & $16(06)$ & $16(0.4)$ & $0.2(0.3)$ & $0.0(02)$ \\
\hline 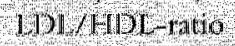 & $30(2,0)$ & $30(1.2)$ & $2.5(1,3)$ & $3001)$ & $-1.3(1.6)^{\star}$ & $0.0(0.9)$ \\
\hline Gr (oninculd) & $19(1,4)$ & $12(05)$ & $17(0.9)$ & $1.5(0.6)$ & $-0.2(0.9)$ & $02(03)$ \\
\hline
\end{tabular}

$\star=\mathrm{p}<0,015, * \star=\mathrm{p}<0.005 . \mathrm{C}$ - total cholesterol (range $41-6.4$ mimol/), LDL $=$ low dersity

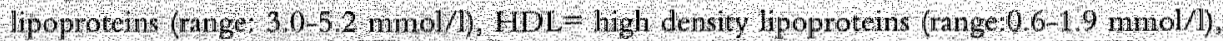

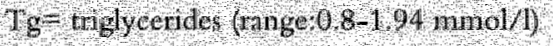

\section{Discussion}

The findings of this study show that in postmenopausal women hormone replacement therapy (HRT) over a period of approximately 2 years does not improve compliance and distensibility, reduce the intima-media thickness or improve the elastic properties, as indicated by the absence of a change in Young's modulus, of the arterial wall of either the common carotid or the common femoral artery. This HRT, however, improves absolute and relative distension (strain) of the common carotid artery, but not in the common femoral artery, and beneficially affects the lipid profile as documented by the decrease in total cholesterol, LDL and the LDL/HDL-ratio. The decrease in pulsatility index during the first two weeks of HRT indicates that oestradiol alone reduces impedance to flow in the uterine artery, an effect likely to be counteracted by gestodene treatment because of the reduction of the decrease in pulsatility index during combined treatment of oestradiol and gestodene.

The increase in absolute and relative distension of the common carotid artery in the HRT group, as compared with the control group, can be explained by the slight increase in these parameters in the former group and a slight decrease in the latter. The increase in these parameters during HRT complies with the observation that absolute distension and relative distension decreases during the menopause [30], indicating that these parameters are indeed influenced by hormonal changes.

The finding that in the HRT group the increase in absolute and relative distension of the common carotid artery is not reflected in an increase in compliance and distensibility may be explanned by the slight, but not significant, increase in pulse 
pressure in this group. It cannot be excluded that the beneficial effect of HRT on absolute and relative distension of this elastic artery is pardy due to the slight but significant increase in mean arterial pressure.

The absence of an effect of HRT on compliance is in agreement with the observation of Tanaka et al, who found no difference in pulse wave velocity in postmenopausal women on HRT compared to a control group [31], but does not comply with the observation of Rajkumar et al who observed an increased systemic arterial compliance and a decreased pulse wave velocity in women on HRT [14]. Menopause was associated with increased arterial stiffness in the common carotid artery of 84 pre- versus 139 postmenopausal women [16]. In a prospective study of 3.5 years menopause negatively affected the systemic arterial compliance (decrease) as well as Peterson's elastic modulus (increase) of the aorta in postmenopausal hypertensive women compared to premenopausal hypertensive controls [13]. Also, aortic root distensibility and relative distension decreased after menopause. Postmenopausal women on long-term HRT had a significantly higher mean systemic arterial compliance and a lower IMT when compared to age-matched postmenopausal controls not taking any medication [15]. Subgroup analysis for oestrogen versus oestrogen plus progestin revealed no differences for these variables. However, the distensibility coefficient was greater in oestrogen-only users. The studies mentioned were practicaly all cross-sectional in design and different vascular parameters (systemic arterial compliance, pulse wave velocity, stiffness) were studied at different levels of the arterial tree (aorta, carotid artery, aortofemoral region) under various circumstances (pre- vs postmenopausal with or without hormone replacement therapy). Therefore, it is difficult to draw uniform conclusions from these studies and a large prospective randomised clinical trial is needed.

The beneficial effect of HRT on the lipid profile is in agreement with the observations of Bush et all, who observed a significant decrease in LDL, and a significant increase in $\mathrm{HDL}$ [32]. Also, in the PEPI-trial a significant reduction in LDL of 10-15\% was observed after a period of two years [33]. However, this beneficial effect likely accounts for only approximately one third of the total beneficial effect of HRT on the risk of cardiovascular disease in postmenopatisal women [32].

The observation that HRT during two years does not affect intima-media thickness is in agreement with Nabulsi et al, who did not observe an effect of menopause or HRT on intima-media thickness in a cross-sectional study on preversus postmenopausal women, of either short- $(<5 \mathrm{yr})$ or long $(>5 \mathrm{yr})$ duration [34]. It does not comply with the findings of McGrath et al, who observed in a cross-sectional study a smaller intima-media thickness in postmenopausal women on HRT compared to age-matched postmenopausal controls not taking any 
medication, all with an average duration of postmenopause of at least two years [15]. Subjects taking oestrogen alone did not significantly differ from subjects taking oestrogen plus progestin regarding the positive effect on intima-media thickness. In our study, the absence of an effect of HRT on intima-media thickness of the common carotid artery wall can possibly be explained by the duration of the study and the power of the method used to assess intima-media thickness. Intina-media thickness increases in time and is linearly related to age. Per decade an average increase of $50-100 \mu \mathrm{m}$ has been observed in men as well as in women [35], leading to an average increase per 2 year of $10-20 \mu \mathrm{m}$ under nomal ageing circumstances. Our intima-media thickness measurement method based on $\mathrm{M}$-line processing is capable of discerning intima-media-thickness with a resolution of about $40 \mu \mathrm{m}[26]$. This means that to observe any significant effect in time, the difference in intima-media-thickness increase between the control- and the HRT-group should have been at least $15 \mu \mathrm{m}$. It is likely that in this relatively healthy study population and in the limited period of observation ( 96 weeks), this difference in intima-media thickness increase is not reached. Also, this result is obtained in the theoretical situation that the artery wall is completely homogeneous.

Reliable assessment of distensibility, compliance and the Young's modulus requires the determination of pulse pressure at the site of measurement of the end-diastolic diameter and the absolute and relative distension or at a representative site elsewhere. It has been shown that for the assessment of these parameters in the carotid artery brachial pulse pressure is a good substitute [22]. Brachial artery pulse pressure, however, is not representative of pulse pressure in the femoral artery (unpublished results from our institute). One should realize, however, that errors due to differences in location of blood pressure measurement and artery wall property assessment will be methodological in nature and of the same order of magnitude at the various moments of determination, because intra-subject variation was determined in time. Therefore, the error made in the determination of pulse pressure will not significantly influence the outcome of the study.

In conclusion, the findings of this study indicate that HRT may be helpful in reducing cardiovascular risk for menopausal women as indicated by the beneficial effects on abolute and relative distension of the common carotid artery and the lipid profile. 


\section{References}

1. Kannel WB, Hontland MC, MCNamara PM, Gordon T: Menopause and risk of condiowascular disease: the Framingham study. Ann Intern Med. 1976;85(4):447-52.

2. Gevers Leuven JA: Sex steroids and lipoprotein merabolism. Phamacol Ther. 1994;64(1): $99-126$.

3. Bush TL, Barrett-Connor E: Noncontraceptive estrogen use and cardiovascular disease. Epidemiol Rev. 1985;7:89-104.

4. Rosano GMC, Chierchia SL, Leonardo F, Beale CM, Collins 1 : Cardioprotective effects of ovarian hormones. Eur Heart J. 1996;17(Suppl D):15-9.

5. Sarrel PM: Ovarian homones and the circulation. Maturitas. 1990;12(3):287-98.

6. Adams MR, Kaplan JR, Manuck CB, Korimik DR, Parks JS, Wolfe MS, Clarkson TB: Inlyibition of coronary artery atherosclerosis by $17 / 3$ estradiol in ovariectomized monkeys. Lack of an effect of added progesterone. Arteriosclerosis. 1990;10:1051-7.

7. Haarbo J, Leth-Espensen $P$, Stender S, Christiansen C: Estrogen monotherapy and combined estrogen-progestogen replacement therapy attenuate aortic accumulation of cholesterol in ovariectomized cholesterol-fed rabbits. I Clin Invest. 1991:87:1274-9.

8. Wagner JD, Clarkson TB, St. Clair RW, Schwenke DC, Shively CA, Adams MR. Estrogen and progesterone replacement therapy redaces low density lipoprotein accumulation in the coromary arteries of surgically postmenopausal cynomolgous monkeys. J Clin Invest. 1991;88:1995-2002.

9. Beldekas $\mathrm{JC}$, Smith B, Gerstenfeld LC, Soneshein GE, Franzblan C: Effects of $17 \beta$-estradiol on the biosynthesis of collagen in cultured bovine aortic smook muscle cells. Biochemistry. $1981 ; 20: 313-20$.

10. Fischer GM, Swain ML: Effects of estradiol and progesterone on the increased synthesis of collagen in atherosclerotic rabbit aortas. Atherosclerosis. 1985;54:177-85.

11. Magness RR, Rosenfeld CR: Locall and systenic estradiol-178: effects on uterine and systemic vasodilation. Am J Physiol. 1989;256(4 Pt 1):E536-42.

12. Penotzi M. Nencioni T, Gabrielli L, Farina M, Castiglioni E, Polvani F: Blood fow variations in internal carotid and middle cerebral arteries induced by postmenopausal homone replacenent therapy. Am J Obstet Gynecol. 1993;169(5):1226-32.

13. Karpanou EA, Vyssoulis GP, Papakyriakou SA. Toutouza MG, Toutouzas PK: Effects of menopatse on aotic root function in hypertensive women. J Am Coll Cardiol, 1996:28(6): 1562-6.

14. Rajkumar C, Kingwell BA, Canneron JD, Waddell 'T, Mehra R, Christophidis N, Konesuroft PA. McGrath $B$, Jemnings $G L$, Sudhir $K$, Dart $A M$ : Hormonal therapy increases arterial compliance in postmenopausal women. J An Coll Cardiol. 1997;30(2);350,6.

15. McGrath BP, Liang Y-L, Teede H, Shiel LM, Cameron JD, Dart A: Age-related deterioration in arterial structure and function in postmenopausal women - impact of homone replacement therapy. Arterioscler Thromb Vase Biol, 1998; 18(7):1149-56.

16. Jonason $T$, Henriksen E, Kangro $T$, Vessby $B$, Ringqvist $I$ : Menopatuse is associated with the stiffuess of the common carotid artery in 50-year-old women. Clin Physiol. 1998; $18(2): 149-55$.

17. Waddel TK, Rajkumar C, Cameron JD, Jennings GL, FKingwell BA: Withdrawal of homonal therapy for 4 weeks decreases arterial compliance in posmenopausal women. J Hypertens. $1999 ; 17(3) \div 413-8$

18. Cacciatore B, Pakkari I, Toiwonen J, Tikkanen M. Ylikorkala $O$ : Randomized comparison of oral and transdermal homone replacement on carotid and utereine artery resistance to blood flow. Obstet Gymecol. 1998:92(4 Pt 1):563-8. 
19. Liang Y $Y$, Tede H, Shiel LM, Thomas A, Craven R, Sachitwanandan N, McNeil J, Cameron JD. Dart A. McGrath BP: Effects of oestrogen and progesterone on age-related changes in arteres of postmenopausal women. Clin Exp Pharmacol Physiol. 1997;24(6):457-9.

20. Gosling RC, Durbar G, King DH, Newman DL, Side CD, Woodcock JP. Fitzgerald DE, Keares JS, MacMillan D: The quantitative analysis of occlusive peripheral arterial disease by a non-intmsive ultrasonic technique. Angiology. 1971,22.52.

21. Hoeks APG, Brands PJ, Smeets FAM, Reneman RS: Assessment of the distensibility of superficiall arteries. Ultrasound Med Biol. 1990;16(2):121-8.

22. Reneman RS, van Merode $T$, Brands PJ, Hoeks APG: Inhomogeneities in arterial wall properties under nomal and pathological condicions. I Hypertens Suppl. 1992;10(6):S35-9.

23. Reneman 12S, Hocks $A P G$, Westerhof $N$ : Non-invasive assessment of artery wall properties in humans - methods and interpretations. I Vasc Invest. 1996;2:53-64.

24. Kool MJ, van Merode T, Reneman RS, Hoeks APG, Struijker Boudier HA, Van Bortel LM: Evaluation of reproducibility of a vessel wall movement detector system for assessment of large artery proplerties. Cardiovasc Res. 1994;28(5):610-4.

25. Willekes $\mathrm{C}$, Hoogland HJ, Hoeks APG, Reneman RS: Bladder filling reduces femoral artery wall distension and strain: beware of a full bladder! Ultrasound Med Biol. 1998;24(6):803-7.

26. Hoeks $A P G$, willekes $C$, Boutouyrie P, Brands PJ, Willigers JM, Reneman RS: Autonated detection of llocal artery wall thickness based on M-line signal processing. Ultrasound Med Biol. $1997 ; 23(7): 1017-23$

27. Hocks APG. Non-invasive study of the local mechanical arterial characteristics in humans. In: Safar ME, O'Rourke MF, eds. The arterial system in hypertension. Dordrecht/Boston/London: Khwwer Academio Publishers; 1993

28. Waite LR, Ford SP, Young DF, Conley AJ: Use of ultrasonic doppler waveforms to estmate changes in uterine artery blood flow and vessel compliance. J Anim Sci. 1990;68:2450-8.

29. Fleiss JL. The Bonferroni correction for multiple comparisons. In: Shewart WA, Wils SS, eds. The design and analysis of climcal experiments. New York: Johm Whiley and Sons; 1986:103-7.

30. Westendorp ICD, Bots ML, Grobbee DE, Reneman RS, Hoeks APG, Van Popele NM, Hofnan A. M. WJC: Menopausal starus and distensibility of the common carotid artery. Arterioscler Thromb Vasc Biol. 1998;19(3):713-7.

31. Tanaka $H$, DeSouza CA, Seals DR: Arterial stiffess and hormone replacement use in healthy posmmeparusal women. J Gerontol. 1998;53A:M344-6.

32. Bush TL: Evidence for primary and secondary prevention of coromary artery disease in women taking oestrogen replacement therapy. Eur Heant J. 1996;17(Suppl D):9-14.

33. Barrett-Connor $E_{n}$ Slone $S$, Greenclale $G$, Kritz-Silverstein D, Espelland $M$, Johnson SR, Wadawiw M, Fineberg SE. The postmenopausal estrogen/progestin interwention study: primaty outcomes in adherent wonen. Maturitas. 1997;27:261-74.

34. Nabulsi AA, Folsom AR, Szklo M, White A, Higgins M, Heiss G: No association of menopause and homone replacement therapy with arotid artery intima-media thickness. Atherosclerosis Risk in Communities (AR.IC) Study Investigators. Cinculation. 1996;94(8):1857 63 .

35. Riley WA, Caven 'T, Romont A, Furberg CD: Assessment of temporal bias in longitudinal neastrements of arotid intimal-medial thickness in the Asymptomatic Carotid Artery Progression Study (ACAPS). ACAPS Research Group. Ultrasonnd Med Biol. 1996;22(4): $405-11$. 


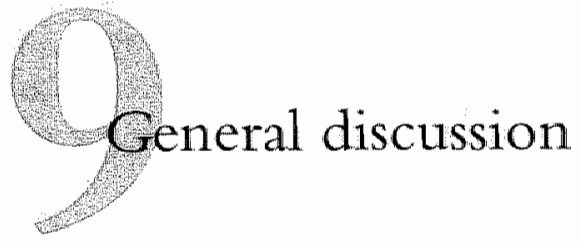


It was the aim of this study to investigate the effects of endogenous and exogenous female sex hormones on dynamic artery wall properties of the common carotid and common femoral arteries. The initial reason for performing this study was that, in previous studies, dynamic artery wall properties were found to be different between men and women with either higher or lower compliance and/or distensibility in women then in men (Introduction, Table 1) [1-9]. We hypothesized that these discrepancies may at least partly be due to the effect of female sex hormones, because pill use and the menstrual cycle were not considered in these studies. The potential effect of female sex hormones can be studied during the normal menstrual cycle (endogenous female sex hormones) or during the use of the pill or HRT (exogenous female sex hormones). The second reason for the present study was the increasing risk of cardiovascular disease in women in the menopause. Oestrogen-deficiency has been hypothesized to be the cause of increased risk of CVD. Oestrogen may influence arterial wall function and structure directly by means of various mechanisms (Introduction, Figure 6), acting on endothelial and/or on vascular smooth muscle cells, because functional oestrogen receptors are present in these cells in different vascular beds [10-15]. Also, a calcium channel blocking effect of oestrogen has been described, leading to vasodilatation in arteries [16]. Oestrogen increases the production of nitric oxide leading to increased vasodilatation. A decrease in the formation of collagen and elastin has been observed under the influence of oestrogens, rendering arteries less stiff $[17,18]$. Also, inhibition of atheroscleratic plaque formation has been observed in animal studies $[19,20]$. Therefore, not only dynamic artery wall properties are possibly influenced by changing levels of female sex hormones, but also artery wall structure, as wall thickness and composition. It is known that artery wall thickness increases with age $[6,21]$ and that atherosclerosis may be associated with increaded artery wall thickness [21]. Because increases in wall thickness may be wery local, especially occurring in arterial bifurcations [22], we developed an ultrasound technique to assess artery wall thickness, as represented by the intima-media thickness, locally. The major findings of our studies are discussed below.

In a pilot study, we observed a decrease in relative and absolute distension of the femoral artery during the luteal phase of the menstrual cycle. Because in this phase of the cycle the women were examined with a full bladder to establish follicle presence and to measure follicle size, an additional study was performed to assess whether a full bladder influenced dynamic artery wall properties. This study, performed on healthy volunteers, revealed a significant lower distension in the femoral artery (by approximately 10\%) with a full than with an empty bladder. End-diastolic diameter of this artery, blood pressure and heart rate were comparable during both moments of assessment. A local viscerovascular reflex, causing 
vasoconstriction locally in the leg arteries $[23,24]$, is believed to be responsible for the observed effect, especially because distension in the common carotid artery was not influenced by a full bladder. Because of this observation, in all the studies described in this thesis the volunteers were asked to void before artery wall properties were determined.

The dynamic artery wall properties of the elastic carotid artery and the muscular femoral artery did not change significantly during the normal mernstrual cycle of healthy young volunteers.

In a group of healthy young volunteers, the use of an oral contraceptive $1 \mathrm{OC}$; Femodeen) did not affect dynamic artery wall properties of the carotid or the femoral artery after three months of use. Plasma hormone levels of 17/-oestradiol and progesterone were significantly different between the normal menstrual cycle and the OC-period. The relative short duration of use may have been of influence, because women tend to take oral contraceptives for a considerable longer time and it is possible that changes in artery wall behaviour due to oral contraceptives occur only after longer usage.

The findings in our studies on the effect of the menstrual cycle or $\mathrm{OC}$ use indicate that neither endogenous nor exogenous female sex hormones can be held responsible for the observed discrepancies in artery wall properties between men and women in the fertile life period in the various studies. Other explanations for these discrepancies may be the differences in the methods used to assess artery wall properties and/or the site of measurement along the arterial tree (Introduction, Table 1). Elastic arteries, like the aorta and the carotid arteries, exhibit a different artery wall behaviour than muscular arteries like the femoral arteries located more peripherally from the heart [25]. The elastic arteries predominantly store volume energy, limiting uncreases in blood pressure, while muscular arteries are predominantly conduit arteries, being more subject to external influences than elastic arteries, because of the larger number of smooth muscle cells present in their walls. Therefore, care has to be taken in comparing measurements obtained from different types of arteries. Also, comparing local and general measurements may obscure conclusions, because dynamic artery wall properties are known to vary along bifurcations [26-28] Therefore, local measurements and measurements made over a larger part of the vascular tree, as by assessing pulse wave velocity, are difficult to compare. In the latter approach the time needed by the pulse wave to travel along the arterial tree, relative to the distance is determined. This method requires a large number of measurements to achieve an accurate estimate while only the distensibility can be computed by means of the Moens-Korteweg equation [29]. Moreover, this method inherently averages over segments of elastic and muscular arteries. A clear advantage is that the measurement can be performed independently from blood pressure measurements. 
We hypothesized that oestrogen-deficiency may influence dynamic properties of arteries as well as their structure after the fertile life period. Therefore, to assess the effects of exogenous female hormones in menopauze (hormone replacement therapy: HRT) on artery wall structure, we developed a new method to measure IMT locally simulaneously with the assessment of artery wall properties. The reasons for measturing locally have been given above. In vitro studies showed that IMT, ranging from $350-1000 \mu \mathrm{m}$, can be measured with high accuracy and great reproducibility. In vivo a very good correlation was found between this technique and the method most frequently used to measure IMT [30]. A good intersession reproducibility was observed in young as well as in older subjects. One of the main advantages of our method is that IMT can be measured locally and simultaneously with dynamic artery wall properties in the same setting. Local assessment of IMT adds to our understanding of vascular adaptation as documented by the finding that local IMT is significantly larger at the bifurcation of the carotid artery than 1 and $2 \mathrm{~cm}$ more proximal in the common carotid artery [31]. It is of interest to note that these local differences in IMT are associated with local differences in wall shear rate, shear rate being lower near the bifurcation than more upstream [32].

Cardiovascular disease (CVD) affects women less commonly than men of comparable age. In the menopause, however, women tend to catch up with men as far as the incidence of cardiovascular disease is concerned. There is increasing evidence that this higher risk is related to oestrogen deficiency in the menopause [33]. Decreased arterial compliance in women after menopause and compared to men (approximately 52 years and older), as observed in the study of Laogun et al and Hansen et al, may have been the result of decreasing levels of endogenous female sex hormones after the menopausal transition $[3,9]$. Therefore, we investigated the effect of HRT on artery wall properties and arterial IMT in menopausal women. Postmenopausal volunteers on sequentially combined HRT (a daily regime of $2 \mathrm{mg}$ of micronised oestradiol sequentially combined with a 16-28 day regime of $25-50 \mu \mathrm{g}$ of gestodene) were compared to age- and postmenopausal duration matched controls. The findings in this study indicate that HRT has no influence on compliance and distensibility of the common carotid and common femoral arteries as well as on IMT in the common carotid artery after 96 weeks of treatment. However, HRT significantly increased absolute and relative distension (strain) of the common carotid artery. That this effect may be related to hormone substicution is indicated by the observation that distension is reduced in postmenopausal women not taking any HRT [34]. The absence of an effect of HRT on IMT might be partly explained by a hypothetically sllower adaptation of structural than functional changes, especially when one considers that women tend to catch up with men regarding the risk of cardiovascular disease a decade after the menopausal transition. The pulsatility index of the uterine artery only revealed a 
significant decrease during the first two weeks of oestrogen-only therapy, while the addition of gestodene during day 16-28 of each cycle rendered the still present decrease no longer statistically significant. The counteractive effect of progestagens on uterine circulation is in agreement with some studies $[35,36]$, but in disagreement with others $[37,38]$. It may quite well be that the type of progestagen used may be the cause of this discrepancy [39]. Gestodene, a 19-nortestosterone derivative, is a progestagen with a relatively low androgenic biophysical profile $[40,41]$.

HRT beneficially affected the lipid profile, inducing significantly lower LDLand non-significantly higher HDL-levels. Total cholesterol levels decreased significantly, while triglyceride levels increased non-significantly. Meta-analysis showed that the effect of HRT on the lipid profile may account for approximately $25-50 \%$ of the decrease in cardiovascular disease observed in women on HRT [42].

\section{Conclusions}

Based upon the findings in our studies, the following conclusions may be drawn:

- neither endogenous (menstrual cycle) nor exogenous (OC use for 3 months) changes in plasma hormone concentrations significantly affect the dynamic properties of the common carotid and common femoral arteries

- HRT may be helpful in reducing cardiovascular risk in postmenopausal women as indicated by the beneficial effects on absolute and relative distension (strain) and the lipid profile

- intima-media thickness can be assessed reliably locally and in time, opening new areas of research to study the relation between artery wall function and structure locally

- intima media thickness was found to vary substantially along arteries

- when examining artery wall behaviour in the femoral artery, the bladder must be empty, because the dynamic artery wall properties of the common femoral artery are affected by a full bladder probably due to a local viscerovascular reflex

\section{Future research}

To further elucidate the role of female sex hormones in the increased cardiovascular risk, a longer term study (>5 yr.) on the effect of HRT in menopausal women on artery wall structure and function in a larger randomized study group is needed. The sensitivity of the measurements may be improved by the comparison of $\mathrm{CC}$ and DC under isobaric conditions. Evenso, the absence of an effect of $\mathrm{OC}$ on dynamic artery wall properties should be confirmed in a longitudinal study of 
longer duration. Furthermore, static and dynamic wall components should be investigated and quantified in larger detail by pressure-diameter loops. Local reliable non-invasive assessment of arterial blood pressure together with intima-media thickness, distension and shear forces will further enhance our understanding of the complex mechanisms involved in the adaptation of arteries to a changing (humoral) environment.

\section{References}

1. London GM: Influence of sex on arterial hemodynamics and blood pressure. Role of body height. Hypertension. 1995;26(3):514-9.

2. Francois B: Alteration in arterial wall elasticity in the young. Clin Gen. 1983;24:287.

3. Laogun AA, Gosling RG: In wiwo arterial compliance in man. Clin Phys Physiol Meas. $1982 ; 3(3): 201-12$.

4. Merode van T, Hick PJ, Hoeks APG, Smeets FAM, Reneman RS: Differences in carotid artery wall properties berween presumed-healthy men and women. Ultrasound Med Biol. 1988;14(T): $571-4$.

5. Riley WA, Bames RW, Schey HM: An approach to the non-invasive periodic assessment of arterial elasticity in the young. Prevent Med. 1984;13:169-84.

6. Riley WA, Barnes RW, Evans GW, Burke GL: Ultrasonic measurement of the elastic modulus of the common carotid artery - the Atherosclerosis Risk in Communities (ARIC) study. Stroke. $1992 ; 23(7): 952-6$

7. Sonesson B, Hansen F, Stale H, Länne T: Compliance and diameter in the human abdominal. aorta-- the intluence of age and sex. Eur J Vasc Surg. 1993;7(6):690-7.

8. van Merode T, Hick PI, Hoeks APG, Smeets FAM, Reneman RS: Differences in carotid artery wall properties between presumed-healthy men and women. Ultrasound Med Biol. $1988 ; 14(7): 571-4$

9. Hansen $F$, Mangell $P$, Sonesson $B$, Länne $T$ : Diameter and compliance in the human common carotid artery - variations with age and sex. Ultrasoland Med Biol. 1995;21(1): 1.9.

10. Lin AL, Shain SA: Estrogen-mediated cytoplasmic and nuclear distribution of rat cardiovascular estrogen receptots. Arteriosderosis. 1985;5(6):668-77.

11. Lin AL, Gonzalez R, Jr., Carey KD, Shain SA: Estradiol-17 beta affects estrogen receptor distribution and elevates progesterone receptor content in baboon aorta. Arteriosclerosis. $1986: 6(5): 465-504$.

12. Lin AL, Gonzalez R, Jr, Carey KD, Shain SA: Gender and baboon anortic steroid homone receptors. Arteriosclerosis. 1987;7(3),248-55.

13. Campisi D, Bivona A, Paterna $S$, Valenza M, Albiero $\mathbb{R}$ : Oestrogen binding sites in fresh human aortic tissue. Int J 'Tissue React. 1987;9(5):393-8.

14. Perrot Applanat M, Groyer Picard MT, Garcia E, Lorenzo F, Milgrom E: Immunocytochemical denonstration of estrogen and progesterone receptors in muscle cells of uterine arteries in rabbits and humans. Endocrinology. 1988;123(3):1511-9.

15. Baysal K, Losordo DW: Oestrogen receptors and cardiovascular disease. Clin Exp Pharmacol Physiol. 1996;23:537-48.

16. Collins P, Beale CM, Rosano GMC: Oestrogen as a calcium channel blocker Eur Heart J. 1996;17(Suppl D):27-31. 
17. Fischer GM, Swain ML: Effects of estradiol and progesterone on the increased synthesis of collagen in atherosclerotic rabbit anortas. Arherosclerosis. $1985 ; 54: 177-85$.

18. Cox RH, Fischer GM: Effects of sex homones on the passive medanical properties of tat carotid arteries. Blood Vessels. 1978; $15266-76$.

19. Clarkson TB, Shively CA, Morgan TM, Korimik DR. Adams MR, Kaplan JR. Onal contraceptives and coronary artery atheroselerosis of cynomolgus nonkeys. Obstet Gymecol. $1990 ; 75(2): 217-22$.

20. Kushawa RS, Lewis DS, Carey KD, McGill Jr HC: Effects of estrogen and progesterone on plasma lipoproteins and experimental atherosclerosis in the baboon (Papio sp.). Arteriosd Thromb. 199:1;11(1):23-31.

21. Bots ML, Hofman A, Grobbee DE: Increased common carotid intima-media thickness. Adaptive response or a reflection of atherosclerosis? Findings from the Rotterdam study. Stroke. $1997 ; 28(12): 2442-7$

22. Zarins CK, Giddens DP, Bharadvaj BK, Sotrinrai VS, Mabon RF, Glagov S: Carotid bifurcation atherosclerosis. Quantitarive correlation of plaque localization with fow velocity profiles and wall shear stress. Circ Res. 1983;53:502-14.

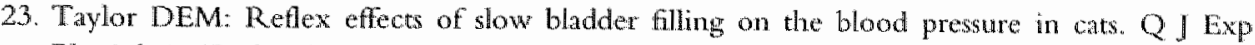
Physiol. 1965;50:263-70.

24. Taylor DEM: Afferent pathways and efferent mechanisms in the bladder viscerovascular reflex. QJ Exp Physiol. 1968;73:425-37.

25. Nichols WN, O'Rourke MF MeDonald's blowd flou in arteries. London: Edward Arnold; 1990.

26. Reneman RS, van Merode 'T, Hick PJ, Hoeks APG: Flow velocity patterns in and distensibility of the carotid artery bulb in subjects of various ages. Circulation. 1985;12:465-71.

27. Merode van $T$, Brands $P J$, Hoeks APG, Reneman RS: Faster ageing of the carotid artery bifurcation in borderline hypertensive subjects. J Hypertens. 1993;11(2):171-6.

28. van Merode T, Brands PJ, Hoeks APG, Reneman RS: Different effects of ageing on elastic and muscular arterial bifurcations in men. J Vasc Res. 1996;33(1):47-52.

29. Hoeks APG, Brands PJ, Willigers JM, Reneman RS: Non-invasive measurement of mechanical properties of arteries in health and disease. Proc Instn Mech Engrs. 1999;21:3(H):195-202.

30. Willekes $C$, Bots ML, Brands PJ, Willigers JM, Hoeks APG, Reneman RS: Evaluation of off-line automated intima-media thickness detection of the comnon carotid artery based on M-line signal processing. Ultrasound Med Biol. 1999;25(1):57-64.

31. Willekes $\mathrm{C}$, Brandid PJ, Willigers JM, Hoeks APG, Reneman RS. Assesment of local diperences in intimamedis thickness in the human common carotid artery. J Vasc Res. $1999 ; 36: 222-8$.

32. Komet $L_{x}$ Lambregts JAC, Hoeks $A P G$, Reneman RS: Differences in near-wall shear rate in the carotid artery within subjects are associated with different intima-media thicknesses. Arterioscler Thromb Vasc Biol. 1998;18(12): 1877-84.

33. Coldiz GA, Willet WC, Stampfer MJ, Rosner B, Speizer FE, Hennekens CH: Menopause and the risk of coronary heart disease in women. N Eng J Med. 1987;316(18): 1105-10.

34. Westendorp ICD, Bots ML, Grobbee DE, Reneman RS, Hocks APG, Van Popele NM, Hofman A, M. WJC: Menopausal status and distersibility of the common carotid artery. Arteriosclet Thromb Vasc Biol. 1998;19(3):713-7.

35. Marsh MS, Boume TH, Whitehead MI, Collins WP, Camplell S: The temporal effect of progestogen on viterine artery pulsatility index in postmenopausal women receiving sequential hormone replacement therapy. Ferci Steril. 1994:62(4):771-4.

36. Hillard TC, Bourne TH, Whitehead MI, Crayford TB, Collins WP "Campbell S: Differential effects of transdemal estradiol and sequental progestogens on impedance to flow within the uterine arteries of postmenopausal women. Fertil Steril. 1992;58(5):959-63. 
37. Cacciatore $\mathrm{B}$ Pakkar I, Twivonen J, Tikkanen $\mathrm{M}$, Ylikorkala $\mathrm{O}$ : Randomized comparison of oral and trangdermal hormone replacement on carotid and utereine artery resistance to blood flow Obstet Gynecol $1998,92(4 \mathrm{Pt} 1): 563-8$.

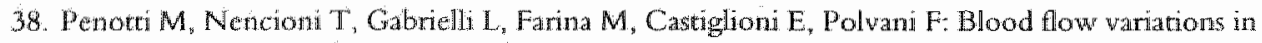
internal carotid and middle cerebral arteries induced by postmenopausal hormone replacement therapy. Am J Obstet Gynecol. 1993;169(5):1226-32.

39. Bonilla-Musoles F, Martí MC, Ballester MJ, Raga F, Osbome NG: Nomal uterine arterial blood flow in postmenopausal women assessed by transvaginal color Doppler ultrasonography. J Ultrasound Med. 1995:14(7):491-4.

40. Wilde MI, Balfour JA: Gestodene. A review of its pharmacology, efficacy and tolerability in combined contraceptive preparations. Drugs. 1995,50(2):364-95.

41. Kuhl H: Comparatiwe phamacology of newer progestogens. Drugs. 1996;51 (2):188-215.

42. Bush TI, Barrett Connor E, Cowan LD, Criqui MH, Wallace RB, Suchindran CM. Tyroler HA, Rifkind BM: Cardiovascular mortality and noncontraceptive use of estrogen in women: results from the Lipid Research Clinics Program Follow-up Study, Circulation. 1987;75(6): $1102-9$. 


\section{Summary}

In humans, distensibility and compliance of especially elastic arteries in the human body decreases during normal ageing. As a consequence, systolic and pulse pressure (i.e. the difference between systolic and diastolic blood pressure) increase as well as the workload of the heart. It has been a matter of debate whether there are differences between men and women in this respect. Discrepancies in literature may be due to not considering the influence of female sex hormones, as might occur during the menstrual cycle and the use of birth control pills. Evenso, women catch up with men regarding the risk of cardiovascular disease in the menopause. Previous studies have shown a decrease in arterial distensibility in the menopause. This is likely, because functional sex hormone receptors are, amongst others, present in the endothelium and vascular smooth muscle cells of large arteries.

It was the aim of this thesis to study the possible influence of female sex hormones as during the menstrual cycle, the use of the oral contraceptive pill and hormone substitution in the menopause on artery wall properties. In these phases in a woman's life, a distinction can be made between different levels of various types of (endogenous and exogenous) female sex hormones. We did not only investigate non-invasively the effect on dynamic function, as distensibility and compliance, but also on artery wall thickness. To this end a new ultrasound technique was developed allowing the local assessment of intima-media thickness simultaneously with artery wall function. The performance of this new technique was evaluated. The studies in this thesis were performed on the common carotid and common femoral arteries.

In chapter 2, the short term effects of physiologically changing female sex hormone levels during the normal menstrual cycle on artery wall properties are described. In five different phases of low and/or high oestrogen and progesteron blood plasma levels, the wall properties of the elastic common carotid and the muscular common femoral artery were investigated. Despite significantly changing female sex homone levels during ultrasonographically proven ovulatory cycles, no short term effects on the dynamic wall properties of these arteries could be detected. Therefore, examination of arteries at different moments in the menstrual cycle does not provide an explanation for the difference in artery wall properties between men and women, as described in previous studies. 
In chapter 3 an observation made during the study described in chapter 2 is explored. While investigating artery wall properties during the menstrual cycle, transabdominal assessment of follicle presence and size required a full bladder. The size of the developing follicle and subsequent disappearance were used to determine the phase of the menstrual cycle and to monitor the time of ovulation. During this examination we did get the impression that bladder filling influenced femoral artery wall properties. Indeed, femoral artery distension was lower in menstrual cycles with a full bladder than in cycles with an empty bladder; the properties of the common carotid artery were not influenced under these circumstances. This observation in the femoral artery can possibly be explained by a local viscerovascular reflex during bladder filling, leading to increased local sympatheric tone. We concluded that bladder filling leads to stiffer femoral artery wall behaviour without measurable vasoconstriction.

In chapter 4 a study on the effect of exogenous female sex hormones on artery wall properties is described. In a group of healthy female volunteers the effect of an oral contraceptive (Femodeen, Schering) was investigated on the dynamic artery wall properties of large elastic and muscular arteries. Artery wall distensibility of the carotid and femoral artery was determined before and after three months of use of this so-called third generation oral contraceptive. Three months of Femodeen administration did not affect wall properties in these arteries, also not at short term between the third week of pill use and the stopweek. In previous studies, three months use of an oral contraceptive significantly increased blood pressure. This effect could not be confirmed in our study. The type of progestagen (gestodene) in the oral contraceptive as used in our study has little androgenic properties. This may explain the absence of a rise in blood pressure, which can be seen as a positive effect. Therefore, the use of an oral contraceptive can also not be held responsible for the difference in artery wall behaviour as observed between men and women.

In chapter 5 a newly developed non-invasive method to determine intima-media thickness (IMT) and dynamic artery wall properties at the same site of the vessel is described. Assessment at the same site is important, because IMT and dynamic function changes along the arterial tree. Only IMT was determined, because the outer layer of the artery wall, the adventitia, cannot be discerned easily from the surrounding tissue using ultrasound. The new technique to assess IMT was evaluated in vitro and in vivo. The technique is based on temporal averaging of the radiofrequency ultrasound signals received along a single line of observation. A laboratory setting was designed to assess the reliability as well as the reproducibility of the method. Using raw radiofrequency signals it is possible to measure the difference in distance between two layers of rubber stretched over a wire, mimicking the artery wall layers. The distance between both layers was varied between 0.3 and $1.0 \mathrm{~mm}$ using steps of 50 micrometer. The method was 
found to be accurate and reproducible in this laboratory setting. In vivo, IMT was determined in volunteers within one session. Little intrasession variation in IMT (standard error of the estimate: in vitro; $0.020 \mathrm{~mm}$, in vivo; $0.045 \mathrm{~mm}$ ) was found.

In chapter 6 the newly developed method was compared with already established methods to measure IMT. Male and female volunteers of both young and older age were compared using four different methods to assess IMT. First, the method was used in combination with two different ultrasound devices exhibiting different resolutions, to assess the effect on the measurement algorithm, if any. Second, the method was compared with the technique using calipers, placed on the ultrasound image to measure IMT, using ultrasound devices displaying adequate zoom capacity. Finally, a comparison was made with the established method based on video-image analysis. Our method and the established methods were comparable in performance. Using two different ultrasound devices did not affect the measurement algorithm. Much to our surprise, placing calipers on the ultrasound image compared equally well with all other methods. A cautious conclusion could be that the predominant restrictive factor in the manual methods is the accuracy of the investigator which is avoided in an automated technique as developed by us.

In chapter 7 a study on the reproducibility of our method to measure IMT in time is presented. Also, the number of measurements needed to perform to reach significant conclusions regarding differences in time was estimated. Differences in IMT, if any, over short segments (i.e., $2 \mathrm{~cm}$ ) in the carotid artery were determined to explore whether local differences in IMT could be assessed. From our data it may be concluded that our intersession intralocation repeatability coefficient $(0.069 \mathrm{~mm}$ in the young group, $0.109 \mathrm{~mm}$ in the old group) is high enough to perform follow-up studies. Also, differences in IMT between the carotid artery bifurcation and $2 \mathrm{~cm}$ more upstream could be determined, especially in the younger age group. The difference in IMT over such a short artery segment may be explained by differences in wall shear stress at the two sites of measurements.

In chapter 8 a study is described, in which the effect of long term administration of female sex homones on artery wall properties, IMT and peripheral resistance in the uterine artery of women in the menopause is investigated. Before starting hormone replacement therapy when very low levels of female sex hormones were detected (at least one year after the menopausal transition) in venous blood plasma, IMT and dynamic artery wall properties were investigated. Then the subjects received hormone replacement therapy (HRT) containing two milligram of micronised oestradiol and 25-50 microgram of gestodene during approximately two years. At different moments in time with corresponding higher levels of oestrogen and progestagen, additional measurements were performed. To exclude ageing effects, a control group was included to determine the same 
end-points. At the end of the study no significant effect on IMT and Young's modulus (as a measure of intrinsic ellastic properties of the artery wall) could be detected. Relative (=strain) and absolute change in diameter (=distension) per heartbeat was decreased significantly after two years of HRT in the carotid artery, but not in the femoral artery. However, a significant increase in mean arterial pressure in the HRT group as observed in our study, may partly be responsible for the observed effect on distensibility. In the initial oestrogen-only phase, peripheral resistance in the uterine artery decreased significantly. During the oestrogen-progesterone combined phase a slighter decrease in peripheral resistance in the uterine artery was observed, not reaching the initial significant decrease in the first two weeks of HRT. In the HRT group, total cholesterol, LDL and the LDL/HDL-ratio decreased significantly after two years of HRT. No significant changes in the lipid profile could be determined in the control group. These results are in accordance with previous studies on HRT and the lipid profile.

In conclusion, the findings in our study indicates that meither endogenous nor exogenous female sex hormones can be held responsible for the previously observed discrepancies in artery wall properties between men and women. It can not be excluded, however, that longer use of exogenous female sex hormones (as in birth control pills) may influence artery wall properties.

HRT in menopausal women improves distension and strain of the carotid artery, which may be considered as beneficial, because it will reduce the workload of the heart. Whether this improvement of artery wall properties in combination with the improved lipid profile explains the lower risk of atherosclerotic disease in menopausal women receiving HRT remains subject to further investigation. 


\section{Samenvatting}

Bij normale veroudering neemt de rekbaarheid van met name de elastische bloedvaten in het menselijk lichaam af. Als gevolg daarvan stijgt de bovenbloeddruk en de polsdruk (het verschil tussen de bovenbloeddruk en de onderbloeddruk) en daardoor ook de belasting voor het hart. Of er verschil is in vaatwandrekbarheid bij mannen en vrouwen is nog onderwerp van discussie. In de literatuur beschreven verschillen kunnen het gevolg zijn van het feit dat het effect van vrouwelijke geslachtshormonen, zoals gedurende de normale menstruele cyclus en het gebruik van de pil, niet in beschouwing zijn genomen. Ook vindt bij vrouwen in vergelijking met mannen na de overgang een inhaalrace plaats ten aanzien van het risico voor hart- en vaatziekten. In eerdere studies is aangetoond dat de absolute en relatieve verandering in diameter per hartslag van de vaatwand daalt na de overgang. Dit is opnieuw een indicatie dat vrouwelijke geslachtshomonen invloed kunnen hebben op de vaatwandeigenschappen, temeer omdat er functionele geslachtshormoonreceptoren gevonden zijn in de endotheellaag en gladde spiercellen van de grote slagaders.

Het doel van dit proefschrift was om mogelijke effecten op te sporen van vrouwelijke geslachtshormonen op de vaatwandeigenschappen gedurende de normale menstruele cyclus, pilgebruik en hormoonsubstitutie na de overgang. In deze fasen in een vrouwenleven kan er onderscheid gemaakt worden tussen wisselende spiegels wan verschillende types (endogene en exogene) geslachtshormonen. Om niet alleen een uitspraak te kunnen doen over eventuele effecten op dynamische vaatwandeigenschappen, maar ook over effecten op structurele vaatwandveranderingen werd een nieuwe meetmethode ontwikkeld, waarmee vatwanddikte (de intima-media dikte) bepaald kan worden. Met deze nicuwe methode, die gebruik makt van ultrageluid, kan tegelijkertijd met de vaatwandrekbarheid de intima-media dikte op dezelfde plats gemeten worden. Deze nieuwe techniek wordt eveneens in dit proefschrift beschreven en de toepasbaarheid geëvalueerd. De studies in dit proefschrift werden verricht op de hals-en liesslagaders bij mensen.

In hoofdstuk 2 worden de korte termijn effecten van fysiologisch wisselende geslachtshormoonspiegels gedurende de normale menstruele cyclus op de vatwandeigenschappen beschreven. In vijf verschillende fases met een lag en/of een hoog oestrogeen en progesteron bloedplasma gehalte, werd gekeken naar de vaatwandeigenschappen van de elastische arteria carotis communis (-halsslagader) en de musculaire arteria femoralis communis (=liesslagader). Ondanks significant 
verschillende hormoonspiegels bij echoscopisch bewezen ovulaties (=eisprong) werd er geen korte termijn effect gemeten op de dynamische vaatwandeigenschappen van de boven genoemde bloedvaten. De metingen in verschillende fases van de menstruele cyclus leveren dan ook geen verklaring op voor de gerapporteerde verschillen tussen mannen en vrouwen.

In hoofdstuk 3 wordt een bevinding uit hoofdstuk 2 uitgediept. Bij het onderzoek naar de vaatwandeigenschappen gedurende het eerste deel van de cyclus moesten de proefpersonen een volle blaas hebben omdat er via de buik gekeken werd naar de grootte van rijpende eitjes in de eierstokken. Dit was nodig on de cyclus goed in kaart te kunnen brengen en het tijdstip van de eisprong optimaal te bepalen. Gedurende dit onderzoek kregen we de indruk dat blaasvulling een invloed had op de vaatwandeigenschappen van de liesslagader. De vaatwandrekbaarheid van de liesslagader was lager gedurende cycli mét volle blaas dan gedurende cycli gemeten zónder blaasvulling; dit effect werd niet gezien in de halsslagader. De meest waarschijnlijke verklaring voor het gevonden verschil is een locale vesicovasculaire (=blaas-vaat) reflex bij een volle blaas warbij de locale sympaticotonus verhoogd is. Dit veroorzaakt naar ons idee een stijver vaatgedrag zonder dat er al een meetbare vaatvernauwing ontstaan is.

In hoofdstuk 4 wordt het effect van exogene geslachtshormonen op vaatwandeigenschappen beschreven. In een groep gezonde vrijwilligsters werd gekeken naar het effect van pilgebruik (Femodeen, Schering) op de dynamische vaatwandeigenschappen van grote elastische en musculaire bloedvaten. Vaatwandrekbalarheid van de hals- en liesslagaders werden gemeten vóór en ná drie maanden gebruik van deze zogenaamde derde generatie pil. Drie maanden gebruik van Femodeen had geen effect op de vaatwandeigenschappen van deze bloedvaten, ook niet op korte termijn gedurende de derde week van pilgebruik vergeleken met de stopweek. In eerdere studies is beschreven dat er bij het gebruik van laag gedoseerde pillen na drie maanden reeds een significant effect op de bloeddruk werd gezien. Dit kon in onze studie niet bevestigd worden. Echter het type progesteron (gestodeen) in de pil van onze studie heeft weinig mannelijke eigenschappen wardoor het wegblijven van een stijging van de bloeddruk als gunstig effect gezien kan worden. Het gebruik van de pil door vrouwelijke vrijwilligsters is derhallve geen verklaring voor het verschil in vaatwandgedrag tussen vrouwen en mannen.

In hoofdstuk 5 wordt een nieuwe niet-invasieve meetmethode beschreven welke naast dynamische vatwandeigenschappen ook de vaatwanddikte op dezelfde plaats kan bepalen. Dit is met name interessant omdat vaatwanddikte en functie van plaats tot plaats in het arteriële systeem verschillen. Omdat de buitenste laag van de vatwand, de adventitia, echoscopisch slecht af te grenzen is van zijn omgeving, moesten we ons beperken tot het meten van de dikte van de twee 
overige vaatwandlagen, de intima en de media. Onze nieuwe vatwanddikte methode werd in vitro zowel als in vivo beproefd. De techniek is gebaseerd op het middelen in de tijd van de ruwe radiofrequente echosignalen langs een enkele meetlijn. Een laboratoriumopstelling werd ontworpen om de betrouwbarheid en de reproduceerbaarheid te testen. Met behulp van ruwe radiofrequente signalen bleek het mogelijk om de afstand tussen twee rubberen lagen gescheiden door een waterlaag in een watertank (de bloedwatwand voorstellend) te meten. Om een mogelijke spreiding van menselijke vaatwanddiktes te imiteren werd met vaste stappen van 50 micrometer over een bereik van 0.3 tot $1.0 \mathrm{~mm}$ de afstand gemeten. In de laboratoriumopstelling bleek onze methode nauwkeurig en reproduceerbaar te zijn. In vivo werd in een groep jonge vrouwen bij herhaling gemeten. Met onze methode kon weinig verschil in vatwanddikte binnen een sessie gevonden worden (standaardfout van de meting: in vitro $0.020 \mathrm{~mm}$, in vivo $0.045 \mathrm{~mm}$ )

In hoofdstuk 6 werd de nieuw ontwikkelde methode vergeleken met reeds gevestigde methodes om vaatwanddikte te meten. In verschillende groepen mannelijke en vrouwelijke vrijwilligers van jongere en oudere leeftijd zijn 4 verschillende methodes voor het meten van de vaatwanddikte met elkar vergeleken. Allereerst werd onze nieuwe methode getest op twee verschillende apparaten met een verschillend oplossend vermogen om te zien of er enig effect was van echogedrag op het meetalgoritme. Vervolgens werden calipers op het echobeeld gezet om op een relatief eenvoudige manier de vaatwanddikte te bepalen op echo-apparaten met voldoende zoomvermogen. Tenslotte maakten we een vergelijking met de geldende methode die gebaseerd is op een off-line computeranalyse van het echobeeld. Het bleek dat onze nieuwe methode vergelijkbare meetresultaten opleverde als de geldende methode. Het meten met rwee verschill= lende echo-apparaten wees uit dat er geen invloed was van het verschillend echogedrag op het meetalgoritme. Tot onze verrassing bleek dat het meten met calipers op het echobeeld vergelijkbare resultaten opleverde als de overige meetmethodes. Een voorzichtige conclusie zou kunnen zijn dat de meest bepalende factor bij het manueel meten van vaatwanddiktes de nauwgezetheid van de onderzoeker is bij het uitvoeren van deze metingen. In een geautomatiseerde methode als door ons ontwikkeld wordt de mogelijke onnauwkeurigheid geintroduceerd door de onderzoeker uitgesloten.

In hoofdstuk 7 wordt een studie naar de reproduceerbaarheid in de tijd van de door ons ontwikkelde methode on vaatwanddikte te meten gepresenteend. Ook werd het aantal metingen dat nodig is om een uitspraak te doen over gevonden veranderingen in de tijd berekend. Tevens werd gekeken naar de verschillen in vaatwanddikte over een kort stuk $(2 \mathrm{~cm})$ in de halsslagader, om te zien of het mogelijk is om lokale verschillen op te sporen. Uit ons onderzoek 
$142]^{\text {Santerwatung }}$

bleek dat de reproduceerbaarheid tussen sessies in de tijd, op dezelfde plats gemeten, voldoende is on follow-up studies uit te voeren (reproduceerbaarheidscoefficiènt: $0.069 \mathrm{~mm}$ in de jongere leeftijdscategorie, $1.09 \mathrm{~mm}$ in de oudere leeftijdscategorie). Daamaast kon ook een significant verschil, met name in de jongere leeftijdscategore, in vatwanddikte gemeten worden in de halsslagader net vóor de splitsing van de halsslagader en 1 en 2 centimeter stroomopwaarts. Naar onze mening zijn verschillen in afschuifsnelheid op deze plaatsen in de a. carotis verantwoordelijk voor deze lokale verschillen in vatwanddikte.

In hoofdstuk 8 wordt een studie beschreven nar het lange termijn effect van vrouwelijke geslachtshormonen op vaatwandeigenschappen, vaatwanddikte en perifere weerstand in de baarmoederslagader bij vrouwen na de overgang. Allereerst werd bij vrouwen met nagenoeg geen enkele eigen hormoonproductie (minimaal een jaar na de overgang) het dynamische en structurele vaatgedrag gemeten voordat begonnen werd met hormoonsubstitutie. De proefpersonen kregen hormoonsubstitutie in de vorm van 2 milligram gemicroniseerd oestradiol gecombineerd met 25-50 microgram gestodeen gedurende bijna twee jaar. Op verschillende momenten in de tijd corresponderend met verschillende niveaus in hormoonspiegels van oestrogeen en progestageen werden metingen uitgevoerd. Om effecten wan veroudering uit te sluiten werd er gebruik gemaakt van een controlegroep waarbij dezelfde eindpunten bepaald werden. Aan het eind van de studie werd geen effect op de vaatwanddikte en de Young's modulus (maat voor de intrinsieke vaatelasticiteit) gemeten. Wel werd na bijna twee jaar hormoongebruik een significante verbetering van de relatieve (=rek) en absolute verandering in diameter per hartslag (=distensie) in de halsslagader gevonden. De liesslagader vertoonde deze verandering niet. In de hormoonsubstitutie groep steeg de gemiddelde bloeddruk echter significant, waarmee een deel van het effect op de distensie verklaard zou kunnen worden. In de hormoongroep was er alleen op korte termijn een toename in de lokale bloedstroom naar de baarmoeder, warbij de fase met alleen oestrogeen de grootste toename liet zien. Tijdens het gebruik van progesteron was er een lichte afname van de perifere weerstand in de arterie die de baarmoeder van bloed voorziet. Op langere termijn leek de relatieve toename in bloedstroom iets af te nemen, echter zonder dat het niveau van vóór de start van de hormoontherapie bereikt wordt. In de hormoongroep daalde het totale cholesterol, het LDL en de LDL/HDL-ratio, terwijl er in de controlegroep geen significante veranderingen werden gevonden. Dit bevestigt de eerdere rapportages van gunstige effecten van hormoonsubstitutie op het lipidenprofiel.

Concluderend: De eerder beschreven verschillen in vatwandgedrag tussen mannen en vrouwen kunnen niet verklaard worden door een verschil in homoonspiegels gedurende de menstruele cyclus en pilgebruik. Het is mogelijk dat langer gebruik van exogene vrouwelijke geslachtshormonen (zoals bijvoor- 
beeld de pil) een effect op het (structureel) vaatwandgedrag heeft. Hormoonsubstitutie bij vrouwen in de overgang verbetert de relatieve en absolute rekbaarheid van de halsslagader, wat gezien kan worden als een positief effect, omdat de werkbelasting van het hart zou kunnen verminderen. Of deze verbetering in vaatwandeigenschappen in combinatie met het verbeteren van het lipidenproifiel het lagere risico op hart- en vaatziekten bij vrouwen met hormoonsubstitutie kan verklaren blijft een onderwerp voor nader onderzoek. 


\section{Dankwoord}

"I thank you from the botrom of my werus. That's like the bottom of my heart, only decper."

Hoe moeilijk is het om op papier tot nitdrukking te brengen wat je voelt en hoe je bepaalde mensen wardeert. Het meeste is al gezegd, maar een aantal zaken moeten me nog even van het hart:

Beste Rob, je wist mij al die jaren te motiveren en te inspireren. Ook moest je wel eens helpen relativeren wanneer ik weer teleurgesteld met mijn hoofd on de deur kwam om te vertellen dat er niet zo veel uit mijn metingen kwam. "Geen resultat is ook resultaat" was dan je gevleugelde antwoord. Bedankt voor al je geduld en het meedelen in jouw kennis en ervaring. Je hebt vele deuren voor me geopend.

Beste Arnold, aanvankelijk voelde ik me heel dom en onwetend rijdens de besprekingen, iedere keer als jij an het woord was. Maar zelfs iemand die vroeger een hekel aan natuurkunde had kan uiteindelijk lol krijgen in de biofysica, zeker als jij weer heel raak in enkele woorden de situatie wist uit te leggen. Vergeef me als het af en toe wat lang duurde voordat het kwartje viel. Bedankt voor alle verhallen, ins en outs en gezellige besprekingen die me iedere keer weer wisten op te beuren en te motiveren.

Beste Henk, ailereerst moet ik je bedanken voor mijn promotieplek warop. jij me als eerste attendeerde. Ik was al bijna op weg nar Eindhoven om daar mijn praktische loopbaan te vervolgen toen jij me tipte als kandidaat voor de AIO-baan waar ik nu uiteindelijk op promoveer. Gedurende onze samenwerking was jij de man met de goede ideeën. Op multimedia en praktiserend echogebied was jij degene die het voortouw nam. Op culinair vlak bleek je ook al deskundig. Bedankt ook voor de lekkere etentjes met de collega-onderzoekers.

Beste Hans, op je eigen manier wist je luister bij te zetten aan mijn onderzoek. Vele kopjes espresso zijn er bij evenvele besprekingen met genoegen in gegaan. Dat later de onderzoekslijn een andere kant opging is voor de kwantiteit van de begeleiding nadelig geweest, echter niet voor de kwaliteit.

Lieve Marga en Carolien; wandelgenoten, promotiegenoten en mu ook mijn paranimfen (terecht, wie anders!), jullie zijn de laatste jaren onmisbaar geweest. Samen lachen, samen praten, samen klagen, toen nog onder het genot van een stevige wandeling of een lekkere borrel. Marga, je was de collega die (net) zo 
"gek" was om op de gekste tijden terug te komen voor onderzoek. Samen hebben we vele uren gespendeerd an metingen, dia"s maken en voordrachten repeteren. Heb ik je ooit al genoeg bedankt voor je fijne begeleiding bij mijn bevalling(en)? Carolien, je was een van mijn eerste collega"s en later ook mijn sport- en vakantiematje war ik samen heel wat kilometers mee heb gebomd/gewandeld/ geschaatst. Dat je later ook praktisch mijn buurvrouw werd is meer dan alleen maar toeval. Ik bewonder je doorzettingsvermogen; dit jaar wordt ook jouw jaar, net als Marga!

Mijn kamergenoten door de jaren heen hebben veel moeten aanhoren in de tijd dat we dat kleine kamertje deelden. Frank, Sylvia, Henriette, Marieke, Frans, Anne en Xavier, niet alleen binnen kantooruren hebben we lief en leed gedeeld. Het streepjessysteem zorgde ervoor dat mijn sociale en culturele niveau op peil bleef. Ook mijn frans heeft er niet onder geleden.

Het meetlab was éen vergaarbak wan jeugdige juver aan onderzoeker-collega"s, WP-ers en student-assistenten. Lilian en Susan, met jullie was het goed pauzeren en discussieren. Jacques, voor alle kleine en grotere klussen warmee je me, soms tegen wil en dank, hielp. Binnenkort heb je meer tijd voor je grote passie, schilderen. Peter, Jean en Steven, jullie hielpen me in mijn strijd om de techniek te begrijpen en in de praktjjk te brengen. Onze jonge honden Marthe en Rajaa hebben de fakkel al overgenomen. Het ga jullie goed!

Mijn overburen van het laboratorium microcirculatie waar altijd een vers kopje koffie (en nog veel meer) klaarstond. Selma, Martijn, Sabrina, Ellen, Roland, Erik, Miriam en Dick (en alle anderen die ik eventueel vergeten ben), ik hoop jullie nog valk tegen te komen.

De secretaresses van de vakgroep Fysiologie, voor alle kleine en grotere boodschappen, handjes hulp en gezelligheid.

Alle andere medewerkers van Fysiologie en Biofysica, voor de samenwerking en het meedelen in de know-how. Mark Spaanderman, Timo Ekhart en Erik van Beek, voor de vele ochtend-meet-uurtjes en de vruchtbare samenwerking.

Alle vrijwillige proefpersonen van mijn onderzoek die zonder morren hun hals- en liesslagaders, bloedserum en vele uren tijd afstonden. Zonder jullie was dit proelschrift niet verschenen. Met name de HRT-en controle-dames die twee jaar lang trouw bleven komen zonder protest, bedankt!

Pie Medical/Esaote; bedankt voor alle (financiële) begeleiding, congressen, beurzen, reizen en gezelligheid, mar vooral voor de mogelijkheid om op een andere manier met ultrageluid om te gaan. Onze symbiose heeft goede vruchten afgeworpen.

De afdeling gynaecologie, minn huidige collega"s en bazen. Bedankt voor het begrip in de wat moeizame startfase na al die jaren uit de praktijk. Een nieuw tijdperk treedt nu an. 
Mijn (schoon-)familie die alle jaren mijn (langzame) progressie op de voet bleef volgen en altijd voor me klaarstond. Woorden schieten hier tekort. Met name voor de "moeders", alle uren "Jochem"--opvang en wat er nog komen zal. Mam, Pap zou ontzettend trots zijn geweest.

Gradus, jij hebt me al het mooiste gegeven wat ik me had kunnen wensen. Ik verbaas me iedere keer weer aver je vermogen om ons thuisfront als een geoliede machine te laten lopen naast je eigen baan, je eigen bedrijf en je (vrijwilligers)hobbie. De illusie dat ik het meeste "werk" heb ik all lang naast me neergelegd. Je enorme talent vader te zijn zul je in de toekomst nog veel kunnen uitoefenen.

Jochem, papa's grote vriend, binnenkort zullen we veel tijd hebben om extra van elkaar te genieten. Ik verheug me er nu al op. Dat de nieuwe baby net zo lief en gemakkelijk mag zijn als jij... 



\section{Curriculum vitae}

Christine Willekes werd op 27 maart 1966 geboren als (onverwacht) deel van een identieke tweeling in de Kweekschool voor Vroedvrouwen in Arnsterdam. In 1984 behaalde ze haar Gymmasium beta diploma aan het Stella Maris college te Meerssen. Van 1984 tot en met maart 1991 studeerde ze medicijnen aan de Universiteit van Maastricht. Vervolgens werkte ze als AGNIO in de Vroedvrouwenschool te Heerlen gedurende bijna twee jaar. Van 1993 tot 1998 was ze assistent in opleiding tot onderzoeker aan de Universiteit van Maastricht, bij de vakgroepen Fysiologie en Biofysica. Vanaf oktober 1998, na de geboorte van haar eerste kind (Jochem), is ze in opleiding tot gynaecologe in het Academisch Ziekenhuis Maastricht (opleider: Prof. J.L.H. Evers). Ten tijde van de verdediging van haar thesis is ze 35 weken zwanger van haar tweede kind. 



\section{List of publications}

\section{Articles}

C. Willekes, H.J. Hooghnd, H.A. Keizer, A.P.G. Hocks, R.S. Reneman. "The influence of temale sex homones on artery wall properties during the nomal menstrual cycle". Cli Sci (Coleh) 1997 ; $92(5): 487-491$.

C. Willekes, H.J. Hoogland, A.P.G. Hoeks, R.S. Renenan. "Bladder filling reducs femonal artery wall distension and strain: beware of a full bladder!" Ultrasound Med Biol 1998; 24(6): 803-7.

C. Willekes, H.J. Hoogland, H.A. Keizer, A.P.G. Hoeks, R.S. Reneman. "Oral contraceptives do not affect artery wall properties". Cltrasound Med Biol 1999; 25(5): $723-8$.

C. Willekes, A.P.G. Hoeks, P.J. Brands, J.M. Willigers, R.S. Reneman. "Evaluation of off-line automated intima-media thickness detection of the common carotid artery based on M-line signal processing". Ultrasound Med Biol 1999; 25(1): 57-64.

C. Willekes, P.J. Brands, J.M. Willigers, A.P.G. Hoeks, R.S. Renenan. "Assessment of local differences in intima-media thickness in the human common carotid artery" I Vasc Res 1999; 36(3): $222-8$.

C. Willekes, H.J. Hoogland, A.P.G. Hoeks, R.S. Reneman. "Homone replacement therapy in postmenopausal women increases absolute and relative distension of the common carotid artery and beneficially affects the lipid profile". Submitted for publication.

A.J.G. Hoeks, C. Willekes, P. Boutouyrie, P.J. Brands, J.M. Willigers, R.S. Renenan. "Automated detection of local artery wall thickness based on M-line signal processing". Ultrisound Med Biol 1997;23(7): 1017-1023.

M.E.A. Spandeman, C. Willekes, A.P.G. Hoeks, T.H.A. Ekhart, L.L.H. Peeters, "The effect of pregnancy on the compliance of large arteries and veins in nomal parous controls and fomerly preeclamptics". Accepted Am J Physiol 2000.

M.M. Illand, C. Willekes, H.J. Hoogland, G.A.J. Dunsclman, J.L.H. Evers. "Modelling endometrial wavelike activity in hypoestrogenic women". Submitted for publication.

M.M. Iland, C. Willekes, P.J. Brands, H.J. Hoogland, J.H.H. Evers, A.P.G. Hoeks. "Tissue motion detection: a method to assess endometrial wavelike activity in the nonpregnant uterus". Submitted for publication.

P.J. Brands, A.P.G. Hoeks, J. Willigers, C. Willekes, R.S. Reneman: "An integrated systcn for the non-invasive assessment of vessel wall and hemodynamic properties of large arteries by means of ultrasound". Eur J Ultrasound. 1999:9(3): 257-66.

E. var Beek, A.J.H.M. Houben, P.N. van Es, C. Willekes, E.C.C.M. Korten, P.W de Lecuw, L.L.H. Peeters. "Peripheral haemodymamics and renal function in relation to the menstrual cycle". Clin Sci (Colch) 1996;91(2): 163-8. 


\section{Abstracts}

C. Willekes, H.A. Keizer, H.J. Hoogland, A.P.G. Hoeks, R.S. Reneman: "The effect of ovaran steroids on elastic properties of female large arteries during the normal menstrual cycle". PAlugers Archiv, 1995: 430(4) (suppl): R97.

C. Willekes, H.J. Hoogland, A.P.G. Hocks, R.S. Rencman: "Effect of HRT on artery wall properties in postmenopausal women". Abstractboek Menopause " 96 Florence Italy: C 43.

C. Willekes, H.J. Hoogland, A.P.G. Hoeks, R.S. Renenan: "HRT in postmenopausal women has different effects on large vs, small peripheral arteries". Abstractboek Menopause "96 Florence Italy: C61.

C. Willekes, H.J. Hoggland, H.A. Keizer, R.S. Reneman. "Hormone replacement therapy in the posmenopause: the effect on artery wall properties". Abstractbook 7 th World Congres on Ultrasound in Obstetrics and Gynecology. 1997: A62.

C. Willekes, H.J. Hoogland, A.P.G. Hocks, R.S. Reneman. "Hormoonsubstitutie in die postmonopauz: inventarisatie van het effect van vatwandeigenschappen van de grote perifere slagaders". Nederlands Tijdsclinift Obstetrie en Gynaecologie Mei 1998; 111 (4): 156.

C. Willekes, M.M. IJland, P.J. Brands, H.J. Hoogland, J.L.H. Evers, A.P.G. Hoeks. "Tissue motion detection: a new method to assess endometrial wavelike activity during the menstrual cycle". Human Reproduction 1998: 13, Abstractbook 1: 224-225. 14th Annual meeting of the society of human reproduction and embryology. Goteborg $21-24$ June.

E. van Beek, A. Houben, P. van Es, C. Willekes, E. Korten, P" de Leeuw, L. Peeters. "Cyclic changes in hemodynamics and renal function in the menstrual cycle'. I Soc Gynecol Invest, 1995; 2(2): 380 . 